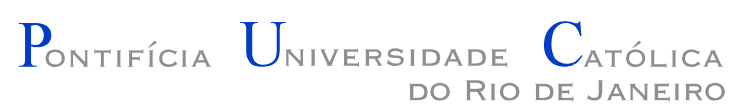

Guilherme de Andrade Martins

\title{
Modelo Fuzzy AHP-TOPSIS para avaliação e seleção de tecnologias de geração de energia elétrica a partir de fontes renováveis
}

Dissertação de Mestrado

Dissertação apresentada como requisito parcial para obtenção do grau de Mestre pelo Programa de Pós-Graduação em Metrologia (Área de concentração: Metrologia para Qualidade e Inovação) da PUC-Rio.

Orientador: Prof. Rodrigo Flora Calili Co-orientadora: Prof. ${ }^{\text {a }}$ Maria Fatima Ludovico de Almeida 


\title{
Guilherme de Andrade Martins
}

\section{Modelo Fuzzy AHP-TOPSIS para avaliação e seleção de tecnologias de geração de energia elétrica a partir de fontes renováveis}

\begin{abstract}
Dissertação apresentada como requisito parcial para obtenção do grau de Mestre pelo Programa de Pós-Graduação em Metrologia (Área de concentração: Metrologia para Qualidade e Inovação) da PUC-Rio. Aprovada pela Comissão Examinadora abaixo assinada.
\end{abstract}

\author{
Prof. Rodrigo Flora Calili \\ Orientador/Presidente \\ Programa de Pós-Graduação em Metrologia - PUC-Rio \\ Prof. a Maria Fatima Ludovico de Almeida \\ Co-orientadora \\ Programa de Pós-Graduação em Metrologia - PUC-Rio \\ Prof. José Francisco Moreira Pessanha \\ Departamento de Estatística - UERJ
}

Prof. Reinaldo Castro Souza

Departamento de Engenharia Elétrica - PUC-Rio

Prof. Daniel Ramos Louzada

Programa de Pós-Graduação em Metrologia - PUC-Rio

Prof. Márcio da Silveira Carvalho
Coordenador Setorial do Centro
Técnico Científico - PUC-Rio

Rio de Janeiro, 3 de maio de 2017 
Todos os direitos reservados. É proibida a reprodução total ou parcial do trabalho sem autorização da universidade, do autor e de seus orientadores.

\section{Guilherme de Andrade Martins}

Bacharel em Engenharia Elétrica pela Pontifícia Universidade Católica do Rio de Janeiro em 2014. Mestrando do Programa de Pós-Graduação em Metrologia da PUC-Rio.

Ficha Catalográfica

Martins, Guilherme de Andrade

Modelo Fuzzy AHP-TOPSIS para avaliação e seleção de tecnologias de geração de energia elétrica a partir de fontes renováveis / Guilherme de Andrade Martins; orientador: Rodrigo Flora Calili; co-orientadora: Maria Fatima Ludovico de Almeida. Rio de Janeiro: PUC, 2017.

v., 105 f.: il.; $30 \mathrm{~cm}$

1. Dissertação (mestrado) - Pontifícia Universidade Católica do Rio de Janeiro, Centro Técnico Científico, Programa de Pós-Graduação em Metrologia.

Inclui referências bibliográficas.

1. Metrologia - Teses. 2. Energias renováveis. 3. Métodos multicritério de apoio à decisão. 4. Lógica fuzzy. 5. AHPTOPSIS.I. II. Calili, Rodrigo Flora. II. Almeida, Maria Fatima Ludovico de. III. Pontifícia Universidade Católica do Rio de Janeiro. Centro Técnico Científico. Programa de Pós-Graduação em Metrologia. IV. Título. 


\section{Agradecimentos}

A Deus, que sempre me dá força e ilumina as minhas decisões, a minha vida e os meus estudos.

Aos meus pais, em especial à minha, Maria Andrade, que sempre apoiam meus projetos, e aos meus irmãos e sobrinhos pelo companheirismo e momentos agradáveis.

À CAPES e à PUC-Rio pelo apoio financeiro e institucional concedido durante esses dois anos de estudos e pesquisa.

Ao Programa de Pesquisa e Desenvolvimento Tecnológico do Setor de Energia Elétrica P\&D da Agência Nacional de Energia Elétrica (ANEEL), pelo apoio desta dissertação.

Ao grupo Enel, e aos colegas do projeto NO.V.A., pela agradável parceria e convivência.

Aos orientadores Rodrigo Flora Calili e Maria Fatima Ludovico de Almeida, pelos ensinamentos, paciência, dedicação e sabedoria.

A todos os funcionários e professores do Pós-MQI/PUC-Rio, pela cordialidade e pelos conhecimentos transmitidos.

Aos colegas do Programa de Pós-graduação em Metrologia da PUC-Rio, pela agradável convivência ao longo desses dois anos e pelos ensinamentos constantes, O agradecimento sincero do autor. 


\section{Resumo}

Martins, Guilherme de Andrade; Calili, Rodrigo Flora (Orientador); Almeida, Maria Fatima Ludovico de (Co-orientadora). Modelo Fuzzy AHP-TOPSIS para avaliação e seleção de tecnologias de geração de energia elétrica a partir de fontes renováveis. Rio de Janeiro, 2017. 105p. Dissertação de Mestrado - Programa de Pós-Graduação em Metrologia. Área de concentração: Metrologia para Qualidade e Inovação, Pontifícia Universidade Católica do Rio de Janeiro.

A avaliação e seleção de tecnologias de geração de energia elétrica a partir de fontes renováveis visa melhorar a eficiência nas decisões de expansão dos sistemas elétricos em geral, elencando tecnologias mais adequadas em função de seus impactos ambientais, sociais, econômicos, técnicos e políticos. Os processos decisórios referentes à escolha de tecnologias de geração de energia caracterizamse por subjetividade, incerteza e ambiguidade. Os métodos multicritério de apoio à decisão, combinados com a lógica dos conjuntos fuzzy constituem uma alternativa adequada para a modelagem de avaliação e seleção de tecnologias em ambientes sob incerteza. O objetivo principal desta dissertação é propor um modelo de avaliação e seleção de tecnologias para geração de energia elétrica a partir de fontes renováveis, com o auxílio de métodos multicritério fuzzy de apoio à decisão. A pesquisa pode ser considerada aplicada, descritiva e metodológica. Quanto aos meios de investigação, a metodologia compreende pesquisa bibliográfica e documental; pesquisa experimental, com a aplicação de métodos multicritério fuzzy de apoio à decisão para hierarquização de alternativas tecnológicas de energia elétrica a partir de fontes renováveis; e desenvolvimento de um estudo empírico no Estado do Rio de Janeiro. Destacam-se como resultados a seleção de tecnologias mais adequadas em função de seus impactos ambientais, sociais, econômicos, técnicos e políticos e a demonstração da aplicabilidade do modelo proposto. No caso do Estado do Rio de Janeiro, a tecnologia que se mostrou mais adequada, dado potencial de fontes renováveis, foi a solar fotovoltaica.

\section{Palavras-chave}

Metrologia; energias renováveis; métodos multicritério de apoio à decisão; lógica fuzzy; AHP-TOPSIS. 


\section{Abstract}

Martins, Guilherme de Andrade; Calili, Rodrigo Flora (Advisor); Almeida, Maria Fatima Ludovico de (Co-advisor). A Fuzzy AHP-TOPSIS model for the assessment and selection of renewable energy generation technologies. Rio de Janeiro, 2017. 105p. Dissertação de Mestrado Programa de Pós-Graduação em Metrologia. Programa de Pós-Graduação em Metrologia. Área de concentração: Metrologia para Qualidade e Inovação, Pontifícia Universidade Católica do Rio de Janeiro.

Assessment and selection of renewable energy generation technologies addresses to improve efficiency in electrical system expansion decisions, by selecting technologies that are more appropriate considering some criteria, like environmental, social, economic, technical and political. The decision-making processes regarding the choice of energy generation technologies are characterized by subjectivity, uncertainty and ambiguity. Multicriteria decision support method, combined with fuzzy logic, is an adequate alternative for measuring and evaluating the performance of technologies in environment under uncertainty. The main aim of this dissertation is to propose a model for selection the performance of technologies for electric power generation from renewable sources, with the support of multicriteria fuzzy decision-making methods. The research can be considered applied, descriptive and methodological. As for means of investigation, the methodology comprises bibliographical and documentary research; Experimental research, with the application of multicriteria fuzzy decision-making methods for hierarchization of technologies for electric power generation alternatives from renewable sources; and development of an empirical study in the State of Rio de Janeiro. The results highlight the selection of the most appropriate technologies according to their environmental, social, economic, technical and political impacts and the demonstration of the applicability of the proposed model. In the case of the State of Rio de Janeiro, the most appropriate technology, given the potential of renewable sources, was solar photovoltaic.

\section{Keywords}

Metrology; renewable energy; multi-criteria decision making; fuzzy logic; AHP- TOPSIS. 


\section{Sumário}

1. Introdução 12

1.1. Definição do problema de pesquisa 14

1.2. Objetivos: geral e específicos 14

1.3. Motivação 15

1.4. Metodologia 16

1.4.1. Fase exploratória e descritiva 17

$\begin{array}{ll}\text { 1.4.2. Fase de pesquisa aplicada } & 18\end{array}$

1.4.3. Fase conclusiva 19

$\begin{array}{ll}\text { 1.5. Estrutura da dissertação } & 19\end{array}$

2. Tecnologias de geração de energia elétrica a partir de fontes $\begin{array}{ll}\text { renováveis } & 21\end{array}$

2.1. As fontes renováveis na matriz elétrica brasileira 21

2.2. As fontes renováveis de energia 23

2.2.1. Hidrelétrica 23

2.2.2. Biomassa 24

2.2.3. Eólica 24

2.2.4. Solar 25

2.2.5. Oceânica 27

2.2.6. Geotérmica 28

2.3. Considerações finais sobre o capítulo 28

3. Avaliação e seleção de tecnologias de geração de energia elétrica a partir de fontes renováveis

3.1. Métodos multicritério de apoio à decisão sob incerteza 30

3.2. Ferramentas para avaliação e seleção de tecnologias de geração de energia elétrica a partir de fontes renováveis

3.3. Critérios e subcritérios para avaliação de tecnologias de geração de energia elétrica a partir de fontes renováveis 
4. Modelo Fuzzy AHP-TOPSIS para avaliação e seleção de tecnologias de geração de energia elétrica a partir de fontes renováveis

4.1. Lógica Fuzzy

4.1.1. Teoria de conjuntos fuzzy

4.1.2. Conjunto fuzzy e números fuzzy

4.2. Visão geral do modelo

4.3. Descrição da fase I - Fuzzy AHP 47

4.4. Descrição da fase II - Fuzzy TOPSIS 49

5. Validação do modelo: estudo empírico no contexto do planejamento energético do Estado do Rio de Janeiro

5.1. Contexto de aplicação: planejamento energético do Estado do Rio de Janeiro

5.2. Coleta, análise e formatação dos dados

5.2.1. Coleta de dados na literatura especializada

5.2.2. Coleta de dados e entrevista com especialistas $\quad 55$

5.2.3. Análise e formatação dos dados 57

5.3. Discussão dos resultados 66

6. Conclusões e recomendações 68

$\begin{array}{ll}\text { Referências bibliográficas } & 72\end{array}$

Apêndice 1 - Descrição dos critérios 77

Apêndice 2 - Formulário de comparação pareada 80

Apêndice 3 - Mensuração e julgamento dos subcritérios de avaliação 84

Apêndice 4 - Questionário submetido aos especialistas 91

Anexo 1 - Processo Analítico Hierárquico (AHP) 98 


\section{Lista de figuras}

Figura 1.1 - Desenho da pesquisa, seus componentes e métodos 17

$\begin{array}{lr}\text { Figura } 1.2 \text { - Mapa conceitual da pesquisa } & 18\end{array}$

Figura 4.1 - Conjunto fuzzy 43

Figura 4.2 - Número fuzzy triangular $A=\left[\mathrm{a}_{1}, \mathrm{a}_{2}, \mathrm{a}_{3}\right]$

Figura 4.3 - Modelo fuzzy AHP-TOPSIS para avaliação e seleção de tecnologias de geração de energia elétrica a partir de fontes

renováveis

Figura 4.4 - Matriz de comparação genérica 48

Figura 4.5 - Matriz de avaliação $\quad 51$

Figura 5.1 - Estrutura hierárquica do modelo para avaliação e seleção de tecnologias de geração de energia elétrica a partir de fontes

renováveis 


\section{Lista de quadros}

Quadro 3.1 - Artigos com afinidade com o tema proposto 33

Quadro 3.2 - Critérios adotados em trabalhos relevantes na literatura 36

Quadro 3.3 - Revisão da literatura sobre critérios e subcritérios 38

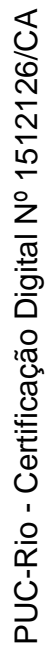

Quadro 3.4 - Critérios e subcritérios propostos 40

Quadro 4.1 - Escala de Saaty 47

Quadro 5.1 - Disponibilidade de potenciais a serem explorados no Estado do Rio de Janeiro 54

Quadro 5.2 - Estrutura hierárquica do instrumento de pesquisa 56 


\section{Lista de tabelas}

Tabela 2.1 - Capacidade Instalada de Geração Elétrica - dez/2015 22

Tabela 3.1 - Quantidade de publicações encontradas na pesquisa 33

Tabela 4.1 - Índice de consistência aleatória (IR) 49

Tabela 4.2 - Termos linguísticos para avaliação 50

Tabela 5.1 - Empreendimentos de Geração de Energia Elétrica em Operação no Estado do Rio de Janeiro 54

Tabela 5.2 - Matriz Comparação Fuzzy: Critérios 58

Tabela 5.3 - Matriz Comparação Fuzzy: Subcritérios subordinados ao critério Técnico 59

đ Tabela 5.4 - Matriz Comparação Fuzzy: Subcritérios subordinados ao critério Ambiental

Tabela 5.5 - Matriz Comparação Fuzzy: Subcritérios subordinados ao critério Econômico

Tabela 5.6 - Matriz Comparação Fuzzy: Subcritérios subordinados ao critério Social

Tabela 5.7 - Matriz Comparação Fuzzy: Subcritérios subordinados ao critério Político

Tabela 5.8 - Razão de consistência das matrizes de critérios e subcritérios

Tabela 5.9 - Pesos dos critérios pelo método Fuzzy AHP 60

Tabela 5.10 - Pesos dos subcritérios pelo método Fuzzy AHP 61

Tabela 5.11 - Matriz de decisão fuzzy das fontes renováveis versus subcritérios

Tabela 5.12 - Peso total dos subcritérios pelo método fuzzy AHP

Tabela 5.13 - Matriz de decisão normalizada e ponderada pelo método fuzzy AHP

Tabela 5.14 - Matriz de distância total positiva e negativa 


\section{1 \\ Introdução}

As tecnologias de geração de energia elétrica a partir de fontes renováveis vêm sendo empregadas na expansão dos sistemas elétricos em geral. Essas tecnologias estão evoluindo rapidamente em resposta aos diversos desafios e preocupações globais, como o crescimento da demanda de energia, a segurança energética e as mudanças climáticas. Diversas políticas e legislações para incentivar a ampliação do uso das fontes renováveis vêm sendo desenvolvidas, mas para atingir o desenvolvimento sustentável é preciso entender e avaliar todos os impactos ambientais, os benefícios e as limitações associadas a cada uma das tecnologias [1].

Atualmente, diversas fontes e tecnologias são necessária para suprir a demanda de energia para a produção e o consumo humano de modo sustentável. Porém, a definição de uma matriz energética ideal não é simples. Para isto, diversos fatores devem ser levados em consideração, tais como a viabilidade de custos, os níveis de emissões, a escassez de recursos, as condições econômicas, geográficas e ambientais em cada região ou país [2]. Os tomadores de decisão e os formuladores de políticas precisam avaliar vários aspectos nos processos decisórios sobre a expansão de energia elétrica.

A literatura tem demonstrado que o desenvolvimento de métodos e critérios para avaliar e selecionar de modo mais confiável a sustentabilidade das opções tecnológicas são cruciais para a seleção dos melhores sistemas de geração de energia elétrica. Esses modelos também servem para identificar os sistemas de fornecimento de energia não sustentáveis, informar aos tomadores de decisão o desempenho integrado das alternativas tecnológicas e monitorar os impactos socioambientais. Os critérios mais utilizados para avaliar e selecionar os sistemas de fornecimento de energia referem-se principalmente a quatro dimensões: (i) técnica; (ii) econômica; (iii) ambiental; e (iv) social [3].

Este tipo de avaliação multidimensional é relevante no campo político internacional. O ano de 2012 foi declarado pela ONU como o "Ano Internacional 
da Energia Sustentável para Todos" (Resolução 65/151), enfatizou-se a importância de se investir no acesso a opções de tecnologias energéticas mais limpas e a necessidade de melhorar o acesso a serviços e recursos energéticos confiáveis, economicamente viáveis, socialmente aceitáveis e ambientalmente racionais, considerando as necessidades específicas de cada país, em particular dos países em desenvolvimento [4]. No Brasil, o desafio do sistema elétrico brasileiro é manter o equilíbrio entre as projeções de crescimento econômico e a expansão da oferta de energia, o "Plano Decenal de Expansão 2024 - PDE 2024", do Ministério de Minas e Energia (MME), é um dos instrumentos de planejamento da expansão eletroenergética e adotou como uma das principais diretrizes a priorização da participação das fontes renováveis para atender o crescimento do consumo de energia elétrica no horizonte decenal [5].

Os métodos multicritério de apoio à tomada de decisão são ferramentas reconhecidas como ideais para a modelagem de problemas em que subjetividade, incerteza e ambiguidades estejam presentes. Dentre estes métodos, destacam-se: ELECTRE - ELimination Et Choix Traduisant la REalité, Analytical Hierarchy Process - AHP; Technique for Order of Preference by Similarity to Ideal Solution - TOPSIS [6]. Os processos decisórios referentes à escolha de tecnologias de geração de energia caracterizam-se por subjetividade, incerteza e ambiguidade. Segundo Wang et al. [3], a teoria dos conjuntos fuzzy tem sido cada vez mais aplicada para cuidar dos critérios qualitativos e da imprecisão inerente às informações avaliadas. De acordo com Cowan et al. [7], há a necessidade de desenvolver melhores modelos que podem lidar com diversos fatores complexos e dinâmicos que muitas vezes estão presentes em problemas de geração de energia, mudanças climáticas e impactos sociais. A lógica fuzzy, a mineração de dados e a visualização de dados são apenas alguns dos exemplos que poderiam ser utilizados [7]. Entende-se que ferramentas de análise multicritério podem ser utilizadas para resolver o problema de analisar vários parâmetros presentes nos processos de seleção das tecnologias de geração, em particular, a combinação desses métodos com a teoria dos conjuntos fuzzy possibilitam o tratamento das incertezas presentes nos processos decisórios. 


\section{1. \\ Definição do problema de pesquisa}

Considerando a crescente demanda de energia elétrica em todo o mundo, o desafio de ofertar energia de modo mais sustentável por meio da descentralização de geração de energia elétrica, alocando-as perto de onde a energia é consumida e considerando a ascensão das fontes de energia renováveis em escala global, definiu-se a seguinte questão principal a ser respondida ao longo da pesquisa:

"Em que medida a aplicação de métodos fuzzy multicritério de apoio à decisão poderá contribuir para a eficácia da avaliação e escolha de tecnologias para geração de energia elétrica a partir de fontes renováveis no Brasil?"

\section{2.}

\section{Objetivos: geral e específicos}

Buscando dar uma contribuição para analisar as opções tecnológicas para geração de energia elétrica a partir de fontes renováveis, o objetivo geral da dissertação é propor um modelo de avaliação e seleção de tecnologias de geração de energia elétrica a partir de fontes renováveis, com o auxílio de métodos multicritério de apoio à decisão sob incerteza.

Em termos específicos, a dissertação busca:

- Caracterizar as alternativas tecnológicas para geração de energia elétrica a partir de fontes renováveis;

- Discutir a importância de se mensurar e avaliar a sustentabilidade econômica, social e ambiental de alternativas tecnológicas para geração de energia elétrica a partir de fontes renováveis em diferentes contextos regionais ou locais;

- Identificar os modelos que empregam métodos multicritério de apoio à decisão para avaliar e selecionar as tecnologias de geração de energia elétrica a partir de fontes renováveis;

- Definir os critérios e subcritérios para avaliar e selecionar as tecnologias de geração de energia elétrica a partir de fontes renováveis; 
- Desenvolver um modelo conceitual de avaliação e seleção de tecnologias para geração de energia elétrica a partir de fontes renováveis, com uso de métodos multicritério de apoio a decisão sob incerteza;

- Demonstrar a aplicabilidade do modelo proposto, mediante o desenvolvimento de um estudo empírico no Estado do Rio de Janeiro;

- Analisar os resultados de modelo proposto e sugerir recomendações e a utilização do modelo proposto com suporte dos métodos multicritério fuzzy de apoio à decisão selecionados, em diferentes contextos regionais ou locais.

\section{3. Motivação}

O desenvolvimento tecnológico permite gerar energia elétrica de diversos modos, os combustíveis utilizados podem ser de dois tipos, renováveis e não renováveis. O primeiro, é o principal responsável pelas atuais inovações tecnológicas como a geração de eletricidade usando a radiação solar ou a energia dos ventos, já as fontes não renováveis são os meios mais maduros e confiáveis para geração de eletricidade. De maneira geral, evidencia-se a necessidade de diversificar a matriz energética em todo o mundo por meio da inserção das fontes renováveis. Portanto, surge a necessidade de avaliar em que medida as diversas tecnologias de geração de energia renovável podem contribuir com a segurança e diversificação da matriz energética.

O Brasil possui recursos energéticos importantes, considerando as fontes renováveis de geração de energia elétrica, em 2012 o Brasil ocupava a $7^{a}$ posição entre os 10 países mais produtores do mundo com 40,3 TWh, ficando atrás de 4 países bem menores em extensão territorial: Alemanha, Espanha, Itália e Japão [8]. Para atender a demanda de energia elétrica no país até o ano de 2024, a EPE estimou que a capacidade instalada de geração de energia elétrica a partir de fontes renováveis deverá crescer 163\%, passando de 21 GW em 2014 para 56 GW em 2024 [5]. Muitos empreendimentos hidráulicos de grande porte e termelétricas estão planejados, mas pouco se sabe sobre os futuros empreendimentos renováveis alternativos que serão construídos para atender a demanda de energia 
elétrica até 2024 , uma vez que grande parte deste potencial se encontra na região Amazônica.

Devido à natureza das fontes alternativas de energia renováveis, entende-se que é importante identificar suas potencialidades. Assim, muitos estudos internacionais abordam a utilidade dos métodos multicritérios de apoio à decisão na priorização e escolha de tecnologias de geração de energia elétrica por tomadores de decisão, porém muitos destes trabalhos não consideram as incertezas inerentes ao processo de tomada de decisão. Além disso, existem lacunas na literatura sobre abordagens semelhantes para o Brasil com a utilização de ferramentas de tomada de decisão sob incerteza.

No contexto da indústria energética brasileira, muitos fatores sociais, políticos e ambientais exercem influência sobre os problemas de geração de energia, portanto, utilizar suporte analítico para apoiar o processo de tomadas de decisão surge como oportunidade na priorização de tecnologias críticas para a geração de energia elétrica [9].

Embora haja poucos estudos nesta área no contexto nacional, existem dados disponíveis que podem ser empregados em análises multicritério, representando as dimensões sociais, econômicas, ambientais e tecnológicas. Sendo assim, essa dissertação busca contribuir no avanço do conhecimento de métodos multicritério para avaliação e seleção de tecnologias para geração de energia elétrica a partir de fontes renováveis no Brasil.

\section{4. Metodologia}

Segundo a taxonomia proposta por Vergara (2002; 2005) [10] [11], a pesquisa pode ser considerada aplicada, descritiva e metodológica (quanto aos fins). Quanto aos meios de investigação, a metodologia compreende:

- Pesquisa bibliográfica e documental sobre os temas centrais da pesquisa, como indicado na fase exploratória e descritiva da Figura 1.1;

- Desenvolvimento do modelo conceitual para avaliação e seleção de tecnologias para geração de energia elétrica a partir de fontes renováveis;

- Aplicação de métodos multicritério fuzzy de apoio à decisão para hierarquização de alternativas tecnológicas de energia elétrica a partir de fontes renováveis. 
A Figura 1.1 apresenta o desenho da pesquisa, destacando-se seus componentes e métodos, de acordo com três fases principais: (i) exploratória e descritiva; (ii) pesquisa aplicada; e (iii) conclusiva.
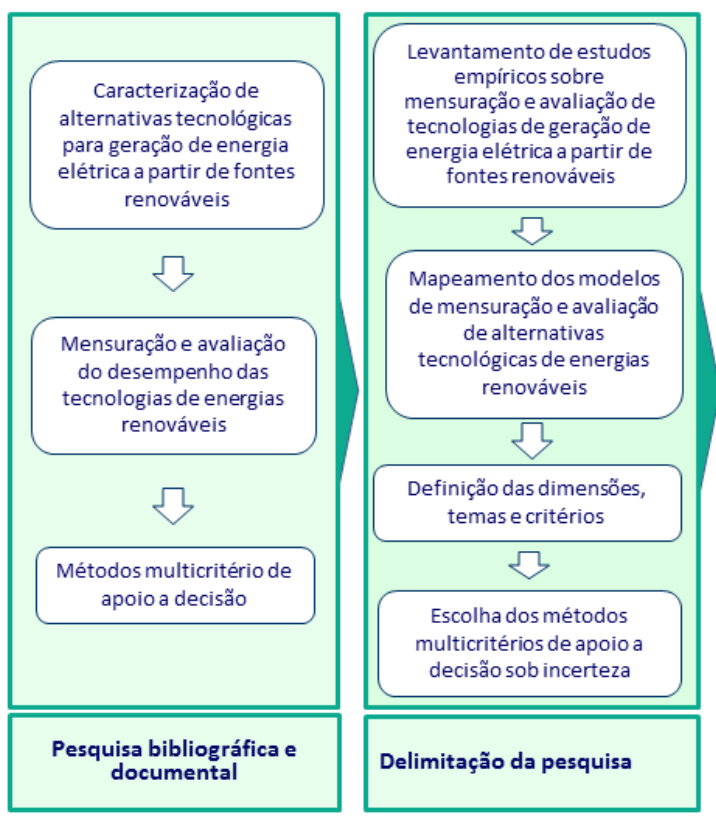

Fase 1- Exploratória e descritiva

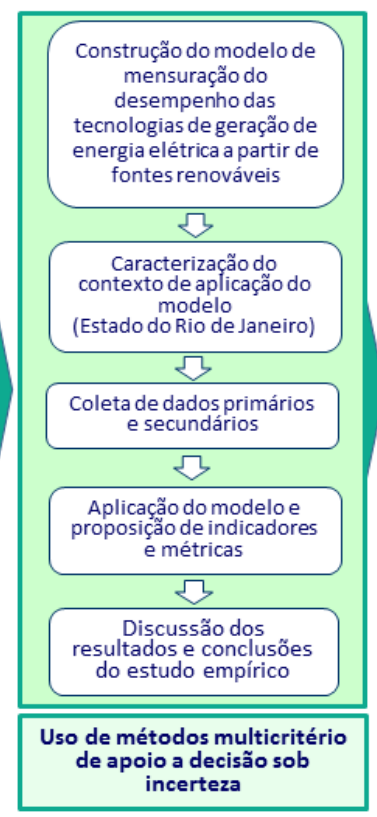

Fase 2- Pesquisa aplicada

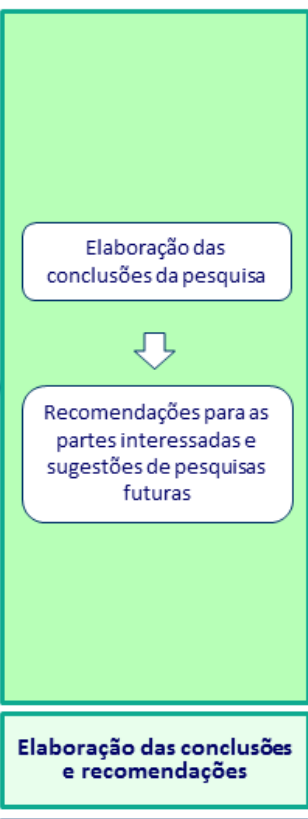

Fase 3 - Conclusiva

Figura 1.1 - Desenho da pesquisa, seus componentes e métodos Fonte: Elaboração própria.

Detalham-se, a seguir, o desenvolvimento de cada fase e os resultados esperados em cada bloco da Figura 1.1. Destaca-se que o desenho da pesquisa foi desenvolvido em total alinhamento com os objetivos enunciados na seção 1.2 deste capítulo.

\subsection{1.}

Fase exploratória e descritiva

A fase exploratória e descritiva foi iniciada com pesquisa bibliográfica e documental, com o objetivo de levantar trabalhos conceituais e documentos de referência para delimitação do tema central da pesquisa - avaliação e seleção de tecnologias de geração de energia elétrica a partir de fontes renováveis. Em seguida, aprofundou-se a revisão bibliográfica, buscando identificar estudos empíricos sobre esse tema, focalizando-se os métodos de apoio à decisão que estavam sendo adotados com esse propósito e os objetos de análise. A partir da constatação de que os métodos multicritério de apoio à decisão eram os mais adotados (AHP; TOPSIS, ELECTRE dentre outros), pesquisou-se se os estudos 
voltados para as tecnologias para geração de energia elétrica a partir de fontes renováveis estavam adotando métodos multicritério combinados com a teoria de conjuntos fuzzy, uma vez que havia o interesse de inserir incertezas à problemática. Identificou-se, assim, uma lacuna na literatura sobre estudos para o Brasil que foi explorada na etapa de pesquisa aplicada.

Apresenta-se na Figura 1.2 uma visão geral e esquemática dos resultados desta primeira fase.
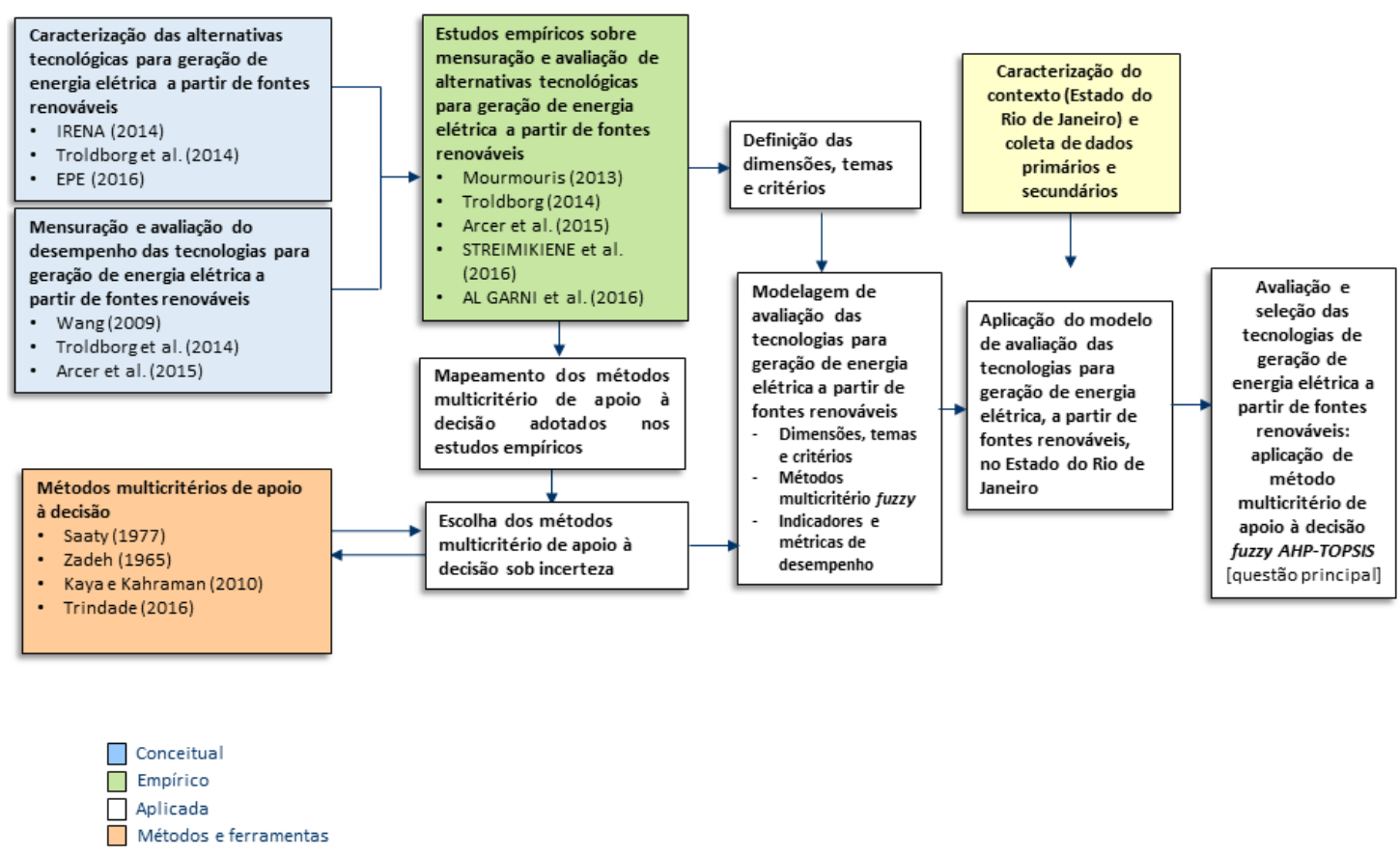

Figura 1.2 - Mapa conceitual da pesquisa

Fonte: Elaboração própria.

O referencial teórico constituiu uma orientação conceitual para a pesquisa, ao compor o vocabulário especializado e organizar o conhecimento sobre avaliação e seleção de tecnologias para geração de energia elétrica a partir de fontes renováveis.

\subsection{2.}

\section{Fase de pesquisa aplicada}

Desenvolveu-se a fase da pesquisa aplicada propriamente dita, a partir dos resultados da revisão bibliográfica e documental, que nortearam a definição dos objetivos da pesquisa e o desenvolvimento do modelo para avaliação e seleção de tecnologias para geração de energia elétrica a partir de fontes renováveis. 


\subsection{3.}

\section{Fase conclusiva}

$\mathrm{Na}$ terceira fase, elaboraram-se a conclusão geral e as específicas em relação a cada um dos objetivos enunciados na seção 1.2, formularam-se um conjunto de recomendações aos diversos atores interessados na aplicação do modelo de avaliação e seleção de tecnologias para geração de energia elétrica a partir de fontes renováveis.

\section{5.}

\section{Estrutura da dissertação}

A dissertação encontra-se estruturada em seis capítulos, incluindo esta introdução.

O capítulo 2 apresenta a composição básica da matriz elétrica brasileira e a descrição sucinta das características, funcionalidades, limitações e potencialidades das tecnologias de geração de energia elétrica partir de fontes renováveis. Encontra-se organizado em duas seções: na primeira, abordam-se o perfil da matriz elétrica brasileira, com destaque para a presença das diversas tecnologias de geração de energia elétrica a partir de fontes renováveis, que participam do sistema de geração de energia elétrica no Brasil. Na segunda seção, conceituam-se as principais tecnologias de geração de energia elétrica partir de fontes renováveis utilizadas no mundo, suas limitações e potencialidades.

No capítulo 3, apresenta o referencial teórico que fundamentou a proposição de um modelo de avaliação e seleção de tecnologias para geração de energia elétrica a partir de fontes renováveis. Apresentam-se a definição dos critérios e subcritérios que foram propostos para compor o método de avaliação multicritérios, baseando-se nos princípios sistêmico, de consistência, da independência, de mensurabilidade e da comparabilidade.

O capítulo 4 apresenta o modelo de avaliação e seleção de tecnologias para geração de energia elétrica a partir de fontes renováveis, que foi baseado nos métodos multicritérios de apoio à decisão fuzzy-AHP e fuzzy-TOPSIS.

No capítulo 5, inicialmente abordam-se as características da região escolhida para a aplicação do método proposto: o Estado do Rio de Janeiro. Na seção seguinte, apresentam-se os principais resultados da simulação, destacando- 
se os pesos atribuídos aos critérios e subcritérios, a matriz de decisão e o resultado da hierarquização das alternativas tecnológicas para geração de energia elétrica a partir de fontes renováveis.

No capítulo 6 apresentam-se as conclusões do estudo, demonstrando a aplicabilidade do modelo para avaliar e selecionar as fontes renováveis e as potencialidades do modelo como ferramenta de apoio à decisão em processos complexos, com fatores conflitantes e de natureza diversa. Além disso, nesta seção, recomendações para estudos futuros são sugeridas para todos os atores interessados no modelo proposto. 


\section{2 \\ Tecnologias de geração de energia elétrica a partir de fontes renováveis}

Apresentam-se neste capítulo as tecnologias de geração de energia elétrica partir de fontes renováveis, a composição básica da matriz elétrica brasileira e descrição sucinta das principais fontes renováveis utilizadas no mundo, visando fundamentar o objetivo desta dissertação.

\section{1.}

\section{As fontes renováveis na matriz elétrica brasileira}

O Brasil possuiu uma posição privilegiada na área energética devido a ampla oferta de fontes renováveis de energia. O Brasil, por possuir uma matriz elétrica limpa, baseada em fonte hidráulica, tem baixos índices de emissões de gases de efeito estufa se comparado com países desenvolvidos. O indicador de emissão de $\mathrm{CO}_{2}$ por exemplo, no Brasil são bem menores em comparação com os outros países. $\mathrm{O}$ indicador de emissões de $\mathrm{CO}_{2}$ pelo uso da energia no Brasil foi de 1,56 $\mathrm{tCO}_{2} /$ tep de energia consumida em 2015 ante 2,25 $\mathrm{tCO}_{2} /$ tep dos países membros da Organização para a Cooperação e Desenvolvimento Econômico (OCDE), sendo a expressiva participação da energia hidráulica e do uso da biomassa na matriz energética brasileira os principais colaboradores [8]. No âmbito da energia elétrica, a potência instalada brasileira de geração correspondeu a 140,9 GW em 2015. Conforme a tabela 2.1, em 2015 a fonte hidráulica respondeu por $65,1 \%$ de participação, seguida pelo gás com $10 \%$ e a biomassa $\operatorname{com} 9,5 \%[8]$.

Estes dados demonstram que a matriz elétrica brasileira é bastante diversificada, com predominância de fontes renováveis de energia em sua composição. Porém, a fonte hidrelétrica é a tecnologia renovável predominante, enquanto a eólica e o biogás possuem um percentual abaixo de $10 \%$ cada, a fonte solar encontra-se na última posição. 
Tabela 2.1 - Capacidade Instalada de Geração Elétrica - dez/2015

\begin{tabular}{|l|c|c|}
\hline Fonte & $\begin{array}{c}\text { Potência instalada } \\
\text { (MW) }\end{array}$ & Estrutura \% \\
\hline Hidrelétrica & 91.650 & 65,1 \\
UHE & 86.366 & 61,3 \\
PCH & 4.886 & 3,5 \\
CGH & 398 & 0,3 \\
\hline Gás & 14.116 & 10 \\
Gás Natural & 12.428 & 8,8 \\
Gás Industrial & 1.688 & 1,2 \\
\hline Biomassa & 13.336 & 9,5 \\
Bagaço de Cana & 10.532 & 7,5 \\
Biogás & 79 & 0,1 \\
Outras & 2.725 & 1,9 \\
\hline Petróleo & 8.722 & 6,2 \\
\hline Nuclear & 1.990 & 1,4 \\
\hline Carvão Mineral & 3.390 & 2,4 \\
\hline Eólica & 7.633 & 5,4 \\
\hline Solar & 31 & 0,022 \\
\hline TOTAL & 140.868 & 100 \\
\hline
\end{tabular}

Notação: UHE - Usina hidrelétrica; PCH - Pequena central hidrelétrica; CGH - Central geradora hidrelétrica

Fonte: EPE (2015).

Apesar de a fonte hidráulica ser considerada limpa, os últimos projetos hidráulicos causaram muita polêmica no Brasil devido a diversos problemas de cunho ambiental, social, além dos altos custos relacionados às etapas de construção e operação das usinas hidrelétricas de grande porte.

Esses projetos levantaram questionamentos da opinião pública devido aos impactos ao meio ambiente, uma vez que as grandes potências hidráulicas remanescentes estão localizadas em áreas bastante afastadas dos centros urbanos, com rica biodiversidade e recursos naturais, como a Floresta Amazônica. Adicionalmente, nos últimos 40 anos registrou-se uma tendência mundial de redução das participações de petróleo e fontes hidráulicas na matriz elétrica e de aumento das participações das demais fontes [12]. O apelo ambiental pela redução de emissões de $\mathrm{CO}_{2}$ em conjunto com o combate as mudanças climáticas são um dos principais fatores que favorecem a adoção de fontes renováveis. Sendo assim, há o desafio de suprir a crescente demanda energética com a incorporação das 
fontes alternativas de energia aos sistemas elétricos existentes de maneira sensata e transparente.

\section{2.}

\section{As fontes renováveis de energia}

Nesta seção, descrevem-se as principais características, funcionalidades, limitações e potencialidades das principais tecnologias de geração de energia renovável são abordadas, evidenciando-se as seguintes fontes: hidrelétricas; biomassa; eólica; solar; oceânica e geotérmica.

\subsection{1.}

\section{Hidrelétrica}

A usina hidrelétrica é uma tecnologia madura e com funcionamento bastante simples, a energia potencial gravitacional de um corpo de água é convertida em energia cinética ao girar uma turbina que alimenta um gerador de eletricidade. Essa tecnologia está presente em aproximadamente 160 países e o total da capacidade instalada no mundo foi $1.060 \mathrm{GW}$ em 2011. Além disso as hidrelétricas também podem ser aproveitadas para outros serviços estratégicos como o controle de cheias e irrigação [13].

Existem duas configurações básicas de usinas hidrelétricas, a primeira é baseada em represas com reservatório para armazenamento de água que permite controlar a quantidade de energia que será gerada, a segunda não possui reservatórios ou são menores e sem capacidade de armazenamento, essa última configuração são chamas de usinas a fio d'água.

No Brasil, as hidrelétricas são classificadas pela Agência Nacional de Energia Elétrica (ANEEL) em Centrais Geradoras Hidrelétricas- CGH (potência instalada até $3 \mathrm{MW}$ ), Pequenas Centrais Hidrelétricas - PCH (superior a $3 \mathrm{MW}$ e igual ou inferior a $30 \mathrm{MW}$ ) e Usinas Hidrelétricas de Energia -UHE (com potência instalada superior a $30 \mathrm{MW}$ ), uma $\mathrm{PCH}$ também é caracterizada pela área do reservatório igual ou inferior a $3 \mathrm{~km}^{2}$ [14]).

Os grandes projetos hidrelétricos (UHE) estão sujeitos à oposição social por causa de seus impactos na disponibilidade hídrica, nos ecossistemas, meio ambiente e na necessidade de realocação de populações que possam ser afetadas pelo projeto. Os principais problemas da energia hidrelétrica são a aceitação 
pública, os altos custos de investimento inicial e longos períodos de retorno de investimentos, longos ciclos de aprovação e construção e longos prazos para obter ou renovar licenças de concessão.

Diferentemente de uma UHE, as hidrelétricas de pequena escala $(\mathrm{PCH}$, CGH) dispõem de uma grande variedade de equipamentos, layouts e materiais, as tecnologias de ponta e os conhecimentos técnicos disponíveis: esses são fatores chaves para a exploração de recursos locais com custos competitivos e sem impactos ambientais significantes [13].

\subsection{2.}

\section{Biomassa}

A biomassa é muito utilizada como combustível para geração de energia, a bioeletricidade é obtida principalmente através da cogeração de processo destinado a geração combinada de energia elétrica e de energia térmica. No Brasil, o bagaço de cana é o principal tipo de combustível oriundo da biomassa. A produção de açúcar e etanol contribuem com a sua economicidade e quantidade, pois sua disponibilidade é decorrente desses processos. As outras fontes de bioeletricidade são, em menor escala, a lenha de florestas plantadas (florestas energéticas) e a lixívia (subproduto do processo de tratamento químico da indústria de papel e celulose) [14].

A biomassa supre aproximadamente $1,5 \%$ da demanda de eletricidade em escala global (cerca de $280 \mathrm{TWh}$ por ano) e a capacidade típica de uma planta é de aproximadamente $10 \mathrm{MW}$, a biomassa é amplamente utilizada em regiões que dispõem de recursos florestais e de resíduos da agricultura, os aspectos sustentável, ambiental e social como a redução de emissões, segurança alimentar, biodiversidade, impacto no solo e na água, se não abordados adequadamente podem apresentar barreias significativas ao uso da biomassa [15].

\subsection{3.}

\section{Eólica}

A energia eólica é a energia dos ventos. Seu aproveitamento ocorre por meio da conversão da energia cinética de translação contida nas massas de ar em movimento em energia cinética de rotação, com o emprego de turbinas eólicas, também denominadas aerogeradores, para a geração de eletricidade. Sempre há 
energia nos ventos, mas a energia eólica é considerada tecnicamente aproveitável quando sua densidade é maior ou igual a $500 \mathrm{~W} / \mathrm{m}^{2}$, a uma altura de $50 \mathrm{~m}$, o que requer velocidade do vento de $7-8 \mathrm{~m} / \mathrm{s}$. Na maior parte dos casos as regiões litorâneas e montanhosas possuem recursos eólicos com maior disponibilidade e qualidade [14].

Os parques eólicos podem ser instalados em terra (onshore), no entanto vários têm sido instalados no mar (offshore), devido a redução da disponibilidade de locais apropriados em terra para novas usinas e também pelo bom potencial. As dimensões e a capacidade média de uma turbina eólica vêm crescendo continuamente, passou de 0,05 MW em 1985 para 2,0 MW em 2014. A maior turbina disponível comercialmente atinge 8,0 MW e tem rotor com 164 metros de diâmetro [16]. Em alguns países as condições dos ventos são boas e os custos da eletricidade convencional são altos, os custos das turbinas eólicas são competitivos, o valor médio do custo nivelado de energia é de US\$109/MW [1].

Dentre as barreias e potencialidade da energia eólica, muitos países oferecem suporte financeiro para assegurar investimentos e reduzir seus riscos por meio do desenvolvimento de regulamentação apropriada e processos administrativos específicos, os impactos ambientais associados as turbinas eólicas como ruídos e poluição visual são preocupações que influem na aceitação pública e requer ações para mitigá-las [16]. A variabilidade de energia eólica gerada é um problema importante para o gerenciamento da energia injetada na rede elétrica e estabilidade do sistema, uma das maneiras de se alcançar alto desempenho de participação da energia eólica no sistema elétrico é utilizar sistemas de transmissão integrados e métodos para estimar a geração de energia como a previsão do tempo [16].

\subsection{4.}

Solar

A energia solar fotovoltaica consiste na conversão da luz solar em eletricidade, o efeito fotovoltaico consiste do aparecimento de uma diferença de potencial nos extremos de uma estrutura de material semicondutor como o silício, por exemplo, produzida pela absorção da luz. 
A energia heliotérmica consiste primeiramente na conversão da energia solar em energia térmica, para depois ser convertida em eletricidade, espelhos são utilizados para concentrar a irradiação solar em ponto focal e aquecer um fluído absorvedor que é utilizado para acionar uma turbina.

A energia solar fotovoltaica é a mais utilizada para gerar energia elétrica, ela pode ser utilizada em escala doméstica nas lajes e telhados de edificações por exemplo, como em escala industrial - fazendas fotovoltaicas.

A incidência dos raios solares no Brasil é mais vertical, condição que favorece elevados índices de irradiação em quase todo o território, e a proximidade com a linha do equador faz com que essa incidência varie pouco ao longo do ano. A densidade da irradiação solar no Brasil varia cerca de 4,4 a 6,2 $\mathrm{kWh} / \mathrm{m}^{2}$, mesmo as áreas com a menor irradiação são superiores às registradas nos principais sítios da Alemanha, um dos países com a maior capacidade instalada fotovoltaica [14].

Entre 2010 e 2015, a capacidade instalada global passou de $40 \mathrm{GW}$ para 227 GW. Estima-se que até 2030 a energia fotovoltaica responderá por $13 \%$ da energia elétrica gerada no mundo ante $2 \%$ em 2016, e o Brasil foi considerado como um dos países mais atrativos para o mercado fotovoltaico [17].

A eficiência da maioria dos módulos fotovoltaicos de silício cristalino é cerca de $12 \%$, mas recordes de $25 \%$ de eficiência em painéis de tecnologias comerciais já foram alcançados. Inúmeras tecnologias estão em desenvolvimento para painéis fotovoltaicos comerciais como células orgânicas e filmes finos avançados. Espera-se, portanto, que a médio prazo a tecnologia atingirá desempenho alto e a mais baixos [18].

Em muitos países com bastante recurso solar disponível e custo de eletricidade alto, a energia fotovoltaica residencial atingiu a paridade tarifária com a eletricidade fornecida pela rede. Por exemplo, na Europa o preço da eletricidade residencial era cerca de 83-291 US\$ por MWh em 2011, enquanto o custo médio da eletricidade de sistemas fotovoltaicos estava entre 160-270 US\$ por MWh [18]. O principal problema da energia fotovoltaica é o fator de capacidade limitado que corresponde a custos de eletricidade mais elevados em relação as demais tecnologias de geração de eletricidade [18]. 
A variação natural da fonte solar é um a restrição que requer o gerenciamento do fornecimento de energia a rede e a utilização de baterias para o armazenamento de energia a fim de promover a participação da energia fotovoltaica no sistema elétrico [18]. Dentre os benefícios, a tecnologia é considerada atrativa como meio de produção de energia e mitigação de gases do efeito estufa, como uma solução de baixo custo para fornecer energia a áreas remotas e como oportunidade de geração de empregos e negócios sustentáveis [18].

\subsection{5.}

\section{Oceânica}

As principais formas de aproveitamento da energia oceânica são ondas, marés, correntes, gradientes de temperatura e gradientes de salinidade. Dentre essas formas, a energia das ondas se destaca pelo fato da onda oceânica poder percorrer centenas de quilômetros sem perdas significativas de energia e por apresentar-se na forma mais concentrada e disponível em abundância nos litorais das cidades costeiras [19]. A principal vantagem desse sistema é sua simplicidade e o fato de geralmente ser confiável, atualmente a tecnologia está em um estágio em que diferentes conceitos estão sendo testados em escala real, com etapas de demonstração comercial em andamento [20].

Outra forma é a energia das marés, que pode ser extraída tanto de sua componente cinética, através de turbinas, como da componente potencial, através de barragens, porém esse tipo de energia é explorado apenas em locais que apresentam elevadas variações diárias de nível [19]. O custo nivelado da energia possui uma média de 289 US\$/MWh, estima-se que em 2030 esse valor será de 120 a 240 US\$/MWh [20]; [1].

Cerca de $2 \%$ do litoral do planeta excede os $30 \mathrm{~kW} / \mathrm{m}$ de densidade de energia de ondas necessária para o aproveitamento energético, mas o regime das ondas varia bastante nas diferentes regiões, resultando em uma variedade de tecnologias que leva a uma falta de coesão industrial e limitação da cadeia de suprimentos de matérias e componentes [20].

Em 2013 existiam mais de 100 projetos de energia de ondas em diversos estágios de desenvolvimento, a Europa está liderando o mercado de tecnologias de geração de energia elétrica a partir de ondas, principalmente por meio de empresas 
start-up, a primeira usina com operação comercial foi inaugurada em 2011 na Espanha com capacidade instalada de $296 \mathrm{~kW}$ [20]. De acordo com estudos realizados no Brasil, o potencial teórico total de ondas e marés é de $114 \mathrm{GW}$ ao longo dos 7,4 mil km de litoral, as regiões do litoral norte e nordeste possuem condições mais favoráveis para a energia das marés enquanto o sul e o sudeste são mais indicados para o aproveitamento da energia das ondas [14].

\subsection{6.}

\section{Geotérmica}

A energia geotérmica (ou geotermal) é aquela obtida pelo calor que existe no interior da Terra, os principais recursos são as fontes de vapor no interior da terra como os gêiseres. Com base na tecnologia e conhecimento atual, há no mundo pelo menos $200 \mathrm{GW}$ de potencial hidrotermal convencional disponível, em janeiro de 2016 o total da capacidade instalada em 24 países atingiu 13,3 GW e a indústria de energia geotérmica projeta que essa capacidade pode chegar a 18,4 GW em 2021 [21].

A primeira usina data de 1904, mas a evolução deste segmento sempre foi lenta e caracterizada pela construção de pequenos números de unidades, em poucos países, não há nenhuma unidade em operação Brasil, nem sob forma experimental [22]. Em contraste com as outras tecnologias, a fonte geotérmica possui algumas vantagens e caracteriza-se pela sua confiabilidade, alto fator de capacidade (frequentemente superior a 90\%), potência constante na base e os custos da eletricidade é um dos mais baratos do mundo $(0,04-0,07 \mathrm{US} \$ / \mathrm{kWh})$ [23].

\section{3.}

\section{Considerações finais sobre o capítulo}

O presente capítulo buscou sintetizar as tecnologias de geração de energias renováveis e evidenciar a importância de cada fonte para suprir a demanda de energia, suas limitações e potencialidades. Ressaltou-se as características da matriz elétrica brasileira e o papel das fontes renováveis no suprimento da demanda de energia no país. Todos esses aspectos foram necessários para caracterizar a temática de interesse desta pesquisa. 


\section{3 \\ Avaliação e seleção de tecnologias de geração de energia elétrica a partir de fontes renováveis}

A avaliação dos sistemas de energia elétrica é processo relevante para os tomadores de decisão. No Brasil, por exemplo, fatores considerados para avaliar as opções para o fornecimento de energia elétrica é a "segurança do sistema elétrico" e a "capacidade das usinas em armazenar energia". Podem-se citar como exemplo destas fontes de geração as hidrelétricas, que costumam apresentar as maiores capacidades de armazenamento de energia devido a seus reservatórios, permitindo o gerenciamento do nível da água e o número de turbinas que são acionadas. O preço quilo watt-hora $(\mathrm{kWh})$ da energia gerada também é um fator relevante. $\mathrm{Na}$ expansão da capacidade de geração, utiliza-se o critério de menor tarifa para definir os vencedores dos leilões de contratação de energia, cabendo aos investidores a decisão de construir novos empreendimentos para suprir a demanda prevista [14] [22]. Esta capacidade de armazenamento é um exemplo de indicador/critério técnico, já o custo do kWh é um indicador/critério econômico.

Vários outros tipos de indicadores são importantes para avaliar a relevância das fontes de energia renovável. Também podem ser citados os indicadores que refletem as características ambientais e sociais nas atividades de geração de energia. Estes, não devem ser negligenciados nas análises, pois representam impactos com forte relação na vida das pessoas.

A aceitação pública dos projetos de geração de energia possui relação com a divulgação eficiente das características dos projetos, como os benefícios e a ações para a mitigação de eventuais impactos. De acordo com Lenzen e Munksgaard (2002) [24], contabilizar os recursos utilizados e a emissão de poluentes geradas pelos sistemas de energia renováveis são importantes para os tomadores de decisão obter estas informações. Muitos desses cálculos fazem parte de análises mais amplas das externalidades decorrentes da produção e utilização da energia, e das avaliações comparativas das opções de fornecimento de energia em relação aos riscos para a saúde e os danos ambientais [24]. 
Carrera e Mack (2010) [25] investigaram na literatura as dimensões utilizadas para avaliar a sustentabilidade das tecnologias de geração de energia e constataram que a simples avaliação das dimensões econômica e ambiental é insuficiente, uma vez que os efeitos sociais do uso de tecnologias energéticas também devem ser considerados. Segundo Baris e Kucukali (2012) [26], a energia é um fator significante para o desenvolvimento econômico e geração de riqueza, mas afirmam que não é possível promover o desenvolvimento sustentável sem proteger o meio ambiente e considerar as condições econômicas.

O papel das fontes renováveis vem se tornando cada vez mais importante devido ao crescimento dos preços do óleo e gás natural em mais de 500\% num período de 15 anos [26]. Segundo Liu (2014) [27], a avaliação da sustentabilidade das fontes renováveis, consideradas uma solução para a mitigação das mudanças climáticas e poluição ambiental, é extremamente complexa e requer o desenvolvimento de indicadores capazes de refletir seus diversos aspectos. Por não haver uma ferramenta comum disponível para avaliar todos os aspectos da sustentabilidade, Liu (2014) [27] propôs um modelo para desenvolver um indicador geral de sustentabilidade para avaliar tecnologias de geração de energia elétrica partir de fontes renováveis, por meio da análise e comparação das diferentes formas de seleção de indicadores e de estratégias de modelagem, concluindo que os indicadores mais relevantes são: emissões de $\mathrm{CO}_{2}$ (ambiental), custos (econômico), geração de empregos e a quantidade de pessoas beneficiadas (social). Carrera e Mack (2010) [25] definiram critérios organizados em quatro grupos: segurança e confiabilidade do fornecimento de energia; estabilidade e legitimidade política; riscos sociais e individuais e; qualidade de vida.

\section{1.}

\section{Métodos multicritério de apoio à decisão sob incerteza}

Quando indicadores de naturezas distintas, como econômico e ambiental, são avaliados em conjunto para alcançar um objetivo especifico, é comum se deparar com dificuldades na delimitação destes indicadores, com diferentes pontos de vista, conflitos de interesse, etc. A natureza multicritério de modelos de avaliação de tecnologias para geração de energia, baseados nas premissas da sustentabilidade, exigem o desenvolvimento de quadros comparativos dinâmicos e 
bem estruturados. Em resposta, a literatura tem avaliado as complexidades que emergem nestes tipos de avaliação. Assim, o uso de ferramentas multicritérios vem sendo propostas para considerar as incertezas associadas as dificuldades que emergem nos processos decisórios.

Segundo Kaya e Kahraman (2010) [28], os julgamentos de questões relacionadas à energia lidam com atributos difíceis de definir e componentes que podem envolver fatores quantitativos e qualitativos. Estes autores complementam e colocam que, em termos de escopo, esse tipo de avaliação pode abranger áreas técnicas, econômicas ou geográficas cujas fronteiras podem ser difíceis de identificar e regiões socioeconômicas que afetam vários grupos de interesse ou partes interessadas, cada uma com suas próprias demandas e necessidades socioeconômicas [28].

Considerando estas dificuldades, os métodos baseados na lógica dos conjuntos fuzzy podem ser úteis na realização de procedimentos de avaliação difíceis, como expressar os termos linguísticos nos processos de tomada de decisão, a fim de resolver a imprecisão, a ambiguidade e a subjetividade do julgamento humano [28]. Baseado na mesma linha de raciocínio, Şengül et al. (2014) [29] combinou a lógica fuzzy com o método multicritério de apoio à decisão TOPSIS (fuzzy-TOPSIS) para a classificação de opções tecnológicas de geração de energia elétrica. A utilização da lógica fuzzy em processos de tomada de decisão tem sido utilizada em vários processos decisórios, alguns exemplos da literatura sobre o tema são apresentados a seguir:

- Chang (1996) [30], introduziu uma nova abordagem com a combinando o método fuzzy com o AHP, propondo um modelo para a seleção de professores universitários à luz de quatro critérios: criatividade matemática, implementações criativas, capacidade administrativa, maturidade pessoal.

- Lima Júnior (2013) [31] comparou o desempenho dos métodos fuzzyAHP e fuzzy-TOPSIS sob o contexto de seleção de fornecedores em geral.

- Liu (2014) [27] utilizou o método fuzzy-AHP para propor a criação de um índice geral de sustentabilidade para avaliar fontes renováveis. 
- Trindade (2016) [6] propôs um modelo que integra os métodos fuzzyAHP e fuzzy-TOPSIS para monitorar e avaliar a capacidade inovativa de empresas.

A aplicação da lógica fuzzy como ferramental de apoio em processos decisórios está presente em diversa áreas do conhecimento. De maneira geral, o que se busca é considerar as incertezas que são inerentes ao julgamento humano nas análises, a fim de auxiliar os tomadores de decisão. Esta dissertação adota o modelo fuzzy AHP-TOPSIS proposto por Trindade (2016) [6], a motivação para adotar este modelo deve-se a combinação dos benefícios da lógica dos conjuntos fuzzy em considerar as incertezas associadas aos processos decisórios com os potenciais dos métodos AHP e TOPSIS. O método AHP é capaz de reduzir decisões complexas em uma série de comparações pareadas e sintetizar os resultados, capturando os aspectos subjetivos e objetivos de uma decisão; o método TOPSIS é utilizado como alternativa à etapa de classificação do AHP para hierarquizar as alternativas, identificando a melhor solução que está mais próxima da solução ideal positiva e mais distante da solução ideal negativa [6].

\section{2. Ferramentas para avaliação e seleção de tecnologias de geração de energia elétrica a partir de fontes renováveis}

A revisão bibliográfica foi o principal meio de investigação deste tema da pesquisa. Procurou-se extensivamente nas bases de dados por artigos relevantes sobre métodos multicritério de apoio à decisão e fontes alternativas de energia elétrica, visando a construção de um modelo que seja capaz de avaliar as opções tecnológicas de geração de energia elétrica partir de fontes renováveis.

Nesta etapa, as duas principais bases de dados utilizadas foram Scopus e Science Direct, utilizaram-se as palavras-chave: "multicriteria" e "renewables" (multicritério e renováveis, respectivamente). O passo seguinte foi filtrar os resultados por idioma: inglês e português. Este filtro foi necessário para aumentar a acessibilidade dos documentos encontrados. No passo seguinte, foram selecionados os estudos mais recentes, partido da hipótese de estariam contidas metodologias mais desenvolvidas e estudadas. Foram analisados os resumos dos 
artigos publicados a partir de 2009, visto que houve um aumento expressivo de artigos publicados nesse período (Tabela 3.1).

Tabela 3.1 - Quantidade de publicações encontradas na pesquisa

\begin{tabular}{|c|c|c|c|c|c|c|c|c|c|c|c|}
\hline Base de dados & $\mathbf{2 0 0 6}$ & $\mathbf{2 0 0 7}$ & $\mathbf{2 0 0 8}$ & $\mathbf{2 0 0 9}$ & $\mathbf{2 0 1 0}$ & $\mathbf{2 0 1 1}$ & $\mathbf{2 0 1 2}$ & $\mathbf{2 0 1 3}$ & $\mathbf{2 0 1 4}$ & $\mathbf{2 0 1 5}$ & $\mathbf{2 0 1 6}$ \\
\hline Scopus & 1 & 4 & 7 & 13 & 14 & 17 & 11 & 19 & 22 & 29 & 21 \\
\hline Science Direct & 4 & 12 & 6 & 20 & 12 & 20 & 15 & 19 & 22 & 23 & 47 \\
\hline
\end{tabular}

Fonte: Elaboração própria.

Os artigos que foram encontrados nas bases de dados abordam assuntos de diversas áreas do conhecimento, tais como engenharia química, energia, agricultura, ciências sociais e economia. Portanto, a análise dos resumos dos artigos buscou identificar os estudos compatíveis com o tema proposto para essa dissertação, cujos critérios determinantes foram a adoção de métodos multicritério para avaliar tecnologias de geração de energia elétrica a partir de fontes renováveis, em relação a cinco critérios de sustentabilidade.

Ao todo, 12 artigos com afinidade com o tema proposto foram selecionados para leitura. Os objetivos e métodos utilizados por estes trabalhos estão apresentados no Quadro 3.1 a seguir.

Quadro 3.1 - Artigos com afinidade com o tema proposto

\begin{tabular}{|l|l|c|}
\hline \multicolumn{1}{|c|}{ Autores } & \multicolumn{1}{|c|}{ Objetivos } & Métodos \\
\hline $\begin{array}{l}\text { ŠTREIMIKIENÉ et al. } \\
\text { (2016) [32] }\end{array}$ & $\begin{array}{l}\text { Estimar as melhores tecnologias para geração de } \\
\text { eletricidade na Lituânia, tendo em conta critérios } \\
\text { quantitativos e qualitativos. }\end{array}$ & $\begin{array}{c}\text { AHP, ARAS } \\
\text { (Additive Ratio } \\
\text { Assessment) }\end{array}$ \\
\hline $\begin{array}{l}\text { AL GARNI et al. (2016) } \\
\text { [33] }\end{array}$ & $\begin{array}{l}\text { Priorizar e classificar as tecnologias de geração de energia } \\
\text { elétrica partir de fontes renováveis para geração de energia } \\
\text { elétrica, visando o planejamento adequado para o } \\
\text { desenvolvimento sustentável. }\end{array}$ & AHP \\
\hline SHMELEV e VAN DEN & $\begin{array}{l}\text { Proposição de análise multicritério para a combinação de } \\
\text { alternativas tecnológicas de energia renovável para o } \\
\text { suprimento de energia de modo sustentável. }\end{array}$ & $\begin{array}{c}\text { MARKAL, APIS } \\
\text { (Aggregated } \\
\text { Preference } \\
\text { Indices System) }\end{array}$ \\
\hline $\begin{array}{l}\text { HADIAN e MADANI } \\
\text { (2015) [34] }\end{array}$ & $\begin{array}{l}\text { Avaliar a conveniência de diferentes fontes de energia em } \\
\text { relação à sustentabilidade. }\end{array}$ & $\begin{array}{c}\text { Mominance, } \\
\text { Lexicographic, }\end{array}$ \\
\hline ARCER et al. (2015) [40] & $\begin{array}{l}\text { Revisão de métodos multicritério de apoio à decisão, } \\
\text { critérios e métodos utilizados para a atribuição dos pesos } \\
\text { dos critérios usados na avaliação de sistemas de energia } \\
\text { sustentáveis. }\end{array}$ & $\begin{array}{l}\text { TOPSIS, SAW } \\
\text { Gased analysis) }\end{array}$ \\
\hline
\end{tabular}


Quadro 3.1 - Artigos com afinidade com o tema proposto (cont.)

\begin{tabular}{|c|c|c|}
\hline Autores & Objetivos & Métodos \\
\hline $\begin{array}{l}\text { ŞENGÜL et al. (2015) } \\
\text { [29] }\end{array}$ & $\begin{array}{l}\text { Desenvolver uma estrutura multicritério de apoio à decisão } \\
\text { para classificação de sistemas de energia renováveis na } \\
\text { Turquia. }\end{array}$ & $\begin{array}{c}\text { Fuzzy } \\
\text { Shannon's } \\
\text { Entropy, Fuzzy } \\
\text { TOPSIS }\end{array}$ \\
\hline $\begin{array}{l}\text { TROLDBORG et al. } \\
\text { (2014) [1] }\end{array}$ & $\begin{array}{l}\text { Avaliação da sustentabilidade e classificação de onze } \\
\text { tecnologias para geração de energia renovável na Escócia. }\end{array}$ & PROMETHEE \\
\hline $\begin{array}{l}\text { SANTOYO-CASTELAZO e } \\
\text { AZAPAGIC (2014) [35] }\end{array}$ & $\begin{array}{l}\text { Proposição de um novo quadro metodológico para } \\
\text { avaliação integrada da sustentabilidade dos sistemas } \\
\text { energéticos. }\end{array}$ & $\begin{array}{l}\text { MAVT (multi- } \\
\text { attribute value } \\
\text { theory) }\end{array}$ \\
\hline $\begin{array}{l}\text { MOURMOURIS e } \\
\text { POTOLIAS (2013) [36] }\end{array}$ & $\begin{array}{l}\text { Analisar e desenvolver uma estrutura multinível para o } \\
\text { planejamento energético e a exploração de fontes de } \\
\text { energia renováveis na ilha de Tassos, Grécia. }\end{array}$ & REGIME \\
\hline $\begin{array}{l}\text { BARIS e KUCUKALI } \\
\text { (2012) [26] }\end{array}$ & $\begin{array}{l}\text { Avaliar o desempenho de tecnologias de geração de } \\
\text { energia renováveis para indicar as melhores opções para a } \\
\text { Turquia. }\end{array}$ & $\begin{array}{c}\text { Classificação } \\
\text { (rank) }\end{array}$ \\
\hline $\begin{array}{l}\text { KAYA e KAHRAMAN } \\
\text { (2010) [28] }\end{array}$ & $\begin{array}{l}\text { Determinar a melhor alternativa tecnológica de geração de } \\
\text { energia elétrica a partir de fontes renováveis para Istambul. }\end{array}$ & $\begin{array}{c}\text { Fuzzy } \\
\text { VIKOR-AHP }\end{array}$ \\
\hline
\end{tabular}

Fonte: Elaboração própria.

Conforme o Quadro 3.1, foram aplicados diversos métodos multicritério de apoio a decisão para avaliar fontes renováveis de energia. Estes estudos demonstram que a presença de fatores subjetivos na avaliação do desempenho geral das tecnologias, parâmetros mensuráveis e não mensuráveis analiticamente, requer a adoção de métodos multicritérios de apoio à decisão como ferramenta de avaliação.

$\mathrm{O}$ método multicritérios de apoio à decisão AHP figura entre os mais frequentes, estando presente em três estudos de um total de 11. Observa-se que a literatura propõe a aplicação de diversos métodos multicritérios em processos decisórios, destacando-se a utilização da teoria dos conjuntos fuzzy para considerar as incertezas.

\section{3.}

\section{Critérios e subcritérios para avaliação de tecnologias de geração de energia elétrica a partir de fontes renováveis}

A seleção dos critérios de decisão para a avaliação das tecnologias deve expressar todas as dimensões envolvidas. Segundo Wang et al. (2009) [3], o desenvolvimento sustentável é um foco importante das agendas econômicas, 
sociais e ambientais em âmbito nacional e internacional. E complementa que, a mensuração da sustentabilidade dos sistemas de geração de energia elétrica é uma questão importante, bem como uma força motriz nas discussões sobre o desenvolvimento sustentável [3].

De acordo com Georgopoulou et al. (1997) [37], nos anos 60 as construções de novas usinas elétricas convencionais para suprir a crescente demanda por energia eram aceitas quase que por unanimidade, entretanto, a deterioração do meio ambiente causada pela construção e operação das usinas estimulou a conscientização dos valores ambientais, tornando o processo de tomada de decisão para construi-las mais complicado. Desde então, observou-se que os assuntos relacionados à sustentabilidade foram difundindo-se na sociedade, aumentando a responsabilidade dos tomadores de decisão em propor soluções que minimizem os impactos negativos sobre as dimensões ambientais, sociais e econômicas. Complementando, a "Declaração de Johanesburgo", na Cúpula Mundial sobre o Desenvolvimento Sustentável (2010), estabeleceu que o desenvolvimento sustentável se baseia em três pilares: desenvolvimento econômico, desenvolvimento social e proteção ambiental [4].

Os processos de tomadas de decisão são amplamente discutidos pela literatura, cuja a importância em considerar os diversos atores envolvidos e dimensões impactadas são evidenciados.

O Quadro 3.2 apresenta o mapeamento das dimensões presentes nos artigos selecionados. Observa-se que as dimensões mais frequentes nos estudos são a ambiental, econômica, social e técnica. Em alguns estudos os aspectos políticos também são abordados, como nos trabalhos de Al Garni et al. (2016) [33] e Štreimikienè et al. (2016) [32].

Para definir os critérios e subcritérios, alguns cuidados devem ser observados para garantir que todas as dimensões e fatores envolvidos estejam representados de modo apropriado. Wang et al. (2009) [3] afirma que aumentar a quantidade de critérios não torna a tomada de decisão necessariamente mais útil no campo de energia sustentável, pelo contrário, menos critérios são benéficos para a avaliação de sistemas de energia. Assim, os critérios devem apresentar relevância, mas sem repetitividade. 
Quadro 3.2 - Critérios adotados em trabalhos relevantes na literatura

\begin{tabular}{|l|l|}
\hline \multicolumn{1}{|c|}{ Autores } & \multicolumn{1}{c|}{ Dimensões / critérios } \\
\hline ŠTREIMIKIENĖ et al. (2016) & $\begin{array}{l}\text { Ambiental, econômico, ética social, política institucional } \\
\text { e técnico. }\end{array}$ \\
\hline AL GARNI et al. (2016) & Ambiental, econômico, sociopolítico e técnico. \\
\hline $\begin{array}{l}\text { SHMELEV e VAN DEN BERGH } \\
\text { (2016) }\end{array}$ & $\begin{array}{l}\text { Ambiental, econômico, entradas de recursos, riscos, } \\
\text { social e técnico. }\end{array}$ \\
\hline HADIAN e MADANI (2015) & Ambiental, econômico e social. \\
\hline ARCER et al. (2015) & Ambiental, econômico, social e técnico. \\
\hline ŞENGÜL et al. (2015) & Ambiental, econômico, social e técnico. \\
\hline TROLDBORG et al. (2014) & Ambiental, socioeconômico e técnico. \\
\hline $\begin{array}{l}\text { SANTOYO-CASTELAZO e } \\
\text { AZAPAGIC (2014) }\end{array}$ & Ambiental, econômico e social. \\
\hline $\begin{array}{l}\text { MOURMOURIS e POTOLIAS } \\
\text { (2013) }\end{array}$ & Ambiental, econômico, social e técnico. \\
\hline BARIS e KUCUKALI (2012) & Ambiental, econômico, social e técnico. \\
\hline KAYA e KAHRAMAN (2010) & Ambiental, econômico, social e técnico. \\
\hline
\end{tabular}

Fonte: Elaboração própria.

Os princípios que devem ser obedecidos para a escolha dos critérios são:

- Princípio sistêmico: os critérios devem refletir as características essenciais e todo o desempenho dos sistemas de energia;

- Princípio de consistência: os critérios devem ser consistentes com os objetivos da tomada de decisão;

- Princípio da independência: os critérios devem refletir o desempenho das alternativas por diferentes aspectos;

- Princípio de mensurabilidade: os critérios devem ser mensuráveis em valores quantitativos tanto quanto possível ou serem qualitativamente expressos;

- Princípio da comparabilidade: os resultados da tomada de decisão são mais racionais, quando a comparabilidade dos critérios é evidente.

Considera-se de muita relevância avaliar a sustentabilidade dos sistemas de geração de energia. Para isso, torna-se necessário desenvolver métodos e critérios de avaliação confiáveis para os processos decisórios de seleção de fontes de energia. A revisão da literatura revela que as avaliações dos sistemas de geração de energia baseiam-se principalmente nos aspectos ambiental, econômico, técnico e social, conforme apresentado no Quadro 3.2. 
Para a definição dos critérios e subcritérios do modelo desta dissertação foram compilados em um quadro todos subcritérios presentes nos estudos avaliados. Isto representou uma etapa importante do processo, pois de posse destas informações, em uma reunião entre o autor e os orientadores desta dissertação, analisaram-se todos os critérios e subcritérios presente nestes estudos, onde no Quadro 3.3 são apresentados os resultados desta análise.

Conclui-se que, de maneira geral, os subcritérios podem representar cinco aspectos. Além dos critérios ambiental, econômico, técnico e social, o critério político também representa as dimensões avaliadas. 
Quadro 3.3 - Revisão da literatura sobre critérios e subcritérios

\begin{tabular}{|c|c|c|c|}
\hline Critério & Subcritério & Literatura & Quantidade \\
\hline \multirow[t]{14}{*}{ Técnico } & Eficiência & $\begin{array}{l}\text { Kaya e Kahraman (2010); Baris e Kucukali (2011); Mourmouris e Potolias (2012); Sengül et al. (2014); Arce et al. } \\
\text { (2015); Al Garni et al. (2016) }\end{array}$ & 6 \\
\hline & Confiabilidade & $\begin{array}{l}\text { Baris e Kucukali (2011); Mourmouris e Potolias (2012); Troldborg et al. (2014); Štreimikienè et al. (2015); Al } \\
\text { Garni et al. (2016) }\end{array}$ & 5 \\
\hline & Disponibilidade/ potencial de recursos & Mourmouris e Potolias (2012); Troldborg et al. (2014); Sengül et al. (2014); Al Garni et al. (2016) & 4 \\
\hline & Maturidade tecnológica & Troldborg et al. (2014); Arce et al. (2015); Al Garni et al. (2016) & 3 \\
\hline & Exergia & Kaya e Kahraman (2010); Arce et al. (2015) & 2 \\
\hline & Tempo de implementação & Baris e Kucukali (2011); & 1 \\
\hline & Quantidade de energia elétrica produzida & Sengül et al. (2014) & 1 \\
\hline & Facilidade de descentralização & Al Garni et al. (2016) & 1 \\
\hline & Capacidade nominal da tecnologia & Štreimikienè et al. (2015) & 1 \\
\hline & Taxa de energia primária & Arce et al. (2015) & 1 \\
\hline & Inovações da tecnologia & Štreimikienè et al. (2015) & 1 \\
\hline & Contribuição para o balanço energético total & Štreimikienè et al. (2015) & 1 \\
\hline & Fator de capacidade & Baris e Kucukali (2011) & 1 \\
\hline & Durabilidade da tecnologia & Štreimikienè et al. (2015) & 1 \\
\hline \multirow[t]{8}{*}{ Ambiental } & Emissões de $\mathrm{CO}_{2 \text { eq }}$ & $\begin{array}{l}\text { Kaya e Kahraman (2010); Baris e Kucukali (2011); Mourmouris e Potolias (2012); Troldborg et al. (2014); } \\
\text { Santoyo-Castelazo e Azapagic (2014); Hadian e Madani (2015); Sengül et al. (2014); Štreimikiené et al. (2015); } \\
\text { Arce et al. (2015); Al Garni et al. (2016); Shmelev e Bergh (2016) }\end{array}$ & 11 \\
\hline & Uso da terra (área requerida) & $\begin{array}{l}\text { Kaya e Kahraman (2010); Mourmouris e Potolias (2012); Troldborg et al. (2014); Hadian e Madani (2015); } \\
\text { Sengül et al. (2014); Al Garni et al. (2016); Shmelev e Bergh (2016) }\end{array}$ & 7 \\
\hline & Impactos no ecossistema & $\begin{array}{l}\text { Baris e Kucukali (2011); Mourmouris e Potolias (2012); Santoyo-Castelazo e Azapagic (2014); Štreimikienè et al. } \\
\text { (2015); }\end{array}$ & 4 \\
\hline & Qualidade ambiental & Mourmouris e Potolias (2012); Troldborg et al. (2014); Arce et al. (2015) & 3 \\
\hline & Uso de água & Hadian e Madani (2015); Shmelev e Bergh (2016) & 2 \\
\hline & Impacto visual & Mourmouris e Potolias (2012); & 1 \\
\hline & Potencial de toxicidade humana & Santoyo-Castelazo e Azapagic (2014) & 1 \\
\hline & Tratamento de resíduos & Štreimikienè et al. (2015) & 1 \\
\hline
\end{tabular}


Quadro 3.3 - Revisão da literatura sobre critérios e subcritérios (cont.)

\begin{tabular}{|c|c|c|c|}
\hline Critério & Subcritério & Literatura & Quantidade \\
\hline \multirow[t]{7}{*}{ Econômico } & Custo de investimento & $\begin{array}{l}\text { Kaya e Kahraman (2010); Baris e Kucukali (2011); Sengül et al. (2014); Santoyo-Castelazo e Azapagic (2014); } \\
\text { Hadian e Madani (2015); Štreimikienè et al. (2015); Arce et al. (2015); Al Garni et al. (2016); Shmelev e Bergh } \\
\text { (2016) }\end{array}$ & 9 \\
\hline & Custos de operação e manutenção & $\begin{array}{l}\text { Kaya e Kahraman (2010); Sengül et al. (2014); Santoyo-Castelazo e Azapagic (2014); Arce et al. (2015); Al Garni } \\
\text { et al. (2016) }\end{array}$ & 5 \\
\hline & Custos nivelados da energia & $\begin{array}{l}\text { Troldborg et al. (2014); Štreimikienè et al. (2015); Arce et al. (2015); Al Garni et al. (2016); Shmelev e Bergh } \\
\text { (2016) }\end{array}$ & 5 \\
\hline & Contribuição para a economia & Mourmouris e Potolias (2012); Troldborg et al. (2014); Al Garni et al. (2016) & 3 \\
\hline & Riscos de investimento & Baris e Kucukali (2011); Štreimikienè et al. (2015) & 2 \\
\hline & Retorno de investimentos & Sengül et al. (2014); Shmelev e Bergh (2016) & 2 \\
\hline & Competitividade da tecnologia & Štreimikienè et al. (2015) & 1 \\
\hline \multirow[t]{3}{*}{ Social } & Aceitação social & $\begin{array}{l}\text { Kaya e Kahraman (2010); Baris e Kucukali (2011); Mourmouris e Potolias (2012); Troldborg et al. (2014); } \\
\text { Štreimikienè et al. (2015); Arce et al. (2015); Al Garni et al. (2016); }\end{array}$ & 7 \\
\hline & Geração de empregos & $\begin{array}{l}\text { Kaya e Kahraman (2010); Baris e Kucukali (2011); Mourmouris e Potolias (2012); Sengül et al. (2014); } \\
\text { Štreimikiené et al. (2015); Al Garni et al. (2016); Shmelev e Bergh (2016) }\end{array}$ & 7 \\
\hline & $\begin{array}{l}\text { Influência no desenvolvimento da sociedade } \\
\text { (educação, cultura etc.) }\end{array}$ & Štreimikienè et al. (2015) & 1 \\
\hline \multirow[t]{6}{*}{ Político } & $\begin{array}{l}\text { Conformidade com as obrigações } \\
\text { internacionais }\end{array}$ & Štreimikienè et al. (2015) & 1 \\
\hline & Regulamentação jurídica das atividades & Štreimikienè et al. (2015) & 1 \\
\hline & $\begin{array}{l}\text { Autonomia (dependência de provisão de } \\
\text { recursos) }\end{array}$ & Štreimikienè et al. (2015) & 1 \\
\hline & Apoio do governo e instituições politicas & Štreimikienè et al. (2015) & 1 \\
\hline & $\begin{array}{l}\text { Influência na sustentabilidade de geração de } \\
\text { energia }\end{array}$ & Štreimikienè et al. (2015) & 1 \\
\hline & $\begin{array}{l}\text { Posição de liderança no fornecimento de } \\
\text { energia }\end{array}$ & Al Garni et al. (2016) & 1 \\
\hline
\end{tabular}

Fonte: Elaboração própria. 
Com o intuito de propor um modelo representativo e abrangente para a avaliação e seleção de tecnologias de geração de energia elétrica a partir de fontes renováveis, levando-se em consideração as premissas para a definição de critérios e subcritérios, para fins da presente pesquisa adotaram-se cinco critérios: (i) técnico; (ii) ambiental; (iii) econômico; (iv) social; e (v) político. Além disso, 21 subcritérios foram propostos e agrupados conforme Quadro 3.4, a seguir.

Quadro 3.4 - Critérios e subcritérios propostos

\begin{tabular}{|c|c|c|}
\hline & Critérios & Subcritérios \\
\hline & \multirow{6}{*}{ Técnico } & Desempenho da tecnologia \\
\hline & & Maturidade tecnológica \\
\hline & & Disponibilidade/potencial de recursos \\
\hline & & Confiabilidade do fornecimento de energia \\
\hline & & Distribuição descentralizada \\
\hline & & Simplicidade de implementação \\
\hline & \multirow{5}{*}{ Ambiental } & Emissões de gases do efeito estufa (GEE) \\
\hline & & Uso da terra \\
\hline 25 & & Conformidade com as condições naturais \\
\hline & & Consumo de água \\
\hline & & Geração de resíduos \\
\hline & \multirow{3}{*}{ Econômico } & Custo nivelado de energia \\
\hline & & Retorno do investimento \\
\hline & & Risco do investimento \\
\hline & \multirow{4}{*}{ Social } & Geração de emprego e renda \\
\hline & & Aceitação social da tecnologia \\
\hline & & Segurança ocupacional \\
\hline & & Desenvolvimento regional local \\
\hline & \multirow{3}{*}{ Político } & Alinhamento com os acordos internacionais \\
\hline & & Alinhamento às políticas nacionais \\
\hline & & Conformidade com os requisitos legais \\
\hline
\end{tabular}

Fonte: Elaboração própria.

A descrição de todos os critérios que fazem parte deste estudo compõe a ficha de avaliação dos critérios e subcritérios que foi submetida aos especialistas e que pode ser consultada no Apêndice 1 . 
Modelo Fuzzy AHP-TOPSIS para avaliação e seleção de tecnologias de geração de energia elétrica a partir de fontes renováveis

Apresenta-se neste capítulo um modelo para avaliação e seleção de tecnologias de geração de energia elétrica a partir de fontes renováveis, baseado na integração de dois métodos multicritério fuzzy de apoio à decisão - fuzzy AHPTOPSIS. Esse modelo baseia-se fundamentalmente no enfoque conceitual e metodológico proposto por Trindade (2016) [6], que propôs um modelo fuzzy AHP-TOPSIS para problemas de mensuração multidimensional da capacidade inovativa de empresas de pequeno e médio porte.

O modelo aqui proposto é composto por etapas organizadas em duas fases: (i) a fase fuzzy AHP, na qual se estabelecem os pesos para os critérios e subcritérios para a avaliação de tecnologias de geração de energia elétrica a partir de fontes renováveis; e (ii) a fase fuzzy TOPSIS, na qual se hierarquizam essas tecnologias, em função do potencial de aproveitamento das alternativas em um determinado contexto de planejamento energético. Antes de descrever o modelo fuzzy AHP-TOPSIS propriamente dito, apresentam-se os conceitos fundamentais da teoria dos conjuntos fuzzy, necessários para justificar a adoção deste método para o problema em questão.

\section{1.}

\section{Lógica Fuzzy}

No desenvolvimento do modelo fuzzy AHP-TOPSIS, adotou-se como variável de quantificação e operações aritméticas o número fuzzy triangular. Apresentam-se os conceitos básicos da teoria de conjuntos fuzzy, utilizando-se as notações matemáticas contidas no trabalho de Pacheco e Vellasco (2007) [38]. 


\subsection{1.}

\section{Teoria de conjuntos fuzzy}

A teoria de conjuntos fuzzy foi introduzida por Zadeh [39] para lidar com a modelagem de sistemas com fronteiras mal definidas. De acordo com Zadeh (1965) [39], encontram-se no mundo real várias classes de objetos que não têm um critério de pertencimento bem definido, estas classes, ainda que imprecisamente definidas, desempenham um papel relevante no que tange o pensamento humano [39]. Para lidar com processos complexos, com informações imprecisas ou aproximadas, o pensamento humano adota estratégias que também possuem natureza imprecisa e que geralmente podem ser expressas em termos linguísticos [38].

O objetivo da teoria de conjuntos fuzzy é lidar com problemas em que a fonte de imprecisão é a ausência de critérios definidos em classes de pertencimento, em vez da presença de variáveis aleatórias [39]. Considera-se que a teoria de conjuntos fuzzy e a lógica fuzzy fornecem o ferramental matemático para traduzir em termos matemáticos a informação imprecisa expressa por um conjunto de regras linguísticas [38].

De acordo com Pacheco e Vellasco (2007) [38], as teorias mais conhecidas para tratar de imprecisão e incertezas são, respectivamente, a teoria dos conjuntos e a teoria de probabilidades. As principais diferenças dessas teorias para lógica fuzzy são: (i) a teoria dos conjuntos não é capaz de lidar com aspectos vagos da informação fornecida por seres humanos; e (ii) a teoria de probabilidades se adequa melhor ao tratamento de dados coletados por meio de repetidas medições.

\subsection{2.}

\section{Conjunto fuzzy e números fuzzy}

A utilização dos conjuntos fuzzy para efetuar operações aritméticas são conhecidos como números fuzzy. Um conjunto fuzzy $F$ atribui a cada elemento do universo um valor entre 0 e 1 , que representa o grau de pertinência de um conceito impreciso ao conjunto fuzzy. Este valor de pertinência é definido pela equação 1 .

$$
F=\{(x, \mu(x)) / x \in U\}
$$


A Figura 4.1 ilustra um conjunto fuzzy, cujo domínio é constituído pelos números reais; o eixo $y$ representa o grau de pertinência ao conjunto, contém valores entre 0 e 1 , a curva representa a função de pertinência do conjunto.

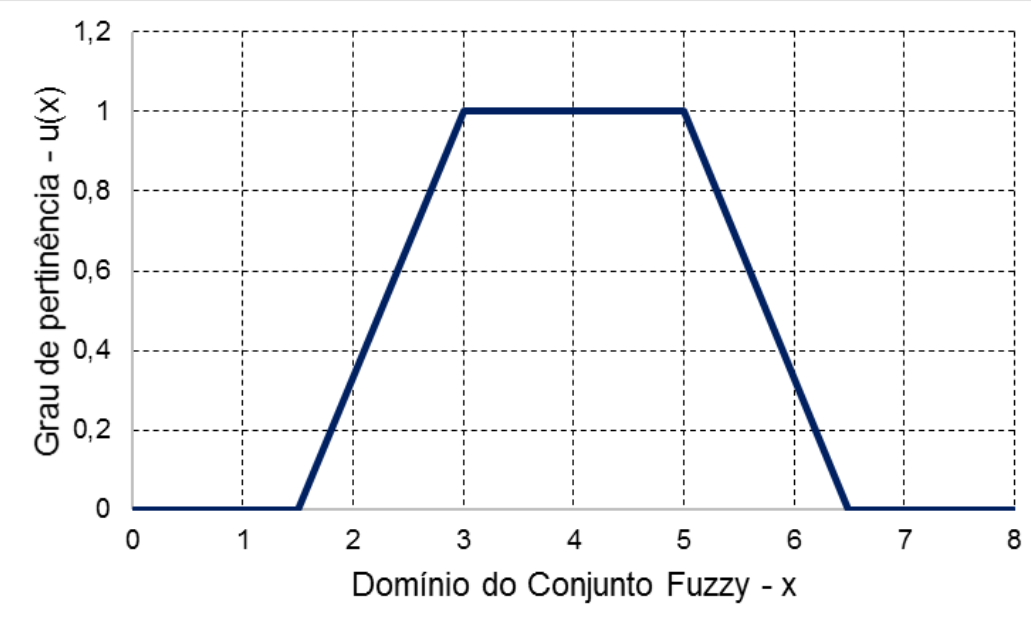

Figura 4.1 - Conjunto fuzzy

Algumas premissas são necessárias para a definição de um úmero fuzzy, as condições necessárias para que um conjunto fuzzy represente um número fuzzy são:

- Estar definido nos números reais;

- A função de pertinência deve ser contínua;

- O conjunto fuzzy deve ser normalizado e;

- O conjunto fuzzy deve ser convexo.

Um número fuzzy é dito triangular, quando a sua função de pertinência é triangular e definida pela expressão seguinte:

$$
\mu_{A}(x)=\left\{\begin{array}{rl}
0, & x \leq a_{1} \\
\frac{x-a_{1}}{a_{2}-a_{1}}, & \cdot \\
& a_{1} \leq x \leq a_{2} \\
\frac{a_{3}-x}{a_{3}-a_{2}}, & \cdot \\
0, & \cdot \\
0, & \cdot \\
0 & x \leq a_{3}
\end{array}\right.
$$


A Figura 4.2 ilustra um número fuzzy triangular. $\mathrm{O}$ eixo $x$ contém os parâmetros que definem o triângulo $\left(\mathrm{a}_{1}, \mathrm{a}_{2}, \mathrm{a}_{3}\right)$ e o eixo $y$ representa o grau de pertinência para cada valor de $\mathrm{x}$.

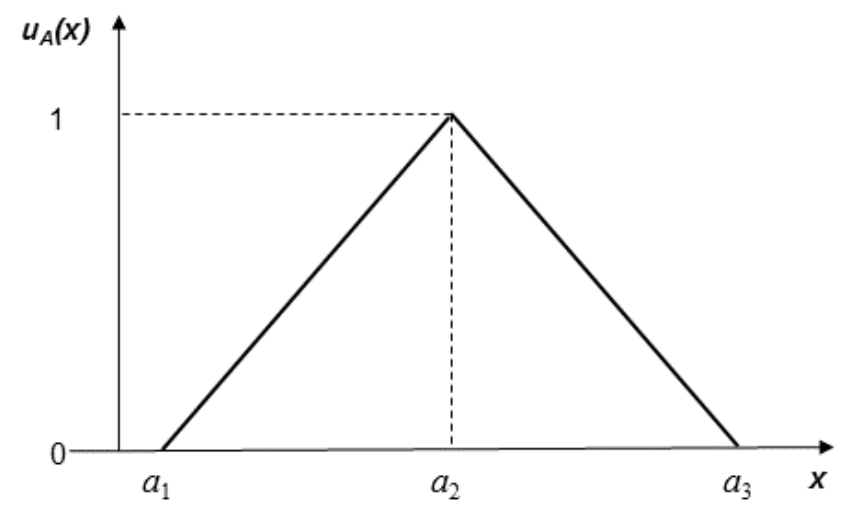

Figura 4.2 - Número fuzzy triangular $A=\left[\mathrm{a}_{1}, \mathrm{a}_{2}, \mathrm{a}_{3}\right]$

O número fuzzy triangular foi escolhido por representa de modo adequado os dados utilizados neste trabalho, os trabalhos de Trindade (2016) [6], Şengül et al. (2015) [29], Arcer et al. (2015) [40] e Kaya e Kahraman (2010) [28] são exemplos de estudos que também optaram pelo número fuzzy triangular. Existem outros tipos de números fuzzy como o gaussiano e o trapezoidal (a curva da Figura 4.1 é um exemplo de número fuzzy trapezoidal).

De maneira geral, números fuzzy fazem parte de um Sistema de Inferência Fuzzy, o objetivo deste tipo de sistema consiste em três etapas principais [41]:

(i) Fuzzyficação: consideram-se as entradas não fuzzy, ou precisas (resultante de medições ou observações), efetuam-se o mapeamento destes dados, o que na prática consiste em converter as variáveis de entrada em números fuzzy;

(ii) Processamento: ocorre o estágio de inferência, em função das regras fuzzy que podem ser fornecidas por especialistas no formato de sentenças linguísticas;

(iii) Defuzzyficação: gera a saída do sistema de inferência fuzzy, é a etapa de intepretação da informação contida no conjunto de fuzzy de saída.

Em síntese, pode-se afirmar que o método multicritério de apoio à decisão desta dissertação, fuzzy AHP-TOPSIS, utiliza principalmente a etapa de 
fuzzyficação na adequação dos dados fornecidos pela literatura e pela avaliação dos especialistas no processo de análise das tecnologias de geração de energia elétrica a partir de fontes renováveis.

\section{2.}

\section{Visão geral do modelo}

A representação gráfica do modelo de avaliação e escolha das fontes renováveis, apresentado na Figura 4.3, compreende duas fases. A primeira, fuzzy AHP, possui quatro etapas, a saber:

- Construção da hierarquia: definição de critérios e subcritérios;

- Cálculo das matrizes de comparação pareadas fuzzy, usando os valores linguísticos - números fuzzy triangular;

- $\quad$ Análise de consistência das matrizes de comparação pareadas fuzzy;

- Obtenção dos pesos dos critério e subcritérios de fuzzy AHP.

Após a avaliação dos pesos de cada critério e subcritério gerados na etapa anterior, inicia-se a segunda fase - fuzzy TOPSIS. Esta fase consiste das seguintes etapas:

- Constituição das matrizes de avaliação das alternativas, agregando os valores linguísticos fornecidos pelos tomadores de decisão;

- Definição da solução ideal positiva e negativa (FPIS e FNIS) e definição da distância para FPIS (D+) e para FNIS (D-);

- Determinação da proximidade relativa do valor ideal e definição do ranking a partir da ordenação decrescente dos valores obtidos por cada alternativa.

Cada uma das etapas do modelo apresentadas na Figura 4.3 são apresentadas nas seções seguintes. 


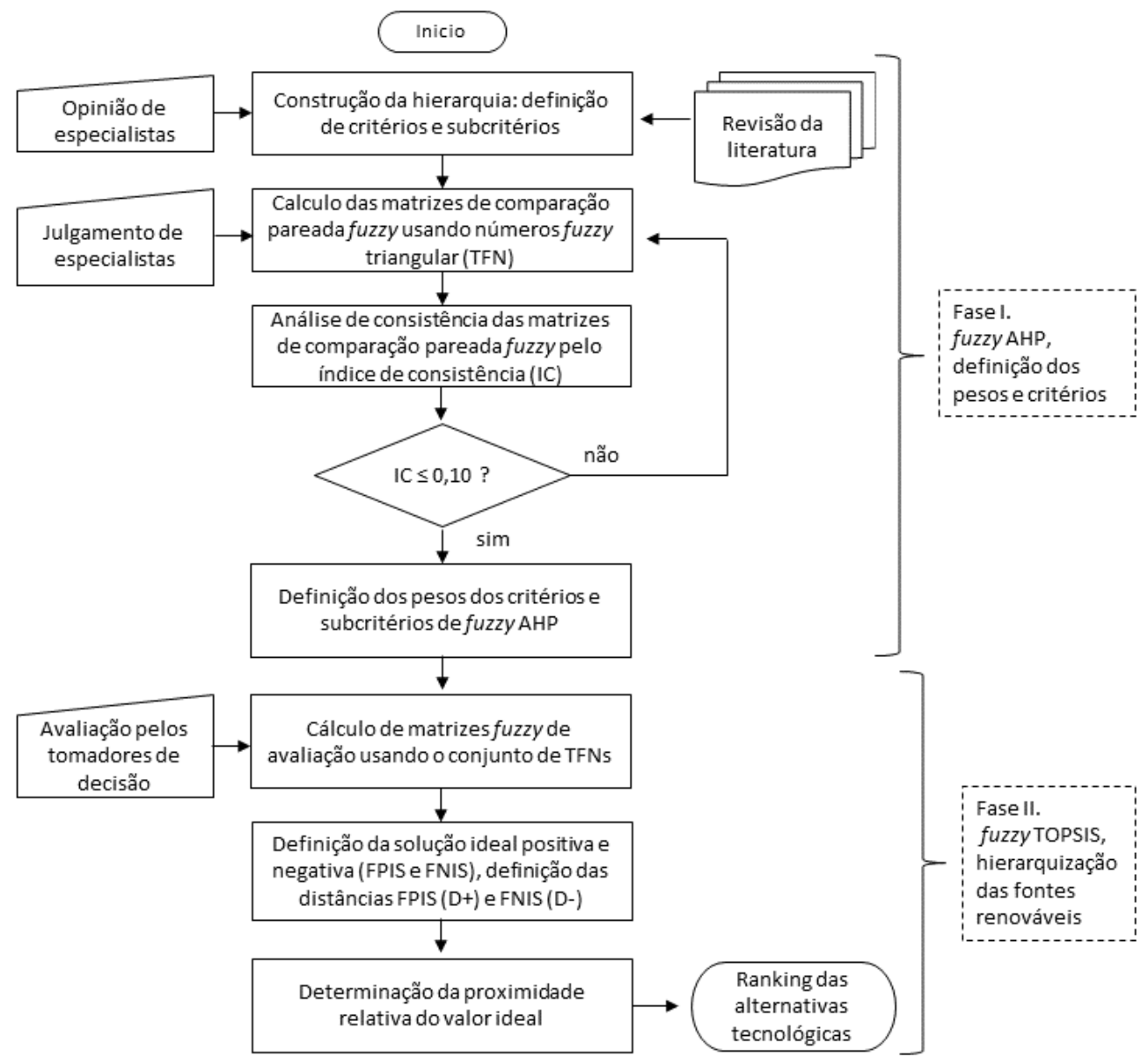

Figura 4.3 - Modelo fuzzy AHP-TOPSIS para avaliação e seleção de tecnologias de geração de energia elétrica a partir de fontes renováveis 


\section{3.}

\section{Descrição da fase I - Fuzzy AHP}

Descrevem-se a seguir as etapas da primeira fase (fuzzy AHP) para estimar os pesos dos critérios e subcritérios.

A partir da estrutura hierárquica de decisão do método multicritério de apoio a decisão, definem-se os critérios e subcritérios, situados no nível da estrutura abaixo do objetivo, que são fatores considerados por exercer influência sobre o objetivo.

Nesta etapa, com a definição dos critérios e subcritérios para avaliar as opções tecnológicas, requerem-se os julgamentos dos especialistas para definir a importância de cada critério e subcritério por meio da comparação par a par, de acordo com a preferência estabelecida entre eles. É neste processo que são calculadas as matrizes de comparação, que neste modelo totalizaram seis matrizes: a primeira matriz contém os cinco critérios, e as demais são compostas pelos subcritérios de cada dimensão avaliada (critérios).

Deste modo, uma escala para avaliar o nível de importância de cada critério e subcritério nas comparações pareadas é definida para a captura do julgamento dos especialistas. A importância de um atributo sobre o outro são representados por números fuzzy triangular. Estes números são calculados em função do julgamento dos especialistas por meio de termos linguísticos baseados na escala de Saaty em 9 níveis, conforme o Quadro 4.1 [42].

Quadro 4.1 - Escala de Saaty

\begin{tabular}{c|l|l}
\hline $\begin{array}{c}\text { Nível de } \\
\text { importância }\end{array}$ & \multicolumn{1}{|c}{ Definição } & \multicolumn{1}{c}{ Explicação } \\
\hline 1 & Mesma importância & $\begin{array}{l}\text { Os dois atributos contribuem igualmente } \\
\text { para o objetivo }\end{array}$ \\
\hline 3 & $\begin{array}{l}\text { Importância moderada de uma } \\
\text { sobre a outra }\end{array}$ & $\begin{array}{l}\text { A experiência e o julgamento favorecem } \\
\text { levemente um atributo em relação ao } \\
\text { outro }\end{array}$ \\
\hline 5 & $\begin{array}{l}\text { Importância grande ou } \\
\text { essencial }\end{array}$ & $\begin{array}{l}\text { A experiência e o julgamento favorecem } \\
\text { fortemente um atributo em relação ao } \\
\text { outro }\end{array}$ \\
\hline 9 & $\begin{array}{l}\text { Importância muito grande ou } \\
\text { demonstrada }\end{array}$ & $\begin{array}{l}\text { Um atributo é muito fortemente } \\
\text { favorecido em relação ao outro; sua } \\
\text { dominação de importância é } \\
\text { demosntrada na prática. }\end{array}$ \\
\hline \multirow{2}{*}{$2,4,6,8$} & $\begin{array}{l}\text { Valores intermediários entre } \\
\text { os valores adjacentes. }\end{array}$ & $\begin{array}{l}\text { A evidência favorece um atributo em } \\
\text { relação ao outro com o mais alto grau de } \\
\text { certeza }\end{array}$ \\
\hline
\end{tabular}


Por definição, o número fuzzy triangular $(1,1,1)$ é utilizado quando dois atributos são considerados igualmente importantes (nível de importância igual a 1 na escala de Saaty). Para representar os demais níveis de importância como um número fuzzy triangular $\left(\mathrm{a}_{1}, \mathrm{a}_{2}, \mathrm{a}_{3}\right)$, contabilizam-se todos os julgamentos em cada comparação pareada e realizam-se operações aritméticas simples para definir os pontos mínimo $\left(\mathrm{a}_{1}\right)$, intermediário $\left(\mathrm{a}_{2}\right)$ e máximo $\left(\mathrm{a}_{3}\right)$.

Com o julgamento dos especialistas monta-se as matrizes de comparação pareada de critérios e subcritérios.

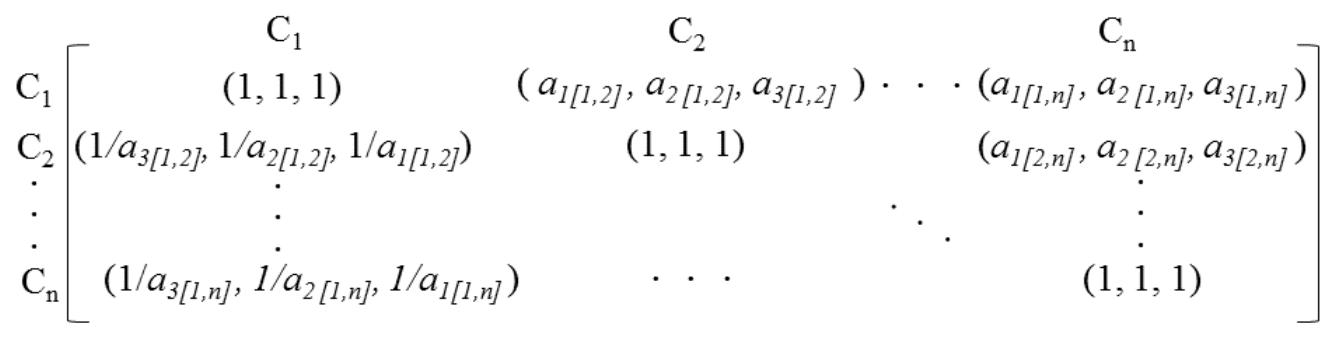

Figura 4.4 - Matriz de comparação genérica

Para exemplificar, a Figura 4.4 apresenta um exemplo de uma matriz de comparação, no qual o critério $\mathrm{C}_{1}$ é preferível ao critério $\mathrm{C}_{2}$, atribuindo-se o valor fuzzy $a_{[1,2]}=\left(a_{1}, a_{2}, a_{3}\right)$ correspondente ao grau de importância do primeiro critério sobre o segundo na posição $(1,2)$ da matriz, sendo assim, na posição $(2,1)$ insere-se o inverso do número fuzzy. O inverso é calculado conforme a expressão a seguir:

$$
a_{[2,1]}=\left(a_{[1,2]}\right)^{-1}=\left(1 / a_{3}, 1 / a_{2}, 1 / a_{1}\right)
$$

A análise de consistência das matrizes de comparação pareadas fuzzy pelo índice de consistência (IC) pode ser realizada com o método clássico AHP, pois quando a comparação da matriz crisp (valores reais fixos) $A$ é consistente, significa que a matriz de comparação fuzzy Ã também é consistente.

$$
\begin{gathered}
R C=\frac{I C}{I R} \\
I C=\frac{\lambda_{\max }-n}{n-1}
\end{gathered}
$$

A razão de consistência (RC), equação 4, é usada para estimar a consistência das comparações pareadas, quando $\mathrm{RC} \leq 0,10$ a consistência é aceita, 
do contrário, é necessário revisar a matriz de comparação. Na equação $5, \lambda_{\max }$ é o maior autovalor e $n$ o tamanho da matriz. O indicie randômico (IR), é um valor tabelado de consistência aleatório, mostrado na tabela 4.1 [42].

Tabela 4.1 - Índice de consistência aleatória (IR)

\begin{tabular}{|c|c|c|c|c|c|c|c|c|}
\hline Tamanho $n$ & 1 & 2 & 3 & 4 & 5 & 6 & 7 & 8 \\
\hline IR & 0 & 0 & 0,52 & 0,89 & 1,11 & 1,25 & 1,35 & 1,40 \\
\hline
\end{tabular}

Para obter os pesos dos critérios e subcritérios fuzzy AHP é utilizado o método da média geométrica. Dada a matriz de comparação fuzzy Ã, o cálculo dos pesos se dá conforme a descrição a seguir:

$$
\begin{gathered}
\tilde{\mathrm{a}}_{i}=\left(\prod_{j=1}^{3} \tilde{\mathrm{a}}_{i j}\right)^{\frac{1}{3}}=\left(\tilde{\mathrm{a}}_{i 1} \times \tilde{\mathrm{a}}_{i 2} \times \tilde{\mathrm{a}}_{i 3}\right)^{\frac{1}{3}} \\
\widetilde{W_{l}}=\frac{\tilde{\mathrm{a}}_{i}}{\sum_{i=1}^{3} \tilde{\mathrm{a}}_{i}} \\
\widetilde{W}=\left\{\widetilde{w}_{1}, \widetilde{w}_{2}, \cdots, \widetilde{w}_{n}\right\}
\end{gathered}
$$

$\mathrm{O}$ vetor $\widetilde{W}$ representa o resultado do cálculo dos pesos, ou seja, contém o peso de cada critério, finalizando a etapa fuzzy AHP.

\section{4. \\ Descrição da fase II - Fuzzy TOPSIS}

Descrevem-se a seguir as etapas da Fase II do modelo, a saber:

- constituição das matrizes de avaliação, utilizando o conjunto de termos linguísticos fuzzy;

- determinação da solução ideal fuzzy positiva e negativa (FPIS e FNIS) e definição da distância para FPIS (D+) e para FNIS (D-) e;

- determinação da proximidade relativa do valor ideal, tendo como resultado a ordenação final.

Com os pesos calculados na última etapa da Fase I, pode-se iniciar a Fase fuzzy TOPSIS. Nesta fase os valores de cada critério e subcritério são fornecidos pelos tomadores de decisão, no processo de avaliação de cada tecnologia. Para esta classificação vaga e subjetiva, é comumente usada a escala Likert de cinco pontos, na qual cada ponto representa um nível de maturidade, e consequentemente, cada nível recebe um valor numérico triangular fuzzy. 
A Tabela 4.2 apresenta a descrição dos termos linguísticos e seus respectivos valores numéricos para os critérios qualitativos.

Tabela 4.2 - Termos linguísticos para avaliação

\begin{tabular}{|l|c|}
\hline Descrição & Nível de maturidade \\
\hline Muito baixo (MB) & 1 \\
\hline Baixo (B) & 2 \\
\hline Médio (M) & 3 \\
\hline Alto (A) & 4 \\
\hline Muito alto (MA) & 5 \\
\hline
\end{tabular}

Fonte: Elaboração própria.

Depois de computada cada nota atribuída pelos respondentes na avaliação das tecnologias, os valores são convertidos para números triangulares fuzzy. Neste modelo, além das notas atribuídas pelos decisores, algumas informações são advindas de fontes de dados sobre o desempenho mensurado das tecnologias como emissões de $\mathrm{CO}_{2}$, dispensando a avaliação subjetiva. Nestes casos, o valor de desempenho da dimensão mensurada de cada tecnologia é convertido para o formato de termos triangulares fuzzy.

A partir dos termos linguísticos e respectivos valores fuzzy, a matriz de decisão $\tilde{D}$ é construída, de acordo com o exemplo a seguir.

$$
\widetilde{D}=\begin{gathered}
A_{1} \\
A_{2} \\
\vdots \\
\vdots \\
A_{s}
\end{gathered}\left[\begin{array}{cccc}
\tilde{x}_{11} & \tilde{x}_{12} & \ldots & \tilde{x}_{1 n} \\
\tilde{x}_{21} & \tilde{x}_{22} & \ldots & \tilde{x}_{2 n} \\
\vdots & \vdots & \vdots & \vdots \\
\tilde{x}_{s 1} & \tilde{x}_{s 2} & \ldots & \vdots \\
x_{s n}
\end{array}\right] i=1,2 \ldots, s ; j=1,2, \ldots, n
$$

Onde $A_{m}$ são as alternativas e $x_{\mathrm{mn}}$ são os valores apontados pelos tomadores de decisão.

Para o entendimento do método fuzzy TOPSIS são necessários expor alguns fundamentos sobre as operações algébricas. Seja $\tilde{A}$ e $\widetilde{B}$ dois números triangulares fuzzy:

$$
\begin{gathered}
\tilde{\mathrm{A}}+\widetilde{\mathrm{B}}=\left[a_{1_{A}}, a_{2_{A}}, a_{3_{A}}\right]+\left[a_{1_{B}}, a_{2_{B}}, a_{3_{B}}\right]=\left[a_{1_{A}}+a_{1_{B}}, a_{2_{A}}+a_{2_{B}}, a_{3_{A}}+a_{3_{B}}\right] \\
\tilde{\mathrm{A}}-\widetilde{\mathrm{B}}=\left[a_{1_{A}}, a_{2_{A}}, a_{3_{A}}\right]-\left[a_{1_{B}}, a_{2_{B}}, a_{3_{B}}\right]=\left[a_{1_{A}}-a_{1_{B}}, a_{2_{A}}-a_{2_{B}}, a_{3_{A}}-a_{3_{B}}\right] \\
\tilde{\mathrm{A}} * \widetilde{\mathrm{B}}=\left[a_{1_{A}}, a_{2_{A}}, a_{3_{A}}\right] *\left[a_{1_{B}}, a_{2_{B}}, a_{3_{B}}\right]=\left[a_{1_{A}} * a_{1_{B}}, a_{2_{A}} * a_{2_{B}}, a_{3_{A}} * a_{3_{B}}\right] \\
\tilde{\mathrm{A}} \\
\tilde{\widetilde{\mathrm{B}}}=\frac{\left[a_{1_{A}}, a_{2_{A}}, a_{3_{A}}\right]}{\left[a_{1_{B}}, a_{2_{B}}, a_{3_{B}}\right]}=\left[\frac{a_{1_{A}}}{a_{3_{B}}}, \frac{a_{2_{A}}}{a_{2_{B}}}, \frac{a_{3_{A}}}{a_{1_{B}}}\right]
\end{gathered}
$$

Dispondo da matriz de avaliação $\widetilde{D}$, figura 4.5 [43], inicia-se o algoritmo do método fuzzy TOPSIS. 


$$
\begin{aligned}
& \begin{array}{lllllll}
\mathrm{C}_{1} & \mathrm{C}_{2} & . . & \mathrm{C}_{\mathrm{j}} & . . & \mathrm{C}_{\mathrm{m}}
\end{array} \\
& \tilde{\mathrm{D}}=\mathrm{A}_{\mathrm{i}} \quad \mathrm{A}_{1}\left[\begin{array}{cccccc}
\tilde{\mathrm{x}}_{11} & \tilde{\mathrm{x}}_{12} & . . & \tilde{\mathrm{x}}_{1 \mathrm{j}} & . . & \tilde{\mathrm{x}}_{1 \mathrm{~m}} \\
\mathrm{~A}_{\mathrm{n}} & : & & : & & : \\
\tilde{\mathrm{x}}_{\mathrm{i} 1} & \tilde{\mathrm{x}}_{\mathrm{i} 2} & . . & \tilde{\mathrm{x}}_{\mathrm{ij}} & . . & \tilde{\mathrm{x}}_{\mathrm{im}} \\
: & : & & : & & : \\
\tilde{\mathrm{x}}_{\mathrm{n} 1} & \tilde{\mathrm{x}}_{\mathrm{n} 2} & . . & \tilde{\mathrm{x}}_{\mathrm{nj}} & . . & \tilde{\mathrm{x}}_{\mathrm{nm}}
\end{array}\right]
\end{aligned}
$$

Figura 4.5 - Matriz de avaliação

O segundo passo é normalizar a matriz $\widetilde{D}$ usando uma escala de transformação linear. A matriz $\widetilde{D}$ normalizada $\widetilde{R}$, é obtida pela equação 15 .

$$
\begin{gathered}
\tilde{R}=\left[\tilde{r}_{i j}\right]_{m \times n} \\
\tilde{r}_{i j}=\left(\frac{a_{1_{i j}}}{a_{3 j^{+}}}, \frac{a_{2_{i j}}}{a_{3 j^{+}}}, \frac{a_{3 i j}}{a_{3 j}^{+}}\right)
\end{gathered}
$$

Sendo $u_{j}^{+}=\max _{\mathrm{i}} \mathrm{u}_{\mathrm{ij}}$

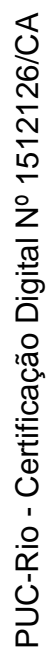

O terceiro passo é obter a matriz ponderada normalizada $\tilde{V}$ por meio da multiplicação dos pesos pelos elementos da matriz normalizada, equação 16.

$$
\begin{aligned}
& \tilde{V}=\left[\tilde{v}_{i j}\right]_{m \times n} \\
& \tilde{v}_{i j}=\tilde{r}_{i j} * \widetilde{w}_{j}
\end{aligned}
$$

No quarto passo, define-se a solução ideal fuzzy positiva (FPIS, $\mathrm{A}^{+}$) e negativa (FNIS, $\mathrm{A}^{-}$), conforme as equações 18 e 19.

$$
\begin{aligned}
& A^{+}=\left\{\tilde{v}_{1}^{+}, \tilde{v}_{2}^{+}, \cdots, \tilde{v}_{m}^{+}\right\} \\
& A^{-}=\left\{\tilde{v}_{1}^{-}, \tilde{v}_{2}^{-}, \cdots, \tilde{v}_{m}^{-}\right\}
\end{aligned}
$$

Onde $\tilde{v}_{1}^{+}=(1,1,1)$ e $\tilde{v}_{1}^{-}=(0,0,0)$.

O quinto passo consiste na definição da distância para FPIS $\left(D^{+}\right)$e para FNIS (D) com a equação 20, equação 21.

$$
\begin{gathered}
D_{i}^{+}=\sum_{j=1}^{n} d_{v}\left(\tilde{v}_{i j}, \tilde{v}_{j}^{+}\right) \\
D_{i}^{-}=\sum_{j=1}^{n} d_{v}\left(\tilde{v}_{i j}, \tilde{v}_{j}^{-}\right) \\
d(\tilde{X}, \tilde{Z})=\sqrt{\frac{1}{3}\left[\left(a_{1_{X}}-a_{1_{Z}}\right)^{2}+\left(a_{2_{X}}-a_{2_{Z}}\right)^{2}+\left(a_{3_{X}}-a_{3_{Z}}\right)^{2}\right]}
\end{gathered}
$$


No último passo, calcula-se os coeficientes de aproximação $C C_{i}$ para cada uma das alternativas avaliadas, conforme a equação 23.

$$
C C_{i}=\frac{D_{i}^{-}}{D_{i}^{+}+D_{i}^{-}}
$$

Com isto, define-se a ordenação final das alternativas avaliadas com os valores de $C C_{i}$, atingindo-se o objetivo final. 


\section{5 \\ Validação do modelo: estudo empírico no contexto do planejamento energético do Estado do Rio de Janeiro}

O capítulo 5 tem por objetivo mostrar os resultados gerados durante o desenvolvimento de um estudo empírico realizado no recorte espacial, Estado do Rio de Janeiro, para aplicação e validação do modelo conceitual apresentado no capítulo 4. Dessa forma, faz-se necessária a apresentação do contexto de aplicação do instrumento de avaliação desenvolvido para fontes renováveis, da coleta de dados, da análise e formatação destes e, consequentemente, da aplicação do modelo proposto, bem como dos resultados encontrados.

\section{1. \\ Contexto de aplicação: planejamento energético do Estado do Rio de Janeiro}

Nesta seção será apresentada a caracterização do sistema elétrico do Estado do Rio de Janeiro, considerando-se as diversas fontes de geração de energia elétrica que são empregadas no Estado.

O Estado do Rio de Janeiro possui área de $43,8 \mathrm{mil} \mathrm{m}^{2}$, sua população estimada é de 16,6 milhões em 2016 e o consumo de eletricidade registrado em 2014 atingiu 54.850 GWh [44] [45].

A matriz elétrica estadual conta com importantes recursos energéticos, o principal recurso são as usinas térmicas: a potência instalada das termelétricas convencionais é 5.165 MW, seguido pelas centrais termonucleares com 1.990 MW. A participação da energia renovável no Estado do Rio de Janeiro se dá principalmente a fonte hidráulica, que ocupa o terceiro lugar geral, com o total de 1.263 MW de potência instalada (UHE, PCH, CGH).

A Tabela 5.1 apresenta em detalhe a composição da matriz energética estadual [45]. 
Tabela 5.1 - Empreendimentos de Geração de Energia Elétrica em Operação no Estado do Rio de Janeiro

\begin{tabular}{|c|c|c|c|}
\hline Fonte & Ano & Quantidade & Potência (MW) \\
\hline UHE & \multirow{6}{*}{2014} & 7 & $1.011,00$ \\
\hline $\mathrm{PCH}$ & & 20 & 243,04 \\
\hline $\mathrm{CGH}$ & & 15 & 8,94 \\
\hline Eólica & & 1 & 28,05 \\
\hline Termelétrica & & 134 & $5.164,98$ \\
\hline Termonuclear & & 2 & $1.990,00$ \\
\hline Solar (distribuída) ${ }^{\mathbf{1}}$ & 2012 & 291 & 2,38 \\
\hline & TOTAL & 470 & $8.448,39$ \\
\hline
\end{tabular}

${ }^{1}$ Geração distribuída de pequeno porte e conforme as regras da Resolução ANEEL n $482 / 2012$.

Fonte: Adaptado de Balanço Energético do Estado do Rio de Janeiro (2014).

Conforme a Tabela 5.1, o percentual de participação de energias não renováveis é bem maior, são elas: gás natural (55\%); nuclear (29\%); outras fósseis (6\%) [45]. No ano de 2014, o Rio de Janeiro produziu mais energia elétrica, 59.298 GWh, do que consumiu, $41.543 \mathrm{GWh}$ [8]. Observa-se que grande parte da geração de energia é realizada a partir de termoeletricidade a partir de gás natural, evidenciando a dependência de combustíveis fosseis e não renováveis.

Os dados levantados na revisão da literatura para realizar esse estudo empírico mostraram que há um potencial de pelo menos 14,6 TW advindo de fontes renováveis de energia que poderiam ser exploradas no estado do Rio de Janeiro [14] [46] [47] [48].

Quadro 5.1 - Disponibilidade de potenciais a serem explorados no Estado do Rio de Janeiro

\begin{tabular}{|l|c|c|}
\hline Tecnologia & Potencial avaliado no RJ (MW) & Fonte \\
\hline Hidráulica & 571 & INEA (2014) \\
\hline Fotovoltaica & 2.685 & EPE (2016) \\
\hline Eólica & $1.524-2.813$ & Amarante et al. (2002) \\
\hline Biomassa & $35-70-93$ & USP (2012) \\
\hline Ondas & 9.800 & EPE (2016) \\
\hline
\end{tabular}

Considerando-se os dados levantados na revisão da literatura e a disponibilidade de dados para a fase aplicada desta pesquisa, selecionaram-se as seguintes fontes renováveis: (i) hidráulica; (ii) fotovoltaica; (iii) eólica; (iv) biomassa; e (v) ondas. 


\section{2.}

\section{Coleta, análise e formatação dos dados}

Esta seção descreve os processos e métodos adotados na Coleta, análise e formatação dos dados.

\subsection{1.}

\section{Coleta de dados na literatura especializada}

Nesta seção, apresentam-se os dados quantitativos encontrados na literatura, que caracterizam o desempenho das tecnologias de geração de energia a partir de fontes renováveis. Esses dados quantitativos referem-se a somente sete subcritérios, a saber: (i) disponibilidade/potencial de recursos; (ii) desempenho da tecnologia; (iii) emissões de gases do efeito estufa; (iv) uso da terra; (v) consumo de água; (vi) custo nivelado de energia; e (vii) geração de emprego e renda (Apêndice 3).

\subsection{2. \\ Coleta de dados e entrevista com especialistas}

A consulta aos especialistas foi feita em duas etapas: (i) a primeira visava definir os pesos dos critérios e subcritérios adotados; e (ii) a segunda com o objetivo de definir os atributos de cada uma das cinco alternativas de fontes renováveis considerando os 14 subcritérios que não tiveram dados obtidos na literatura.

Na primeira etapa - definição dos pesos dos critérios e subcritérios elaborou-se e aplicou-se um instrumento de pesquisa, que é apresentado no Apêndice 4. Para tanto quatro especialistas foram consultados e duas reuniões de trabalho foram realizadas.

Os critérios discutidos foram agrupados em cinco dimensões: (i) técnica; (ii) ambiental; (iii) econômica; (iv) social; e (v) política. A seguir, as definições destes critérios são descritas:

- Técnico: nesta dimensão, analisam-se as características técnicas das tecnologias, de modo que se tenha uma visão geral do avanço tecnológico e potencial que é possível atingir com cada uma das fontes renováveis. 
- Ambiental: nesta dimensão, analisam-se as interações de cada uma das opções com o meio ambiente, seus principais impactos e intensidade dos recursos naturais consumidos para as tecnologias operarem.

- Econômico: nesta dimensão, avaliam-se a viabilidade financeira do uso das tecnologias, os custos envolvidos e ganhos econômicos.

- Social: nesta dimensão, analisam-se o papel das fontes renováveis no desenvolvimento social associado ao uso destas, ou seja, o quão a sociedade se beneficia com a geração de energia.

- Político: nesta dimensão, avaliam-se os níveis de incentivos legais associados a cada tecnologia.

O Quadro 5.2 apresenta a estrutura hierárquica do instrumento de pesquisa, evidenciando-se critérios e subcritérios e que foram discutidos nesta etapa do trabalho.

Quadro 5.2 - Estrutura hierárquica do instrumento de pesquisa

\begin{tabular}{|c|c|}
\hline Critérios & Subcritérios \\
\hline \multirow{6}{*}{ Técnico } & $\mathrm{T}_{1}$ Desempenho da tecnologia \\
\hline & $\mathrm{T}_{2}$ Maturidade tecnológica \\
\hline & $\mathrm{T}_{3}$ Disponibilidade/potencial de recursos \\
\hline & $\mathrm{T}_{4}$ Confiabilidade do fornecimento de energia \\
\hline & $\mathrm{T}_{5}$ Distribuição descentralizada \\
\hline & $\mathrm{T}_{6}$ Simplicidade de implementação \\
\hline \multirow{5}{*}{ Ambiental } & $A_{1}$ Emissões de gases do efeito estufa (GEE) \\
\hline & $\mathrm{A}_{2}$ Uso da terra \\
\hline & $\mathrm{A}_{3}$ Conformidade com as condições naturais \\
\hline & $\mathrm{A}_{4}$ Consumo de água \\
\hline & $\mathrm{A}_{5}$ Geração de resíduos \\
\hline \multirow{3}{*}{ Econômico } & $C_{1}$ Custo nivelado de energia \\
\hline & $\mathrm{C}_{2}$ Retorno do investimento \\
\hline & $C_{3}$ Risco do investimento \\
\hline \multirow{4}{*}{ Social } & $\mathrm{S}_{1}$ Geração de emprego e renda \\
\hline & $S_{2}$ Aceitação social da tecnologia \\
\hline & $\mathrm{S}_{3}$ Segurança ocupacional \\
\hline & $\mathrm{S}_{4}$ Desenvolvimento regional local \\
\hline \multirow{3}{*}{ Político } & $\mathrm{P}_{1}$ Alinhamento com os acordos internacionais \\
\hline & $P_{2}$ Alinhamento às políticas nacionais \\
\hline & $\mathrm{P}_{3}$ Conformidade com os requisitos legais \\
\hline
\end{tabular}

Na segunda etapa, para a definição dos atributos dos critérios, - cujos dados não estavam disponíveis na literatura, adotou-se uma escala Likert de cinco 
pontos, visando obter a opinião dos especialistas quanto ao nível de maturidade em relação a cada um dos 14 subcritérios restantes.

Os níveis de maturidade considerados foram: 1 - muito baixa; 2 - baixa; 3 moderada; 4 - alta; 5 - muito alta.

Foram objeto de consulta a especialistas os seguintes subcritérios: (i) maturidade tecnológica; (ii) confiabilidade do fornecimento de energia; (iii) distribuição descentralizada; (iv) simplicidade de implementação; (v) conformidade com as condições naturais; (vi) geração de resíduos; (vii) retorno do investimento; (viii) risco do investimento; (ix) aceitação social da tecnologia; (x) segurança ocupacional; (xi) desenvolvimento regional local; (xii) alinhamento com os acordos internacionais; (xiii) alinhamento às políticas nacionais; e (xiv) conformidade com os requisitos legais. Os dados referentes a esses subcritérios encontram-se no Apêndice 3.

\subsection{3.}

\section{Análise e formatação dos dados}

Os resultados da etapa anterior deram origem a um banco de dados das tecnologias de geração de energia elétrica a partir de fontes renováveis a serem hierarquizadas com a aplicação do modelo proposto no capítulo 4 .

Com base nesses dados, procedeu-se a uma análise preliminar dos julgamentos doe especialistas, considerando-se as médias aritméticas e a dispersão das notas atribuídas aos critérios e subcritérios. Dessa forma, foi possível compor os indicadores dos pesos das dimensões avaliadas. Na sequência, os resultados desta análise preliminar foram formatados para aplicação propriamente dita do modelo em duas fases considerando: (i) fuzzy-AHP; e (ii) fuzzy-TOPSIS.

\section{Fase I - Fuzzy AHP}

\section{Construção da hierarquia: Definição de critérios e subcritérios}

Os critérios referem-se às cinco dimensões adotadas (técnica, ambiental, econômica, social e política), conforme a estrutura hierárquica apresentada na Figura 5.1. 


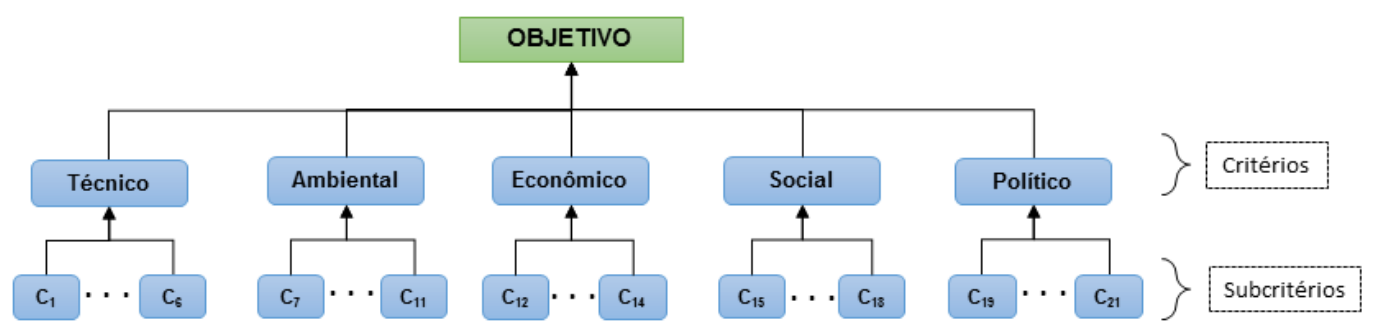

Figura 5.1 - Estrutura hierárquica do modelo para avaliação e seleção de tecnologias de geração de energia elétrica a partir de fontes renováveis

Fonte: Elaboração própria.

\section{Matrizes de comparação pareadas fuzzy usando 'Triangular Fuzzy Numbers' (TFN)}

Nessa etapa, procedeu-se ao preenchimento do cálculo/definição das matrizes pareadas, consultando-se quatro especialistas da área acadêmica e de energia, como anteriormente falado. Foram feitas duas rodadas de reuniões onde, primeiramente, os especialistas faziam a análise pareada dos critérios/subcritérios sem que os outros verificassem suas respostas, preenchendo o formulário que consta no Apêndice 2. Numa segunda etapa, tentou-se chegar a um consenso da análise pareada feita pelos especialistas com vistas a definir os parâmetros $\mathrm{a}_{1}, \mathrm{a}_{2} \mathrm{e}$ a3 do número fuzzy triangular mostrado na Figura 4.1.

De posse dos dados coletados com as opiniões dos especialistas, foram criadas as matrizes de comparação dos critérios (Tabela 5.2), subcritérios "Técnico" (Tabela 5.3), subcritérios “Ambiental" (Tabela 5.4), subcritérios "Econômico" (Tabela 5.5), subcritérios "Social" (Tabela 5.6) e subcritérios "Político" (Tabela 5.7).

Tabela 5.2 - Matriz Comparação Fuzzy: Critérios

\begin{tabular}{|l|c|c|c|c|c|}
\hline Dimensões & Ambiental & Econômico & Político & Social & Técnico \\
\hline Ambiental & $(1 ; 1 ; 1)$ & $(0,2 ; 0,25 ; 0,33)$ & $(1 ; 1 ; 2)$ & $(1 ; 2 ; 3)$ & $(0,17 ; 0,2 ; 0,25)$ \\
\hline Econômico & $(3 ; 4 ; 5)$ & $(1 ; 1 ; 1)$ & $(3 ; 4 ; 5)$ & $(3 ; 4 ; 5)$ & $(1 ; 2 ; 3)$ \\
\hline Político & $(0,5 ; 1 ; 1)$ & $(0,2 ; 0,25 ; 0,33)$ & $(1 ; 1 ; 1)$ & $(0,33 ; 0,5 ; 1)$ & $(0,2 ; 0,25 ; 0,33)$ \\
\hline Social & $(0,33 ; 0,5 ; 1)$ & $(0,2 ; 0,25 ; 0,33)$ & $(1 ; 2 ; 3)$ & $(1 ; 1 ; 1)$ & $(0,25 ; 0,33 ; 0,33)$ \\
\hline Técnico & $(4 ; 5 ; 6)$ & $(0,33 ; 0,5 ; 1)$ & $(3 ; 4 ; 5)$ & $(3 ; 3 ; 4)$ & $(1 ; 1 ; 1)$ \\
\hline
\end{tabular}


Tabela 5.3 - Matriz Comparação Fuzzy: Subcritérios subordinados ao critério Técnico

\begin{tabular}{|c|c|c|c|c|c|c|}
\hline Subcritérios & $\mathbf{T}_{\mathbf{4}}$ & $\mathbf{T}_{\mathbf{6}}$ & $\mathbf{T}_{\mathbf{3}}$ & $\mathbf{T}_{\mathbf{2}}$ & $\mathbf{T}_{\mathbf{1}}$ & $\mathbf{T}_{\mathbf{5}}$ \\
\hline $\mathrm{T}_{4}$ & $(1 ; 1 ; 1)$ & $(2 ; 3 ; 4)$ & $(0,33 ; 0,5 ; 1)$ & $(1 ; 1 ; 2)$ & $(3 ; 3 ; 3)$ & $(2 ; 3 ; 4)$ \\
\hline $\mathrm{T}_{6}$ & $(0,25 ; 0,33 ; 0,5)$ & $(1 ; 1 ; 1)$ & $(0,25 ; 0,33 ; 0,5)$ & $(0,33 ; 0,5 ; 1)$ & $(1 ; 2 ; 3)$ & $(0,5 ; 0,5 ; 1)$ \\
\hline $\mathrm{T}_{3}$ & $(1 ; 2 ; 3)$ & $(2 ; 3 ; 4)$ & $(1 ; 1 ; 1)$ & $(1 ; 2 ; 3)$ & $(1 ; 2 ; 3)$ & $(1 ; 2 ; 3)$ \\
\hline $\mathrm{T}_{2}$ & $(0,5 ; 1 ; 1)$ & $(1 ; 2 ; 3)$ & $(0,33 ; 0,5 ; 1)$ & $(1 ; 1 ; 1)$ & $(2 ; 3 ; 4)$ & $(1 ; 2 ; 3)$ \\
\hline $\mathrm{T}_{1}$ & $(0,33 ; 0,33 ; 0,33)$ & $(0,33 ; 0,5 ; 1)$ & $(0,33 ; 0,5 ; 1)$ & $(0,25 ; 0,33 ; 0,5)$ & $(1 ; 1 ; 1)$ & $(1 ; 1 ; 3)$ \\
\hline $\mathrm{T}_{5}$ & $(0,25 ; 0,33 ; 0,5)$ & $(1 ; 2 ; 2)$ & $(0,33 ; 0,5 ; 1)$ & $(0,33 ; 0,5 ; 1)$ & $(0,33 ; 1 ; 1)$ & $(1 ; 1 ; 1)$ \\
\hline
\end{tabular}

Tabela 5.4 - Matriz Comparação Fuzzy: Subcritérios subordinados ao critério Ambiental

\begin{tabular}{|c|c|c|c|c|c|}
\hline Subcritérios & $\mathbf{A}_{\mathbf{1}}$ & $\mathbf{A}_{\mathbf{3}}$ & $\mathbf{A}_{\mathbf{2}}$ & $\mathbf{A}_{\mathbf{4}}$ & $\mathbf{A}_{\mathbf{5}}$ \\
\hline $\mathrm{A}_{1}$ & $(1 ; 1 ; 1)$ & $(2 ; 3 ; 3)$ & $(1 ; 2 ; 3)$ & $(1 ; 2 ; 3)$ & $(1 ; 2 ; 3)$ \\
\hline $\mathrm{A}_{3}$ & $(0,33 ; 0,33 ; 0,5)$ & $(1 ; 1 ; 1)$ & $(1 ; 1 ; 2)$ & $(1 ; 1 ; 2)$ & $(1 ; 1 ; 2)$ \\
\hline $\mathrm{A}_{2}$ & $(0,33 ; 0,5 ; 1)$ & $(0,5 ; 1 ; 1)$ & $(1 ; 1 ; 1)$ & $(1 ; 1 ; 2)$ & $(1 ; 2 ; 3)$ \\
\hline $\mathrm{A}_{4}$ & $(0,33 ; 0,5 ; 1)$ & $(0,5 ; 1 ; 1)$ & $(0,5 ; 1 ; 1)$ & $(1 ; 1 ; 1)$ & $(1 ; 2 ; 3)$ \\
\hline $\mathrm{A}_{5}$ & $(0,33 ; 0,5 ; 1)$ & $(0,5 ; 1 ; 1)$ & $(0,33 ; 0,5 ; 1)$ & $(0,33 ; 0,5 ; 1)$ & $(1 ; 1 ; 1)$ \\
\hline
\end{tabular}

Tabela 5.5 - Matriz Comparação Fuzzy: Subcritérios subordinados ao critério Econômico

\begin{tabular}{|c|c|c|c|}
\hline Subcritérios & $\mathbf{E}_{\mathbf{1}}$ & $\mathbf{E}_{\mathbf{2}}$ & $\mathbf{E}_{\mathbf{3}}$ \\
\hline $\mathrm{E}_{1}$ & $(1 ; 1 ; 1)$ & $(1 ; 1 ; 2)$ & $(1 ; 2 ; 3)$ \\
\hline $\mathrm{E}_{2}$ & $(0,5 ; 1 ; 1)$ & $(1 ; 1 ; 1)$ & $(0,5 ; 0,5 ; 1)$ \\
\hline $\mathrm{E}_{5}$ & $(0,33 ; 0,5 ; 1)$ & $(1 ; 2 ; 2)$ & $(1 ; 1 ; 1)$ \\
\hline
\end{tabular}

Tabela 5.6 - Matriz Comparação Fuzzy: Subcritérios subordinados ao critério Social

\begin{tabular}{|c|c|c|c|c|}
\hline Subcritérios & $\mathbf{S}_{\mathbf{1}}$ & $\mathbf{S}_{\mathbf{2}}$ & $\mathbf{S}_{\mathbf{3}}$ & $\mathbf{S}_{\mathbf{4}}$ \\
\hline $\mathrm{S}_{1}$ & $(1 ; 1 ; 1)$ & $(1 ; 2 ; 3)$ & $(1 ; 2 ; 3)$ & $(0,5 ; 1 ; 1)$ \\
\hline $\mathrm{S}_{2}$ & $(0,33 ; 0,5 ; 1)$ & $(1 ; 1 ; 1)$ & $(0,33 ; 0,5 ; 1)$ & $(0,33 ; 0,5 ; 1)$ \\
\hline $\mathrm{S}_{3}$ & $(0,33 ; 0,5 ; 1)$ & $(1 ; 2 ; 3)$ & $(1 ; 1 ; 1)$ & $(0,33 ; 0,5 ; 1)$ \\
\hline $\mathrm{S}_{4}$ & $(1 ; 1 ; 2)$ & $(1 ; 2 ; 3)$ & $(1 ; 2 ; 3)$ & $(1 ; 1 ; 1)$ \\
\hline
\end{tabular}

Tabela 5.7 - Matriz Comparação Fuzzy: Subcritérios subordinados ao critério Político

\begin{tabular}{|c|c|c|c|}
\hline Subcritérios & $\mathbf{P}_{\mathbf{1}}$ & $\mathbf{P}_{\mathbf{2}}$ & $\mathbf{P}_{\mathbf{3}}$ \\
\hline $\mathrm{P}_{1}$ & $(1 ; 1 ; 1)$ & $(1 ; 1 ; 1)$ & $(2 ; 2 ; 3)$ \\
\hline $\mathrm{P}_{2}$ & $(1 ; 1 ; 1)$ & $(1 ; 1 ; 1)$ & $(1 ; 2 ; 3)$ \\
\hline $\mathrm{P}_{3}$ & $(0,33 ; 0,5 ; 0,5)$ & $(0,33 ; 0,5 ; 1)$ & $(1 ; 1 ; 1)$ \\
\hline
\end{tabular}

\section{Análise da consistência das matrizes de comparação pareadas fuzzy pelo índice de consistência}

Segundo Patil \& Kant (2012) [49], quando a matriz de comparação crisp A é consistente significa que a matriz comparação fuzzy $\tilde{A}$ também é consistente. Devido a isto, preliminarmente ao preenchimento das matrizes pareadas, optou-se pela utilização do software IPÊ durante a avaliação dos especialistas para capturar os julgamentos, permitindo a verificar se as matrizes são consistentes. O sistema 
IPÊ, versão 1.0, foi desenvolvido pela Universidade Federal Fluminense (UFF), com o objetivo de implementar o algoritmo do AHP, proposto por Thomas L. Saaty [50].

Os valores capturados foram quais critérios são preferíveis aos seus pares, e o nível de preferência utilizado o elemento central $m$ do número triangular fuzzy como o valor correspondente a pontuação utilizada pelo Ipê, que são os 9 pontos de Saaty. Esse procedimento facilitou a análise, dado que inicialmente concluiu-se que uma das matrizes de comparação não era consistente $(R C \leq 0,10)$, isso permitiu a reavaliação dos julgamentos de modo rápido. Portando, todas as seis matrizes são consistentes, como mostrado na Tabela 5.8.

Tabela 5.8 - Razão de consistência das matrizes de critérios e subcritérios

\begin{tabular}{|l|c|}
\hline \multicolumn{2}{|c|}{ Razão de Consistência $(\boldsymbol{R C})$} \\
\hline Critérios & 0,056 \\
\hline Técnico & 0,046 \\
\hline Ambiental & 0,022 \\
\hline Econômico & 0,000 \\
\hline Social & 0,023 \\
\hline Político & 0,000 \\
\hline
\end{tabular}

\section{Obtenção dos pesos dos critérios e subcritérios pelo método Fuzzy AHP}

Os pesos foram calculados pelo método da média geométrica, explicitado no capítulo 4, o algoritmo foi implementado no software Matlab. Os resultados desta etapa são apresentados na Tabela 5.9 e Tabela 5.10.

Tabela 5.9 - Pesos dos critérios pelo método Fuzzy AHP

\begin{tabular}{|l|ccc|}
\hline \multirow{2}{*}{ Dimensão } & \multicolumn{3}{|c|}{ Peso dos critérios } \\
\cline { 2 - 4 } & $a_{1}$ & $a_{2}$ & $a_{3}$ \\
\hline Técnico & 0,1623 & 0,3319 & 0,818 \\
\hline Ambiental & 0,0183 & 0,0496 & 0,1041 \\
\hline Econômico & 0,2133 & 0,5383 & 1,1959 \\
\hline Social & 0,0181 & 0,0465 & 0,1142 \\
\hline Político & 0,0168 & 0,0336 & 0,0998 \\
\hline
\end{tabular}


Tabela 5.10 - Pesos dos subcritérios pelo método Fuzzy AHP

\begin{tabular}{|c|c|c|c|c|c|}
\hline \multirow[t]{2}{*}{ Dimensão } & \multirow{2}{*}{\multicolumn{2}{|c|}{ Subcritérios }} & \multicolumn{3}{|c|}{ Peso dos subcritérios } \\
\hline & & & $a_{1}$ & $a_{2}$ & $a_{3}$ \\
\hline \multirow{6}{*}{ Técnico } & $\mathrm{T}_{1}$ & Desempenho da tecnologia & 0,012 & 0,033 & 0,190 \\
\hline & $\mathrm{T}_{2}$ & Maturidade tecnológica & 0,040 & 0,201 & 0,793 \\
\hline & $T_{3}$ & Disponibilidade/potencial de recursos & 0,072 & 0,401 & 1,649 \\
\hline & $\mathrm{T}_{4}$ & Confiabilidade do fornecimento de energia & 0,091 & 0,263 & 1,099 \\
\hline & $T_{5}$ & Distribuição descentralizada & 0,012 & 0,061 & 0,240 \\
\hline & $\mathrm{T}_{6}$ & Simplicidade de implementação & 0,013 & 0,042 & 0,218 \\
\hline \multirow{5}{*}{ Ambiental } & $A_{1}$ & Emissões de GEE & 0,124 & 0,475 & 1,354 \\
\hline & $A_{2}$ & Uso da Terra & 0,054 & 0,165 & 0,568 \\
\hline & $A_{3}$ & Conformidade com as condições naturais & 0,068 & 0,114 & 0,497 \\
\hline & $\mathrm{A}_{4}$ & Consumo de água & 0,043 & 0,165 & 0,451 \\
\hline & $A_{5}$ & Geração de resíduos & 0,026 & 0,082 & 0,313 \\
\hline \multirow[t]{3}{*}{ Econômico } & $\mathrm{E}_{1}$ & Custo nivelado de energia & 0,245 & 0,413 & 0,783 \\
\hline & $E_{2}$ & Retorno do investimento & 0,155 & 0,260 & 0,431 \\
\hline & $\mathrm{E}_{3}$ & Risco do investimento & 0,170 & 0,328 & 0,543 \\
\hline \multirow{4}{*}{ Social } & $\mathrm{S}_{1}$ & Geração de emprego e renda & 0,111 & 0,355 & 0,800 \\
\hline & $\mathrm{S}_{2}$ & Aceitação social da tecnologia & 0,046 & 0,112 & 0,384 \\
\hline & $\mathrm{S}_{3}$ & Segurança ocupacional & 0,067 & 0,178 & 0,554 \\
\hline & $\mathrm{S}_{4}$ & Desenvolvimento regional local & 0,140 & 0,355 & 1,008 \\
\hline \multirow{3}{*}{ Político } & $\mathrm{P}_{1}$ & Alinhamento com os acordos internacionais & 0,133 & 0,250 & 0,318 \\
\hline & $\mathrm{P}_{2}$ & Alinhamento às políticas nacionais & 0,167 & 0,250 & 0,318 \\
\hline & $P_{3}$ & Conformidade com os requisitos legais & 0,305 & 0,500 & 0,832 \\
\hline
\end{tabular}

\section{Fase II - Fuzzy TOPSIS}

\section{Criação das matrizes fuzzy de avaliação usando o conjunto de termos linguísticos fuzzy}

A partir do resultado dos pesos dos critérios e subcritérios, construiu-se a matriz de decisão $\widetilde{D}$, apresentada na Tabela 5.11. 
Tabela 5.11 - Matriz de decisão fuzzy das fontes renováveis versus subcritérios

\begin{tabular}{|c|c|c|c|c|c|c|c|c|c|c|c|c|c|c|c|}
\hline \multirow{2}{*}{$\widetilde{\boldsymbol{D}}$} & \multicolumn{3}{|c|}{ Hidráulica } & \multicolumn{3}{|c|}{ Fotovoltaica } & \multicolumn{3}{|c|}{ Eólica } & \multicolumn{3}{|c|}{ Biomassa } & \multicolumn{3}{|c|}{ Ondas } \\
\hline & $a_{1}$ & $a_{2}$ & $a_{3}$ & $a_{1}$ & $a_{2}$ & $a_{3}$ & $a_{1}$ & $a_{2}$ & $a_{3}$ & $a_{1}$ & $a_{2}$ & $a_{3}$ & $a_{1}$ & $a_{2}$ & $a_{3}$ \\
\hline $\mathrm{T}_{1}$ & 4,75 & 5,00 & 5,00 & 0,62 & 0,65 & 0,68 & 1,81 & 1,90 & 2,00 & 1,29 & 1,36 & 1,43 & 1,29 & 1,36 & 1,43 \\
\hline $\mathrm{T}_{2}$ & 5,00 & 5,00 & 5,00 & 3,00 & 4,00 & 5,00 & 4,00 & 4,00 & 5,00 & 3,00 & 4,00 & 5,00 & 1,00 & 2,00 & 3,00 \\
\hline$T_{3}$ & 0,28 & 0,29 & 0,31 & 1,30 & 1,37 & 1,44 & 0,78 & 1,11 & 1,44 & 0,02 & 0,04 & 0,05 & 4,75 & 5,00 & 5,00 \\
\hline $\mathrm{T}_{4}$ & 4,00 & 5,00 & 5,00 & 2,00 & 3,00 & 5,00 & 2,00 & 3,50 & 5,00 & 3,00 & 4,00 & 5,00 & 1,00 & 2,00 & 3,00 \\
\hline$T_{5}$ & 1,00 & 2,00 & 3,00 & 3,00 & 4,00 & 5,00 & 2,00 & 3,50 & 5,00 & 3,00 & 4,00 & 5,00 & 1,00 & 2,00 & 3,00 \\
\hline $\mathrm{T}_{6}$ & 1,00 & 2,00 & 2,00 & 3,00 & 4,00 & 5,00 & 3,00 & 4,00 & 5,00 & 3,00 & 3,00 & 4,00 & 1,00 & 2,00 & 3,00 \\
\hline$A_{1}$ & 4,42 & 4,85 & 4,98 & 2,69 & 4,53 & 4,93 & 4,05 & 4,74 & 4,94 & 0,00 & 4,32 & 4,89 & 4,62 & 4,82 & 4,91 \\
\hline$A_{2}$ & 0,00 & 4,62 & 4,99 & 4,62 & 4,88 & 4,99 & 4,85 & 4,85 & 4,99 & 0,38 & 1,92 & 4,23 & 4,77 & 4,88 & 4,99 \\
\hline$A_{3}$ & 1,00 & 3,00 & 5,00 & 3,00 & 4,00 & 5,00 & 3,00 & 3,50 & 4,00 & 3,00 & 3,50 & 4,00 & 2,00 & 3,00 & 4,00 \\
\hline $\mathrm{A}_{4}$ & 2,10 & 2,22 & 2,33 & 4,74 & 4,99 & 5,00 & 4,75 & 5,00 & 5,00 & 0,00 & 0,00 & 0,00 & 4,75 & 5,00 & 5,00 \\
\hline$A_{5}$ & 1,00 & 2,00 & 3,00 & 1,00 & 2,00 & 3,00 & 1,00 & 2,00 & 3,00 & 2,00 & 3,00 & 4,00 & 2,00 & 2,00 & 3,00 \\
\hline $\mathrm{E}_{1}$ & 3,92 & 4,50 & 4,92 & 0,00 & 2,17 & 4,58 & 3,96 & 4,42 & 4,79 & 2,92 & 3,92 & 4,67 & 1,67 & 3,46 & 3,92 \\
\hline$E_{2}$ & 1,00 & 2,00 & 4,00 & 3,00 & 3,00 & 4,00 & 3,00 & 4,00 & 5,00 & 1,00 & 4,00 & 5,00 & 1,00 & 1,00 & 4,00 \\
\hline$E_{3}$ & 2,00 & 3,00 & 5,00 & 2,00 & 3,00 & 5,00 & 3,00 & 3,50 & 4,00 & 3,00 & 3,50 & 4,00 & 1,00 & 2,00 & 4,00 \\
\hline $\mathrm{S}_{1}$ & 1,47 & 1,55 & 1,63 & 4,75 & 5,00 & 5,00 & 0,93 & 0,98 & 1,03 & 1,15 & 1,21 & 1,27 & 1,18 & 1,25 & 1,31 \\
\hline $\mathrm{S}_{2}$ & 3,00 & 4,00 & 4,00 & 4,00 & 5,00 & 5,00 & 3,00 & 4,00 & 5,00 & 3,00 & 3,00 & 3,00 & 2,00 & 3,00 & 3,00 \\
\hline $\mathrm{S}_{3}$ & 2,00 & 4,00 & 5,00 & 1,00 & 3,00 & 5,00 & 1,00 & 3,00 & 5,00 & 3,00 & 3,00 & 4,00 & 1,00 & 2,00 & 3,00 \\
\hline $\mathrm{S}_{4}$ & 1,00 & 3,00 & 5,00 & 1,00 & 3,50 & 5,00 & 1,00 & 2,50 & 4,00 & 3,00 & 4,00 & 5,00 & 1,00 & 3,00 & 4,00 \\
\hline $\mathrm{P}_{1}$ & 4,00 & 4,00 & 5,00 & 4,00 & 4,50 & 5,00 & 4,00 & 4,50 & 5,00 & 3,00 & 4,00 & 5,00 & 4,00 & 4,00 & 5,00 \\
\hline $\mathrm{P}_{2}$ & 4,00 & 4,50 & 5,00 & 4,00 & 4,00 & 5,00 & 4,00 & 4,00 & 5,00 & 2,00 & 4,00 & 4,00 & 1,00 & 3,00 & 4,00 \\
\hline$P_{3}$ & 3,00 & 4,00 & 5,00 & 4,00 & 4,50 & 5,00 & 3,00 & 4,00 & 5,00 & 3,00 & 4,00 & 5,00 & 1,00 & 2,00 & 3,00 \\
\hline
\end{tabular}

A multiplicação dos pesos dos critérios pelo peso das dimensões resulta no vetor peso total $\widetilde{W}$, apresentado na Tabela 5.12. 
Tabela 5.12 - Peso total dos subcritérios pelo método fuzzy AHP

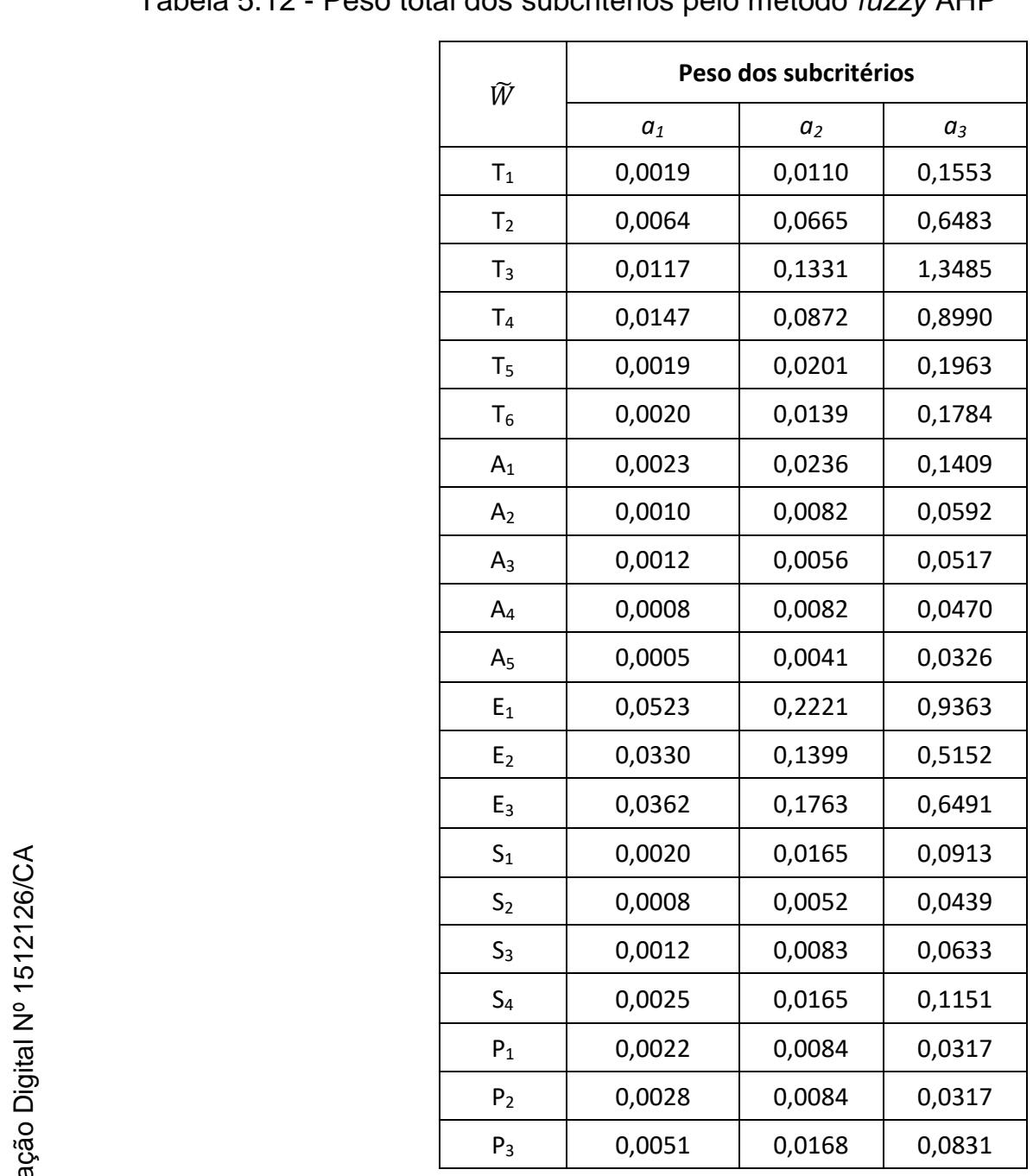

A matriz de avaliação é normalizada, utiliza-se as equações 15 e 17 para chegar a matriz normalizada e ponderada $\tilde{V}$, apresentada na Tabela 5.13. Com isso, a matriz de decisão está pronta para o cálculo das distâncias positiva e negativas. 
Tabela 5.13 - Matriz de decisão normalizada e ponderada pelo método fuzzy AHP

\begin{tabular}{|c|c|c|c|c|c|c|c|c|c|c|c|c|c|c|c|}
\hline \multirow[b]{2}{*}{$\widetilde{\boldsymbol{V}}$} & \multicolumn{3}{|c|}{ Hidráulica } & \multicolumn{3}{|c|}{ Fotovoltaica } & \multicolumn{3}{|c|}{ Eólica } & \multicolumn{3}{|c|}{ Biomassa } & \multicolumn{3}{|c|}{ Ondas } \\
\hline & $a_{1}$ & $a_{2}$ & $a_{3}$ & $a_{1}$ & $a_{2}$ & $a_{3}$ & $a_{1}$ & $a_{2}$ & $a_{3}$ & $a_{1}$ & $a_{2}$ & $a_{3}$ & $a_{1}$ & $a_{2}$ & $a_{3}$ \\
\hline $\mathrm{T}_{1}$ & 0,01 & 0,07 & 1,00 & 0,00 & 0,01 & 0,14 & 0,00 & 0,03 & 0,40 & 0,00 & 0,02 & 0,29 & 0,00 & 0,02 & 0,29 \\
\hline $\mathrm{T}_{2}$ & 0,01 & 0,10 & 1,00 & 0,01 & 0,08 & 1,00 & 0,01 & 0,08 & 1,00 & 0,01 & 0,08 & 1,00 & 0,00 & 0,04 & 0,60 \\
\hline $\mathrm{T}_{3}$ & 0,00 & 0,01 & 0,06 & 0,00 & 0,03 & 0,29 & 0,00 & 0,02 & 0,29 & 0,00 & 0,00 & 0,01 & 0,01 & 0,10 & 1,00 \\
\hline $\mathrm{T}_{4}$ & 0,01 & 0,10 & 1,00 & 0,01 & 0,06 & 1,00 & 0,01 & 0,07 & 1,00 & 0,01 & 0,08 & 1,00 & 0,00 & 0,04 & 0,60 \\
\hline $\mathrm{T}_{5}$ & 0,00 & 0,04 & 0,60 & 0,01 & 0,08 & 1,00 & 0,00 & 0,07 & 1,00 & 0,01 & 0,08 & 1,00 & 0,00 & 0,04 & 0,60 \\
\hline $\mathrm{T}_{6}$ & 0,00 & 0,03 & 0,40 & 0,01 & 0,06 & 1,00 & 0,01 & 0,06 & 1,00 & 0,01 & 0,05 & 0,80 & 0,00 & 0,03 & 0,60 \\
\hline$A_{1}$ & 0,01 & 0,16 & 1,00 & 0,01 & 0,15 & 0,99 & 0,01 & 0,16 & 0,99 & 0,00 & 0,14 & 0,98 & 0,01 & 0,16 & 0,98 \\
\hline$A_{2}$ & 0,00 & 0,13 & 1,00 & 0,02 & 0,14 & 1,00 & 0,02 & 0,13 & 1,00 & 0,00 & 0,05 & 0,85 & 0,02 & 0,14 & 1,00 \\
\hline $\mathrm{A}_{3}$ & 0,00 & 0,07 & 1,00 & 0,01 & 0,09 & 1,00 & 0,01 & 0,08 & 0,80 & 0,01 & 0,08 & 0,80 & 0,01 & 0,07 & 0,80 \\
\hline $\mathrm{A}_{4}$ & 0,01 & 0,08 & 0,47 & 0,02 & 0,17 & 1,00 & 0,02 & 0,17 & 1,00 & 0,00 & 0,00 & 0,00 & 0,02 & 0,17 & 1,00 \\
\hline$A_{5}$ & 0,00 & 0,06 & 0,75 & 0,00 & 0,06 & 0,75 & 0,00 & 0,06 & 0,75 & 0,01 & 0,09 & 1,00 & 0,01 & 0,06 & 0,75 \\
\hline $\mathrm{E}_{1}$ & 0,04 & 0,22 & 1,00 & 0,00 & 0,10 & 0,93 & 0,04 & 0,21 & 0,97 & 0,03 & 0,19 & 0,95 & 0,02 & 0,17 & 0,80 \\
\hline$E_{2}$ & 0,01 & 0,11 & 0,80 & 0,04 & 0,16 & 0,80 & 0,04 & 0,22 & 1,00 & 0,01 & 0,22 & 1,00 & 0,01 & 0,05 & 0,80 \\
\hline$E_{3}$ & 0,02 & 0,16 & 1,00 & 0,02 & 0,16 & 1,00 & 0,03 & 0,19 & 0,80 & 0,03 & 0,19 & 0,80 & 0,01 & 0,11 & 0,80 \\
\hline $\mathrm{S}_{1}$ & 0,01 & 0,06 & 0,33 & 0,02 & 0,18 & 1,00 & 0,00 & 0,04 & 0,21 & 0,01 & 0,04 & 0,25 & 0,01 & 0,05 & 0,26 \\
\hline $\mathrm{S}_{2}$ & 0,01 & 0,09 & 0,80 & 0,02 & 0,12 & 1,00 & 0,01 & 0,09 & 1,00 & 0,01 & 0,07 & 0,60 & 0,01 & 0,07 & 0,60 \\
\hline $\mathrm{S}_{3}$ & 0,01 & 0,10 & 1,00 & 0,00 & 0,08 & 1,00 & 0,00 & 0,08 & 1,00 & 0,01 & 0,08 & 0,80 & 0,00 & 0,05 & 0,60 \\
\hline $\mathrm{S}_{4}$ & 0,00 & 0,09 & 1,00 & 0,00 & 0,10 & 1,00 & 0,00 & 0,07 & 0,80 & 0,01 & 0,11 & 1,00 & 0,00 & 0,09 & 0,80 \\
\hline $\mathrm{P}_{1}$ & 0,06 & 0,21 & 1,00 & 0,06 & 0,24 & 1,00 & 0,06 & 0,24 & 1,00 & 0,04 & 0,21 & 1,00 & 0,06 & 0,21 & 1,00 \\
\hline $\mathrm{P}_{2}$ & 0,07 & 0,24 & 1,00 & 0,07 & 0,21 & 1,00 & 0,07 & 0,21 & 1,00 & 0,04 & 0,21 & 0,80 & 0,02 & 0,16 & 0,80 \\
\hline$P_{3}$ & 0,04 & 0,16 & 1,00 & 0,05 & 0,18 & 1,00 & 0,04 & 0,16 & 1,00 & 0,04 & 0,16 & 1,00 & 0,01 & 0,08 & 0,60 \\
\hline
\end{tabular}

\section{Determinação da solução ideal fuzzy positiva e negativa (FPIS e FNIS) e cálculo da distância para FPIS (D+) e para FNIS (D-)}

A padronização foi feita através dos cálculos apresentado no capítulo 4. Com os valores padronizados e calibrados fuzzy, foram calculadas as distâncias entre esses dados e as soluções ideal fuzzy positiva e negativa, que são os valores máximos e mínimos de cada subcritério respectivamente.

Na sequência, foram geradas as matrizes de distâncias $A^{+}$e $A^{-}$, por meio das equações 20 e 21 respectivamente. Os resultados são apresentados na Tabela 5.14 . 
Tabela 5.14 - Matriz de distância total positiva e negativa

\begin{tabular}{|c|c|c|c|c|c|c|c|c|c|c|}
\hline \multirow{3}{*}{ Subcritérios } & \multicolumn{10}{|c|}{ FONTES RENOVÁVEIS } \\
\hline & \multicolumn{5}{|c|}{ Distância total positiva $\left(A^{+}\right)$} & \multicolumn{5}{|c|}{ Distância total negativa $\left(A^{-}\right)$} \\
\hline & Hidráulica & Fotovoltaica & Eólica & Biomassa & Ondas & Hidráulica & Fotovoltaica & Eólica & Biomassa & Ondas \\
\hline $\mathrm{T}_{1}$ & 0,78 & 0,95 & 0,88 & 0,91 & 0,91 & 0,58 & 0,08 & 0,23 & 0,17 & 0,17 \\
\hline $\mathrm{T}_{2}$ & 0,77 & 0,78 & 0,78 & 0,78 & 0,83 & 0,58 & 0,58 & 0,58 & 0,58 & 0,35 \\
\hline$T_{3}$ & 0,98 & 0,90 & 0,91 & 1,00 & 0,77 & 0,04 & 0,17 & 0,17 & 0,01 & 0,58 \\
\hline $\mathrm{T}_{4}$ & 0,77 & 0,79 & 0,79 & 0,78 & 0,83 & 0,58 & 0,58 & 0,58 & 0,58 & 0,35 \\
\hline$T_{5}$ & 0,83 & 0,78 & 0,79 & 0,78 & 0,83 & 0,35 & 0,58 & 0,58 & 0,58 & 0,35 \\
\hline $\mathrm{T}_{6}$ & 0,87 & 0,79 & 0,79 & 0,80 & 0,84 & 0,23 & 0,58 & 0,58 & 0,46 & 0,35 \\
\hline$A_{1}$ & 0,75 & 0,75 & 0,75 & 0,76 & 0,75 & 0,58 & 0,58 & 0,58 & 0,57 & 0,58 \\
\hline$A_{2}$ & 0,77 & 0,76 & 0,76 & 0,80 & 0,76 & 0,58 & 0,58 & 0,58 & 0,49 & 0,58 \\
\hline$A_{3}$ & 0,79 & 0,78 & 0,79 & 0,79 & 0,79 & 0,58 & 0,58 & 0,46 & 0,46 & 0,46 \\
\hline $\mathrm{A}_{4}$ & 0,84 & 0,74 & 0,74 & 1,00 & 0,74 & 0,27 & 0,59 & 0,59 & 0,00 & 0,59 \\
\hline $\mathrm{A}_{5}$ & 0,80 & 0,80 & 0,80 & 0,78 & 0,80 & 0,43 & 0,43 & 0,43 & 0,58 & 0,43 \\
\hline $\mathrm{E}_{1}$ & 0,71 & 0,78 & 0,71 & 0,73 & 0,75 & 0,59 & 0,54 & 0,58 & 0,56 & 0,47 \\
\hline$E_{2}$ & 0,78 & 0,75 & 0,72 & 0,73 & 0,80 & 0,47 & 0,47 & 0,59 & 0,59 & 0,46 \\
\hline$E_{3}$ & 0,74 & 0,74 & 0,74 & 0,74 & 0,78 & 0,59 & 0,59 & 0,48 & 0,48 & 0,47 \\
\hline $\mathrm{S}_{1}$ & 0,88 & 0,74 & 0,92 & 0,91 & 0,90 & 0,19 & 0,59 & 0,12 & 0,15 & 0,15 \\
\hline $\mathrm{S}_{2}$ & 0,78 & 0,76 & 0,77 & 0,82 & 0,82 & 0,47 & 0,58 & 0,58 & 0,35 & 0,35 \\
\hline $\mathrm{S}_{3}$ & 0,77 & 0,78 & 0,78 & 0,79 & 0,83 & 0,58 & 0,58 & 0,58 & 0,46 & 0,35 \\
\hline $\mathrm{S}_{4}$ & 0,78 & 0,77 & 0,79 & 0,77 & 0,79 & 0,58 & 0,58 & 0,46 & 0,58 & 0,46 \\
\hline $\mathrm{P}_{1}$ & 0,71 & 0,70 & 0,70 & 0,72 & 0,71 & 0,59 & 0,59 & 0,59 & 0,59 & 0,59 \\
\hline $\mathrm{P}_{2}$ & 0,69 & 0,70 & 0,70 & 0,73 & 0,76 & 0,59 & 0,59 & 0,59 & 0,48 & 0,47 \\
\hline $\mathrm{P}_{3}$ & 0,74 & 0,72 & 0,74 & 0,74 & 0,81 & 0,59 & 0,59 & 0,59 & 0,59 & 0,35 \\
\hline
\end{tabular}

Fonte: Elaboração própria. 


\section{Determinação da proximidade relativa do valor ideal}

A proximidade relativa à solução ideal fuzzy é calculada por meio das distâncias totais positivas e negativas, e é denominada de coeficiente de proximidade $(C C i)$. Este será apresentado na Tabela 5.15 e representa o índice de desempenho de cada tecnologia de fontes renováveis à luz dos cinco critérios.

Tabela 5.15 - Matriz de distância total positiva e negativa

\begin{tabular}{|c|c|c|c|}
\hline \multirow{2}{*}{ Tecnologias } & \multicolumn{2}{|c|}{ Distâncias } & \multirow{2}{*}{$\mathcal{*}$ C $\boldsymbol{C}_{\boldsymbol{i}}$} \\
\cline { 2 - 3 } & $D^{+}$ & $D^{-}$ & \\
\hline Hidráulica & 16,5461 & 10,0361 & 0,3775 \\
\hline Fotovoltaica & 16,2781 & 11,0220 & 0,4037 \\
\hline Eólica & 16,3441 & 10,5166 & 0,3915 \\
\hline Biomassa & 16,8254 & 9,3000 & 0,3560 \\
\hline Ondas & 16,7945 & 8,9019 & 0,3464 \\
\hline
\end{tabular}

\section{Ordenação final das tecnologias de geração de energia a partir de fontes renováveis}

Conforme o coeficiente de proximidade (CCi), a hierarquização das tecnologias de geração de energia a partir de fontes renováveis, sendo a primeira aquela com maior valor do Coeficiente de Proximidade (CCi), a saber: (i) fotovoltaica $(0,404)$; (ii) eólica $(0,392)$; (iii) hidrelétrica $(0,378)$; (iv) biomassa $(0,356)$; e (v) ondas $(0,346)$.

\section{3. \\ Discussão dos resultados}

Esta seção sintetiza os fatos pertinentes ao resultado final da modelagem proposta nesta dissertação, aplicada ao planejamento energético do Estado do Rio de Janeiro, apontando-se as tecnologias de geração de energia elétrica com mais benefícios potenciais para o Estado, na perspectiva do desenvolvimento sustentável.

Durante o julgamento dos especialistas em relação aos pesos dos critérios e subcritérios, observou-se uma tendência de preferência pelo critério 'Econômico'. A título de ilustração, no agrupamento de subscritérios do critério 'Social', considerou-se o subcritério Desenvolvimento regional local o mais importante, provavelmente por suas interseções com critério 'Econômico'. 
A fonte de geração fotovoltaica foi a que apresentou maior pontuação dentre as cinco avaliadas para o Estado do Rio de Janeiro. Particularmente, em relação ao subcritério 'Riscos de investimento', a tecnologia fotovoltaica foi a que apresentou menor risco, segundo o modelo proposto, seguida pela fonte de geração hidráulica. Além disso, com relação ao subcritério 'Retorno do investimento', a fonte de geração de energia solar e a eólica foram as mais bem avaliadas, com menor payback esperado.

Em relação ao subcritério 'Custo nivelado de energia', os julgamentos sobre a tecnologia fotovoltaica apresentaram uma maior dispersão em relação às demais tecnologias, tendendo mais para valores inferiores (78,04 - 936,48 US\$/MWh). Já a melhor pontuação em relação a esse subcritério foi para a fonte hidráulica (15,61 $-202,90$ US\$/MWh) [1].

Apesar da tecnologia de ondas ter um potencial mais elevado, em relação ao subcritério 'Disponibilidade/potencial de recursos' no Estado do Rio de Janeiro, esta tecnologia obteve a menor pontuação geral no ranking. Já a fonte solar obteve o segundo lugar, o que também contribuiu para atingir o primeiro lugar no ranking geral, como já abordado.

No que tange ao subcritério 'Confiabilidade do fornecimento de energia', os especialistas consideraram a fonte hidráulica como a mais bem avaliada. Entretanto, verificou-se no questionário que esta resposta pode estar enviesada, pois se pretendia obter respostas em relação a usinas do tipo $\mathrm{PCH}$ e não hídricas com reservatório. Seria recomendável que no formulário esta fonte fosse descrita com mais detalhes para que este tipo de confusão não ocorresse.

Com relação ao subcritério 'Maturidade tecnológica', a fonte hidráulica obteve o peso mais alto, já a tecnologia de ondas obteve pontuação baixa, o que também contribuiu com posição desta no último lugar do ranking geral. 


\section{6 Conclusões e recomendações}

A presente pesquisa contribuiu para o avanço do conhecimento sobre avaliação e seleção das opções tecnológicas para geração de energia elétrica a partir de fontes renováveis, aplicando-se método multicritério de apoio à decisão combinados com a teoria de conjuntos fuzzy. Deste modo, um modelo conceitual e respectivo instrumento de diagnóstico e avaliação do desempenho das fontes renováveis foram desenvolvidos e aplicados escolher as opções mais favoráveis considerando as especificidades do Estado do Rio de Janeiro. Os resultados obtidos ao longo da pesquisa aqui relatada permitiram que o objetivo geral da dissertação fosse alcançado, qual seja: "propor um modelo de avaliação e seleção do desempenho de tecnologias para geração de energia elétrica a partir de fontes renováveis, com o auxílio de métodos multicritério de apoio à decisão sob incerteza".

As abordagens conceituais e metodológicas discutidas nos capítulos 3 e 4 fundamentaram o desenvolvimento do referido modelo, contribuindo de forma significativa para que os objetivos específicos da dissertação fossem alcançados.

Com relação ao primeiro e segundo objetivos específicos - "Caracterizar as alternativas tecnológicas para geração de energia elétrica a partir de fontes renováveis" e "discutir a importância de se avaliar a sustentabilidade econômica, social e ambiental de alternativas tecnológicas para geração de energia elétrica a partir de fontes renováveis em diferentes contextos regionais ou locais”, os resultados da revisão bibliográfica sobre as fontes renováveis e métodos de avaliação das alternativas, revelaram que a maioria das abordagens buscam se distanciar do modo de avaliação unidimensional, focado apenas nos aspectos econômicos ou ambientais. Assim, evidencia-se a importância em avaliar globalmente todas as dimensões influenciadas pela utilização de tecnologias para geração de energia elétrica, dentre elas, as fontes renováveis que mesmo sem utilizar recursos finitos para geração de energia, podem causar impactos negativos dependendo da situação. Para evitar esses problemas, análises que considerem 
principalmente as dimensões econômica, técnica, ambiental e social se tornam evidente a fim de promover o desenvolvimento sustentável do meio social em que as tecnologias são inseridas.

O terceiro objetivo - "identificar e analisar os modelos que veem sendo adotados para se avaliar a sustentabilidade de tecnologias de geração e que empregam métodos multicritério de apoio à decisão", os resultados da revisão bibliográfica sobre os modelos para avaliar as fontes renováveis revelaram que a maioria das abordagens utilizam modelos multicritério de apoio à decisão para solucionar as questões que envolvem diversos atores no processo decisório, métodos como o AHP, ELECTREE e TOPSIS são bastante utilizadas, além de novas propostas de utilização e combinações de métodos, entre eles a inserção da teoria dos conjuntos fuzzy nas análises. Essa revisão bibliográfica permitiu concluir que o uso de modelos multicritério fuzzy para avaliar o desempenho das fontes renováveis vem sendo utilizados em alguns estudos, porém, não foram identificados exemplos de aplicação no Brasil.

Com relação ao quarto e quinto objetivos específicos - "definir os critérios e subcritérios para avaliar as tecnologias de geração de energia elétrica a partir de fontes renováveis" e "desenvolver um modelo conceitual e avaliação do desempenho de tecnologias para geração de energia elétrica a partir de fontes renováveis, com uso de métodos multicritério de apoio a decisão sob incerteza", foi plenamente atingido, como reportado capítulo 4. Concebeu-se um modelo integrado fuzzy AHP-TOPSIS, que considera a complexidade, subjetividade e incerteza como características inerentes à avaliação e seleção de tecnologias de geração de energia elétrica a partir de fontes renováveis. Acredita-se que esse modelo tem um amplo potencial de aplicação no planejamento energético de diferentes contextos regionais.

Os resultados do estudo empírico abrangendo o potencial de aproveitamento dos recursos renováveis do Estado do Rio de Janeiro para geração de energia elétrica permitiram demonstrar teoricamente a aplicabilidade do modelo proposto nesta pesquisa. Atingiu-se assim o sexto objetivo especifico da dissertação. Esses resultados evidenciaram ainda os seguintes diferenciais do modelo proposto em relação as técnicas que não utilizam recursos para considerar as incertezas nas análises: (i) o grande número de critérios e subcritérios podem ser considerados em sua totalidade, representando diferentes dimensões, observando-se os 
princípios sistêmico, consistência, independência, mensurabilidade e comparabilidade; (ii) consideram-se os julgamentos de especialistas quanto à importância/preferência de cada critério e subcritério; (iii) a abrangência das funções de pertinência no ambiente da lógica fuzzy corroboram para a consideração das incertezas enfrentadas pelos decisores, tornando o modelo desenvolvido mais realístico para avaliar tecnologias de geração de energia elétrica.

Contextualizando-se esses resultados, de fato, a tecnologia de Ondas recebeu as menores pontuações segundo os julgamentos dos especialistas, apesar de ter um dos maiores potencias de geração estimado, já a fonte fotovoltaica, é considerada a tecnologia de geração de energia renovável que mais gera empregos no mundo, esta foi avaliada como satisfatória segundo a maioria do critérios, mas em alguns teve um desempenho menor, inclusive menor que o das "ondas", por exemplo, o potencial estimado para geração de energia "fotovoltaica" é cerca de $1 / 4$ do potencial das "ondas".

Os resultados indicam que o modelo fuzzy AHP-TOPSIS é um tipo de análise multicritério consistente, com a capacidade de processar os dados de diversas dimensões para exibir um resultado global. Somados a isto, a possibilidade de inserir dados com alto nível de dispersão, torna o método mais confiável, no caso das emissões de $\mathrm{CO}_{2}$ por exemplo, se fosse utilizado apenas o valor médio em algum tipo de análise, essa poderia ser considerada menos crível, sabendo que as emissões da tecnologia eólica por exemplo, tem média estimada de $34,2 \mathrm{gCO}_{2 \mathrm{eq}} / \mathrm{kWh}$, com valores que variam de 8 a $124 \mathrm{gCO}_{2 \mathrm{eq}} / \mathrm{kWh}$.

Portando, o modelo considera a estrutura hierárquica e multidimensional da pesquisa realizada, permitindo atribuir pesos, de acordo com a importância de cada dimensão e tema, ou seja, cada nível hierárquico. O modelo também leva em consideração a complexidade, subjetividade e incerteza, sendo essas características inerentes ao processo de avaliação dos aspectos não mensuráveis ou de difícil mensuração, que precisam ser considerados nos processos decisórios em energia.

Para trabalhos futuros de desdobramento da pesquisa e aprofundamento dos resultados, propõem-se: 
- Aplicação do modelo em outras regiões, como forma de comparar os resultados e destacar as diferenças que poderiam surgir;

- Aplicação deste questionário de avaliação das fontes renováveis para o julgamento de especialista de grupos mais heterogêneos, como representantes da sociedade em geral, políticos, arquitetos e ambientalistas;

- Com uma amostra maior, análises estatísticas poderão ser feitas, principalmente buscando-se a correlação de preferencias tecnologias por grupos de especialistas, além de desenvolver análises com máxima proximidade da realidade;

- Elaboração e comparação de novos métodos híbridos de lógica fuzzy e métodos multicritérios como fuzzy ELECTRE, PROMETHEE, VIKOR, dentre outros;

- Investigar a utilização de diferentes funções de pertinência como trapezoidal e gaussiana, ao invés de Números Fuzzy Triangular (TFN);

- Concentrar esforços para aquisição de dados mais exatos sobre o desempenho das fontes alternativas, como quantidade de empregos gerados e geração de resíduos, reduzir a quantidades de avaliações subjetivas pode melhorar a confiabilidade das análises.

Pelos aspectos descritos e resultados gerados na fase aplicada da pesquisa, considera-se que o modelo de avaliação e seleção das fontes renováveis poderá contribuir com diversos processos de tomada de decisão na área de energia e estimular novos estudos para melhorar as técnicas de análise multicritério de apoio à decisão. 


\section{Referências bibliográficas}

1. TROLDBORG, M.; HESLOP, S.; HOUGH, R. L. Assessing the sustainability of renewable energy technologies using multi-criteria analysis: Suitability of approach for national-scale assessments and associated uncertainties. Renewable and Sustainable Energy Reviews, v.39, p. 1173-1184, 2014.

2. SHMELEV, S. E.; BERGH, J. C. J. M. V. D. Optimal diversity of renewable energy alternatives under multiple criteria: Anapplication to the UK. Renewable and Sustainable Energy Reviews, v. 60, p. 679-691, 2016.

3. WANG, J.-J. et al. Review on multi-criteria decision analysis aid in sustainable energy decision-making. Renewable and Sustainable Energy Reviews, v.13, p. 2263-2278, 2009.

4. ASSEMBLÉIA GERAL DA ONU (AG). Resolução 65/151. AG Index: A/RES/65/151, 16 fev. 2011. Disponivel em: 〈www.un.org〉. Acesso em 16 abr. 2017.

5. EPE. Plano Decenal de Expansão de Energia 2024. Ministério de Minas e Energia, Empresa de Pesquisa Energética. Brasília: MME/EPE, 2015.

6. TRINDADE, J. E. D. O. Mensuração e avaliação da capacidade inovativa de micro, pequenas e médias empresas: aplicação de métodos multicritério fuzzy de apoio à decisão. Rio de Janeiro, 2016. 107p. Dissertação (Mestrado). Programa de Pós-graduação em Metrologia. Pontifícia Universidade Católica do Rio de Janeiro.

7. COWAN, K. R. et al. Forecasting the adoption of emerging energy technologies: managing climate change and evolving social values. In: PICMET 2009. Proceedings... Portland: PICMET, 2009. p. 3048-3058.

8. EPE. Anuário Estatístico de Energia Elétrica 2015 ano base 2014. Empresa de Pesquisa Energética. Brasília: EPE, 2015.

9. CLEMENTE, T. R. N. et al. Aplicação do promethee-roc na priorização de tecnologias críticas para a geração de energia. In: XXXV ENEGEP Fortaleza: ABEPRO, 2015. 13p.

10. VERGARA, S. C. Metodologia do trabalho científico. São Paulo: Cortez, 2002. 
11. VERGARA, S. C. Métodos de pesquisa em administração. São Paulo: Atlas, 2005 .

12. MME. Resenha Energética Brasileira. Ministério de Minas e Energia. Brasília: MME, 2016.

13. IEA-ETSAP; IRENA. Hydropower technology brief. 2015. Disponivel em: <www.irena.org>. Acesso em: 12 mar. 2017.

14. EPE. Energia renovável: hidráulica, biomassa, eólica, solar, oceânica Empresa de Pesquisa Energética. Brasília: EPE, 2016.

15. IEA-ETSAP; IRENA. Biomass for heat and power. 2015. Disponivel em: <www.irena.org/Publications>. Acesso em: 15 mar. 2017.

16. IEA-ETSAP; IRENA. Wind Power. IRENA, março 2016. Disponivel em: <www.irena.org>. Acesso em: 16 fev. 2017.

17. IRENA. Letting in the light: how solar photovoltaics will revolutionise the electricity system. IRENA, 2016. Disponivel em: <http://www.irena.org>. Acesso em: 06 abr. 2017.

18. IEA-ETSAP; IRENA. Solar photovoltaics - technology brief. IRENA, 2013. Disponivel em: <www.irena.org>. Acesso em: 23 mar. 2017.

19. MACHADO, G. A. Energia oceânica em zonas costeiras urbanas: estudo de caso no Bairro do Leme, Rio de Janeiro, 2016. 99p. Dissertação (Mestrado). Programa de Pós-Graduação em Engenharia Urbana e Ambiental. Pontifícia Universidade Católica do Rio de Janeiro, Rio de Janeiro.

20. IRENA. Wave energy technology brief. IRENA, 2014. Disponivel em: <www.irena.org>. Acesso em: 18 mar. 2017.

21. MATEK, B. Annual U.S. \& Global Geothermal Power Production Report. Geothermal Energy Association, 2016. Disponivel em: <www.geoenergy.org>. Acesso em: 10 abr. 2017.

22. CCEE. Câmara de Comercialização de Energia Elétrica, 2017. Disponivel em: <www.ccee.org.br>. Acesso em: 11 abr. 2017.

23. AMPONSAH, N. Y. et al. Greenhouse gas emissions from renewable energy sources: A review of lifecycle considerations. Renewable and Sustainable Energy Reviews, v.39, p. 461-475, 2014.

24. LENZEN, M.; MUNKSGAARD, J. Energy and $\mathrm{CO}_{2}$ life-cycle analyses of wind turbines-review and applications. Renewable Energy, v.26, p. 339-362, 2002. 
25. CARRERA, D. G.; MACK, A. Sustainability assessment of energy technologies via social indicators: results of a survey among European energy experts. Energy Policy, v.38, p.1030-1039, 2010.

26. BARIS, K.; KUCUKALI, S. Availibility of renewable energy sources in Turkey: Current situation, potential,government policies and the EU perspective. Energy Policy, v. 42, p.377-391, 2012.

27. LIU, G. Development of a general sustainability indicator for renewable energy systems: A review. Renewable and Sustainable Energy Reviews, v.31, p. 611-621, 2014.

28. KAYA, T.; KAHRAMAN, C. Multicriteria renewable energy planning using an integrated fuzzy VIKOR \& AHP methodology: The case of Istanbul. Energy, v.35, p. 2517-2527, 2010.

29. ŞENGÜL, Ü. et al. Fuzzy TOPSIS method for ranking renewable energy supply systems in Turkey. Renewable Energy, v.75, p. 617-625, 2014.

30. CHANG, D.-Y. Applications of the extent analysis method on fuzzy AHP. European Journal of Operational Research, v.95, p. 649-655, 1996.

31. LIMA JÚNIOR, Francisco Rodrigues. Comparação entre os métodos Fuzzy TOPSIS e Fuzzy AHP no apoio à tomada de decisão para seleção de fornecedores. 2013. Dissertação (Mestrado em Processos e Gestão de Operações) - Escola de Engenharia de São Carlos, Universidade de São Paulo, São Carlos, 2013.

32. ŠTREIMIKIENĖ, D.; ŠLIOGERIENè, J.; TURSKIS, Z. Multi-criteria analysis of electricity generation technologies in Lithuania. Renewable Energy, v.85, p.148-156, 2016.

33. AL GARNI, H. et al. A multicriteria decision making approach for evaluating renewable. Sustainable Energy Technologies and Assessments, v.16, p.137$150,2016$.

34. HADIAN, S.; MADANI, K. A system of systems approach to energy sustainability assessment: Are all renewables really green?. Ecological Indicators, v.52, p. 194-206, 2015.

35. SANTOYO-CASTELAZO, E.; AZAPAGIC, A. Sustainability assessment of energy systems: integrating environmental, economic and social aspects. Journal of Cleaner Production, v.80, p. 119-138, 2014.

36. MOURMOURIS, J. C.; POTOLIAS, C. A multi-criteria methodology for energy planning and developing renewable energy sources at a regional level: A case study Thassos, Greece. Energy Policy, v. 52, p. 522-530, 2013 
37. GEORGOPOULOU, E.; LALAS, D.; PAPAGIANNAKIS, L. A Multicriteria Decision Aid approach for energy planning problems: The case of renewable energy option. European Journal of Operational Research, v. 103, p. 38-54, 1997.

38. PACHECO, M. A. C.; VELLASCO, M. B. R. Sistemas inteligentes de apoio à decisão: análise econômica de projetos de desenvolvimento de campos de petróleo sob incerteza. 1.ed. Rio de Janeiro: Editora Interciência, 2007. 306p.

39. ZADEH, L. A. Fuzzy sets. Information and Control, v.8, p. 338-353, 1996.

40. ARCE, M. E. et al. The use of grey-based methods in multi-criteria decision analysis for the evaluation of sustainable energy systems: A review. Renewable and Sustainable Energy Reviews, v.47, p. 924-932, 2015.

41. TANSCHEIT, R. Sistemas fuzzy. Inteligência computacional aplicada (ELE1361). Disponivel em: <www.academico.ica.ele.puc-rio.br>. Acesso em: 8 mai. 2017.

42. MELLO, A. F. P. Monitoramento e avaliação da regulamentação sobre recolhimento de alimentos no Brasil: proposição de indicadores e métricas. Rio de Janeiro, 2015. 185p. Dissertação (Mestrado). Programa de Pósgraduação em Metrologia. Pontifícia Universidade Católica do Rio de Janeiro, Rio de Janeiro.

43. LIMA JUNIOR, F. R.; CARPINETTI, L. C. R. Uma comparação entre os métodos TOPSIS e Fuzzy-TOPSIS no apoio à tomada de decisão multicritério para seleção de fornecedores. Gest. Prod., São Carlos, v. 22, n. 1, p. 17-34, Mar. 2015.

44. IBGE. Estados@, 2016. Disponivel em: <http://www.ibge.gov.br>. Acesso em: 15 fev. 2017.

45. RIO DE JANEIRO. Secretaria de Desenvolvimento, Energia, Indústria e Serviços. Balanço Energético do Estado do Rio de Janeiro 2014. Rio de Janeiro: SEDEIS, 2014.

46. INEA. RT-05 - Aproveitamentos hidrelétricos no Estado do Rio de Janeiro. Rio de Janeiro: Governo do Estado do Rio de Janeiro, 2014.

47. AMARANTE, O. A. C. D.; SILVA, F. D. J. L. D.; RIOS FILHO, L. G. R. F. Atlas Eólico do Estado do Rio de Janeiro. Rio de Janeiro: Governo do Estado do Rio de Janeiro, 2002.

48. USP; Grupo de Pesquisa em Bioenergia - GBIO. Atlas de Biomassa. 2012. Disponivel em: <http://www.iee.usp.br>. Acesso em: 14 set. 2016. 
49. PATIL, S. K.; KANT, R. A fuzzy AHP-TOPSIS framework for ranking the solutions of Knowledge Management adoption in Supply Chain to overcome its barriers. Expert Systems with Applications, v.41, p. 679-693, 2014.

50. COSTA, H. G. IPÊ 1.0: guia do usuário. Niterói: UFF, 2004. 


\section{Apêndice 1 - Descrição dos critérios}

\section{Critério: Técnico}

Desempenho da tecnologia. Esse subcritério retrata o quão eficiente uma determinada tecnologia é em converter sua fonte de energia primária em energia elétrica. O desempenho ideal seria uma eficiência de $100 \%$, mas isso varia, principalmente em função de limitações tecnológicas e condições ambientais.

Maturidade tecnológica. Esse subcritério qualitativo reflete o estado da arte, o nível de difusão e a disponibilidade comercial de uma dada tecnologia.

Disponibilidade/potencial de recursos. Esse subcritério quantitativo reflete o peso de cada tecnologia de energia renovável devido a disponibilidade dos recursos naturais para o suprimento de energia aos sistemas de geração.

Confiabilidade do fornecimento de energia. A confiabilidade é a capacidade de um sistema de energia em realizar o que foi projetado e sua resistência a falhas ou interrupções, o subcritério é avaliado qualitativamente.

Distribuição descentralizada. Descentralização é uma vantagem importante das fontes alternativas, construí-las próxima aos consumidores reduz os gargalos e perdas na distribuição, adia os investimentos em grandes sistemas de geração e apoia a adaptação das redes inteligentes. O subcritério avalia qualitativamente a facilidade de adotar a tecnologia próxima aos centros de consumo de energia.

Simplicidade de implementação. O subcritério representa qualitativamente o período de tempo gasto durante a construção e instalação das usinas. Quanto menor for o tempo, melhor.

\section{Critério: Ambiental}

Emissões de gases do efeito estufa (GEE). A produção de energia é a principal causa dos $\mathrm{GEE}-\mathrm{CO}_{2}, \mathrm{CH}_{4}, \mathrm{~N}_{2} \mathrm{O}, \mathrm{HFCs}$, PFC e $\mathrm{SF}_{6}$ - evita-los é importante porque esses gases impactam diretamente na vida humana e indiretamente na sociedade. A unidade padrão para medir quantitativamente os gases do efeito estufa é $\mathrm{CO}_{2} \mathrm{eq}$, que expressa o impacto de cada um dos gases em termos de quantidade de $\mathrm{CO}_{2}$ necessária para causar a mesma quantidade de aquecimento.

Uso da terra (área). A área requerida para a implantação das fontes energias renováveis é um subcritério quantitativo importante a considerar, visto que talvez tenham que competir por terras utilizadas para outros fins como agricultura, recreação e conservação ambiental. É avaliado e expresso como $\mathrm{m}^{2}$ por $\mathrm{kW}$ de potência instalada. 
Conformidade com as condições naturais locais. Esse subcritério qualitativo representa os impactos ao ecossistema associados às fontes alternativas como ruídos, odores, reação negativa da população ao impacto visual, potenciais riscos aos animais silvestres e a biodiversidade etc.

Consumo de água. Um dos efeitos secundários mais notável nos processos de produção de energia é o esgotamento dos recursos hídricos, a pegada hídrica representa a quantidade total de água doce utilizada para produzir diferentes produtos e é uma métrica confiável para avaliar a eficiência do uso da água. A unidade de medida é expressa em $\mathrm{m}^{3}$ por unidade de eletricidade gerada.

Geração de resíduos ao final do ciclo de vida. O descarte e tratamento dos resíduos gerados pelas tecnologias de fontes alternativas ao longo de todo o ciclo de vida é um subcritério qualitativo importante para avaliar os impactos ao meio ambiente.

\section{Critério: Econômico}

Custo Nivelado de Energia. É um subcritério quantitativo bastante simples para comparar distintas tecnologias de geração, os parâmetros fundamentais para seu cálculo são: os custos de investimento, combustível, operação e manutenção (O\&M), vida útil, fator de capacidade médio e taxa de desconto. A unidade de avaliação é em $\$ / M W h$.

Retorno do investimento (Payback). Esse subcritério quantitativo refere-se ao período de tempo necessário para "pagar" a soma do investimento original em um projeto de energia. É mensurado em anos.

Risco do investimento. Avalia o grau de incerteza nos custos de investimento dos projetos de geração, as incertezas podem envolver problemas geológicos, ambientais, trabalhistas e conexão à rede elétrica por exemplo. É um subcritério qualitativo.

\section{Critério: Social}

Geração de emprego e renda. Esse subcritério quantitativo demonstra o potencial de criação de postos de trabalho como consequência da implementação de sistemas de fornecimento de energia, desde a construção até o desmantelamento, incluindo operação e manutenção. É avaliado em empregos gerados por MWh.

Aceitação social da tecnologia. Esse subcritério qualitativo baseia-se na avaliação da aceitação popular das diversas tecnologias de geração de energia elétrica partir de fontes renováveis. A oposição pública ao desenvolvimento e investimento em novas usinas de energia renováveis é considerado um obstáculo chave para a expansão das fontes renováveis.

Toxicidade humana e segurança ocupacional. O subcritério mensura qualitativamente o grau de segurança das tecnologias de geração de energia para a saúde humana. Durante todas das fases de um projeto devem ser considerados o 
potencial de intoxicação, o risco de acidentes ocupacionais e fatais, os perigos a saúde pública e etc.

Desenvolvimento regional local. O subcritério estima qualitativamente os impactos positivos na localidade onde um novo projeto de geração de energia é desenvolvido, como a criação de novos empregos e negócios, beneficiando as áreas educacional, cultural e científica.

\section{Critério: Político}

Alinhamento com os acordos internacionais. Avalia a contribuição de uma dada tecnologia para a conformidade com os atos internacionais - tratados, convenções, acordos, protocolos etc. - relacionados ao desenvolvimento sustentável: COP-21 e Rio+20 por exemplo. É um subcritério qualitativo.

Alinhamento às políticas públicas nas esferas federal e estadual. O subcritério qualitativo avalia o atendimento aos requisitos exigidos pelas políticas públicas de incentivo as fontes de energias renováveis como Proinfa, PNEf e BNDES Finem - Geração de energia.

Conformidade com os requisitos legais. O subcritério reflete a conformidade de uma dada tecnologia com a regulamentação, normatização e padronização referentes a geração de energia elétrica. Exemplos: PRODIST (Normas e padrões da ANEEL dos sistemas de distribuição de energia elétrica), Resolução normativa 482/2012 e 687/2015 (Estabelece condições gerais para microgeração e minigeração de energia elétrica), Decreto 5163/2004 (Regulamenta a comercialização, concessão e geração de energia elétrica). A avaliação é qualitativa. 


\section{Apêndice 2 - Formulário de comparação pareada}

Nome do Especialista:

Foco principal: Avaliação e seleção de tecnologias para geração de energia elétrica a partir de fontes renováveis.

\section{CRITÉRIOS}

\begin{tabular}{|c|c|c|}
\hline \multicolumn{2}{|l|}{ Preferência } & Julgamento \\
\hline$\square$ Ambiental & $\square$ Econômico & $\square 1 \square 2 \square 3 \square 4 \square 5 \square 6 \square 7 \square 8 \square 9$ \\
\hline$\square$ Ambiental & $\square$ Político & $\square 1 \square 2 \square 3 \square 4 \square 5 \square 6 \square 7 \square 8 \square 9$ \\
\hline$\square$ Ambiental & $\square$ Social & $\square 1 \square 2 \square 3 \square 4 \square 5 \square 6 \square 7 \square 8 \square 9$ \\
\hline$\square$ Ambiental & $\square$ Técnico & $\square 1 \square 2 \square 3 \square 4 \square 5 \square 6 \square 7 \square 8 \square 9$ \\
\hline$\square$ Econômico & $\square$ Político & $\square 1 \square 2 \square 3 \square 4 \square 5 \square 6 \square 7 \square 8 \square 9$ \\
\hline$\square$ Econômico & $\square$ Social & $\square 1 \square 2 \square 3 \square 4 \square 5 \square 6 \square 7 \square 8 \square 9$ \\
\hline$\square$ Econômico & $\square$ Técnico & $\square 1 \square 2 \square 3 \square 4 \square 5 \square 6 \square 7 \square 8 \square 9$ \\
\hline$\square$ Político & $\square$ Social & $\square 1 \square 2 \square 3 \square 4 \square 5 \square 6 \square 7 \square 8 \square 9$ \\
\hline$\square$ Político & $\square$ Técnico & $\square 1 \square 2 \square 3 \square 4 \square 5 \square 6 \square 7 \square 8 \square 9$ \\
\hline$\square$ Social & $\square$ Técnico & $\square 1 \square 2 \square 3 \square 4 \square 5 \square 6 \square 7 \square 8 \square 9$ \\
\hline
\end{tabular}


Critério TÉCNICO: subcritérios

\begin{tabular}{|c|c|c|}
\hline \multicolumn{2}{|l|}{ Preferência } & \multirow{2}{*}{$\begin{array}{l}\text { Julgamento } \\
\square 1 \square 2 \square 3 \square 4 \square 5 \square 6 \square 7 \square 8 \square 9\end{array}$} \\
\hline $\begin{array}{l}\square \text { Confiabilidade do } \\
\text { fornecimento de energia }\end{array}$ & $\begin{array}{l}\square \text { Simplicidade de } \\
\text { implementação }\end{array}$ & \\
\hline $\begin{array}{l}\square \text { Confiabilidade do } \\
\text { fornecimento de energia }\end{array}$ & $\begin{array}{l}\square \text { Disponibilidade/potencial } \\
\text { de recursos para geração } \\
\text { de energia }\end{array}$ & $\square 1 \square 2 \square 3 \square 4 \square 5 \square 6 \square 7 \square 8 \square 9$ \\
\hline $\begin{array}{l}\square \text { Confiabilidade do } \\
\text { fornecimento de energia }\end{array}$ & $\begin{array}{l}\square \text { Maturidade da } \\
\text { tecnologia }\end{array}$ & $\square 1 \square 2 \square 3 \square 4 \square 5 \square 6 \square 7 \square 8 \square 9$ \\
\hline $\begin{array}{l}\square \text { Confiabilidade do } \\
\text { fornecimento de energia }\end{array}$ & $\begin{array}{l}\square \text { Desempenho da } \\
\text { tecnologia }\end{array}$ & $\square 1 \square 2 \square 3 \square 4 \square 5 \square 6 \square 7 \square 8 \square 9$ \\
\hline $\begin{array}{l}\square \text { Confiabilidade do } \\
\text { fornecimento de energia }\end{array}$ & $\begin{array}{l}\square \text { Distribuição } \\
\text { descentralizada }\end{array}$ & $\square 1 \square 2 \square 3 \square 4 \square 5 \square 6 \square 7 \square 8 \square 9$ \\
\hline $\begin{array}{l}\square \text { Simplicidade de } \\
\text { implementação }\end{array}$ & $\begin{array}{l}\square \text { Disponibilidade/potencial } \\
\text { de recursos para geração } \\
\text { de energia }\end{array}$ & $\square 1 \square 2 \square 3 \square 4 \square 5 \square 6 \square 7 \square 8 \square 9$ \\
\hline $\begin{array}{l}\square \text { Simplicidade de } \\
\text { implementação }\end{array}$ & $\begin{array}{l}\square \text { Maturidade da } \\
\text { tecnologia }\end{array}$ & $\square 1 \square 2 \square 3 \square 4 \square 5 \square 6 \square 7 \square 8 \square 9$ \\
\hline $\begin{array}{l}\square \text { Simplicidade de } \\
\text { implementação }\end{array}$ & $\begin{array}{l}\square \text { Desempenho da } \\
\text { tecnologia }\end{array}$ & $\square 1 \square 2 \square 3 \square 4 \square 5 \square 6 \square 7 \square 8 \square 9$ \\
\hline $\begin{array}{l}\square \text { Simplicidade de } \\
\text { implementação }\end{array}$ & $\begin{array}{l}\square \text { Distribuição } \\
\text { descentralizada }\end{array}$ & $\square 1 \square 2 \square 3 \square 4 \square 5 \square 6 \square 7 \square 8 \square 9$ \\
\hline $\begin{array}{l}\square \text { Disponibilidade/potencial } \\
\text { de recursos para geração de } \\
\text { energia }\end{array}$ & $\begin{array}{l}\square \text { Maturidade da } \\
\text { tecnologia }\end{array}$ & $\square 1 \square 2 \square 3 \square 4 \square 5 \square 6 \square 7 \square 8 \square 9$ \\
\hline $\begin{array}{l}\square \text { Disponibilidade/potencial } \\
\text { de recursos para geração de } \\
\text { energia }\end{array}$ & $\begin{array}{l}\square \text { Desempenho da } \\
\text { tecnologia }\end{array}$ & $\square 1 \square 2 \square 3 \square 4 \square 5 \square 6 \square 7 \square 8 \square 9$ \\
\hline $\begin{array}{l}\square \text { Disponibilidade/potencial } \\
\text { de recursos para geração de } \\
\text { energia }\end{array}$ & $\begin{array}{l}\square \text { Distribuição } \\
\text { descentralizada }\end{array}$ & $\square 1 \square 2 \square 3 \square 4 \square 5 \square 6 \square 7 \square 8 \square 9$ \\
\hline$\square$ Maturidade da tecnologia & $\begin{array}{l}\square \text { Desempenho da } \\
\text { tecnologia }\end{array}$ & $\square 1 \square 2 \square 3 \square 4 \square 5 \square 6 \square 7 \square 8 \square 9$ \\
\hline$\square$ Maturidade da tecnologia & $\begin{array}{l}\square \text { Distribuição } \\
\text { descentralizada }\end{array}$ & $\square 1 \square 2 \square 3 \square 4 \square 5 \square 6 \square 7 \square 8 \square 9$ \\
\hline$\square$ Desempenho da tecnologia & $\begin{array}{l}\square \text { Distribuição } \\
\text { descentralizada }\end{array}$ & $\square 1 \square 2 \square 3 \square 4 \square 5 \square 6 \square 7 \square 8 \square 9$ \\
\hline
\end{tabular}


Critério AMBIENTAL: subcritérios

\begin{tabular}{|l|l|l|}
\hline Preferência & Julgamento \\
\hline$\square$ Emissões de GEE & $\begin{array}{l}\square \text { Conformidade com as } \\
\text { condições naturais locais }\end{array}$ & $\square$ 1 $\square 2 \square 3 \square 4 \square 5 \square 6 \square 7 \square 8 \square 9$ \\
\hline$\square$ Emissões de GEE & $\square$ Uso da terra & $\square 1 \square 2 \square 3 \square 4 \square 5 \square 6 \square 7 \square 8 \square 9$ \\
\hline$\square$ Emissões de GEE & $\square$ Consumo de água & $\square 1 \square 2 \square 3 \square 4 \square 5 \square 6 \square 7 \square 8 \square 9$ \\
\hline$\square$ Emissões de GEE & $\begin{array}{l}\square \text { Geração de resíduos no } \\
\text { fim do ciclo de vida }\end{array}$ & $\square 1 \square 2 \square 3 \square 4 \square 5 \square 6 \square 7 \square 8 \square 9$ \\
\hline $\begin{array}{l}\square \text { Conformidade com as } \\
\text { condições naturais locais }\end{array}$ & $\square$ Uso da terra & $\square 1 \square 2 \square 3 \square 4 \square 5 \square 6 \square 7 \square 8 \square 9$ \\
\hline $\begin{array}{l}\square \text { Conformidade com as } \\
\text { condições naturais locais }\end{array}$ & $\square$ Consumo de água \\
\hline $\begin{array}{l}\square \text { Conformidade com as } \\
\text { condições naturais locais }\end{array}$ & $\begin{array}{l}\square \text { Geração de resíduos no } \\
\text { fim do ciclo de vida }\end{array}$ & $\square 1 \square 2 \square 3 \square 4 \square 5 \square 6 \square 7 \square 8 \square 9$ \\
\hline$\square$ Uso da terra & $\square$ Consumo de água & $\square 1 \square 2 \square 3 \square 4 \square 5 \square 6 \square 7 \square 8 \square 9$ \\
\hline$\square$ Uso da terra & $\begin{array}{l}\square \text { Geração de resíduos no } \\
\text { fim do ciclo de vida }\end{array}$ & $\square 1 \square 2 \square 3 \square 4 \square 5 \square 6 \square 7 \square 8 \square 9$ \\
\hline$\square$ Consumo de água & $\begin{array}{l}\square \text { Geração de resíduos no } \\
\text { fim do ciclo de vida }\end{array}$ & $\square 1 \square 2 \square 3 \square 4 \square 5 \square 6 \square 7 \square 8 \square 9$ \\
\hline
\end{tabular}

\section{Critério ECONÔMICO: subcritérios}

\begin{tabular}{|l|l|l|}
\hline Preferência & Julgamento \\
\hline$\square$ Custo de energia nivelado & $\begin{array}{l}\square \text { Retorno do } \\
\text { investimento }\end{array}$ & $\square 1 \square 2 \square 3 \square 4 \square 5 \square 6 \square 7 \square 8 \square 9$ \\
\hline$\square$ Retorno do investimento & $\square$ Risco do investimento & $\square 1 \square 2 \square 3 \square 4 \square 5 \square 6 \square 7 \square 8 \square 9$ \\
\hline$\square$ Risco do investimento & $\begin{array}{l}\square \text { Custo de energia } \\
\text { nivelado }\end{array}$ & $\square 1 \square 2 \square 3 \square 4 \square 5 \square 6 \square 7 \square 8 \square 9$ \\
\hline
\end{tabular}


Critério SOCIAL: subcritérios

\begin{tabular}{|l|l|l|}
\hline \multicolumn{2}{|l|}{ Preferência } & Julgamento \\
\hline $\begin{array}{l}\square \text { Geração de emprego e } \\
\text { renda }\end{array}$ & $\begin{array}{l}\square \text { Aceitação social da } \\
\text { tecnologia }\end{array}$ & $\square 1 \square 2 \square 3 \square 4 \square 5 \square 6 \square 7 \square 8 \square 9$ \\
\hline $\begin{array}{l}\square \text { Geração de emprego e } \\
\text { renda }\end{array}$ & $\begin{array}{l}\square \text { Toxicidade humana e } \\
\text { segurança ocupacional }\end{array}$ & $\square 1 \square 2 \square 3 \square 4 \square 5 \square 6 \square 7 \square 8 \square 9$ \\
\hline $\begin{array}{l}\square \text { Geração de emprego e } \\
\text { renda }\end{array}$ & $\begin{array}{l}\square \text { Desenvolvimento } \\
\text { regional local }\end{array}$ & $\square 1 \square 2 \square 3 \square 4 \square 5 \square 6 \square 7 \square 8 \square 9$ \\
\hline $\begin{array}{l}\square \text { Aceitação social da } \\
\text { tecnologia }\end{array}$ & $\begin{array}{l}\square \text { Toxicidade humana e } \\
\text { segurança ocupacional }\end{array}$ & $\square 1 \square 2 \square 3 \square 4 \square 5 \square 6 \square 7 \square 8 \square 9$ \\
\hline $\begin{array}{l}\square \text { Aceitação social da } \\
\text { tecnologia }\end{array}$ & $\begin{array}{l}\square \text { Desenvolvimento } \\
\text { regional local }\end{array}$ & $\square 1 \square 2 \square 3 \square 4 \square 5 \square 6 \square 7 \square 8 \square 9$ \\
\hline $\begin{array}{l}\square \text { Toxicidade humana e } \\
\text { segurança ocupacional }\end{array}$ & $\begin{array}{l}\square \text { Desenvolvimento } \\
\text { regional local }\end{array}$ & $\square 1 \square 2 \square 3 \square 4 \square 5 \square 6 \square 7 \square 8 \square 9$ \\
\hline
\end{tabular}

\section{Critério POLÍTICO: subcritérios}

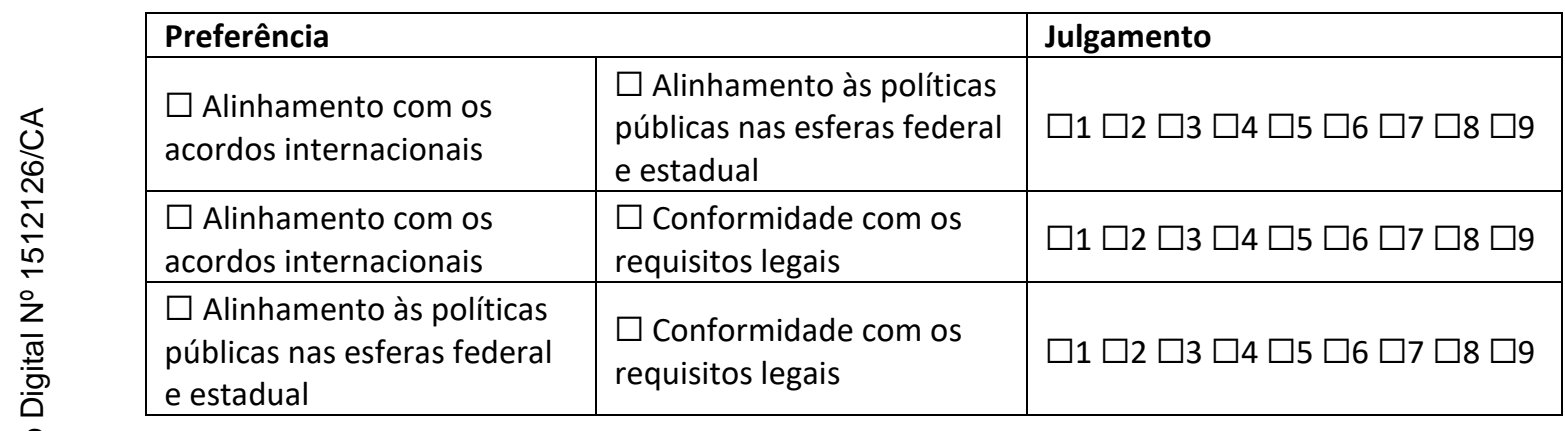




\section{Apêndice 3 - Mensuração e julgamento dos subcritérios de avaliação}

Descrevem-se a seguir os resultados da mensuração e julgamento dos subcritérios baseados nos julgamentos dos especialistas e em dados da literatura. A escala de avaliação utiliza números triangulares fuzzy, que variam de 1 a 5 , que quanto maior melhor. A figura 1 apresenta o exemplo da escala utilizado como referência a seguir.

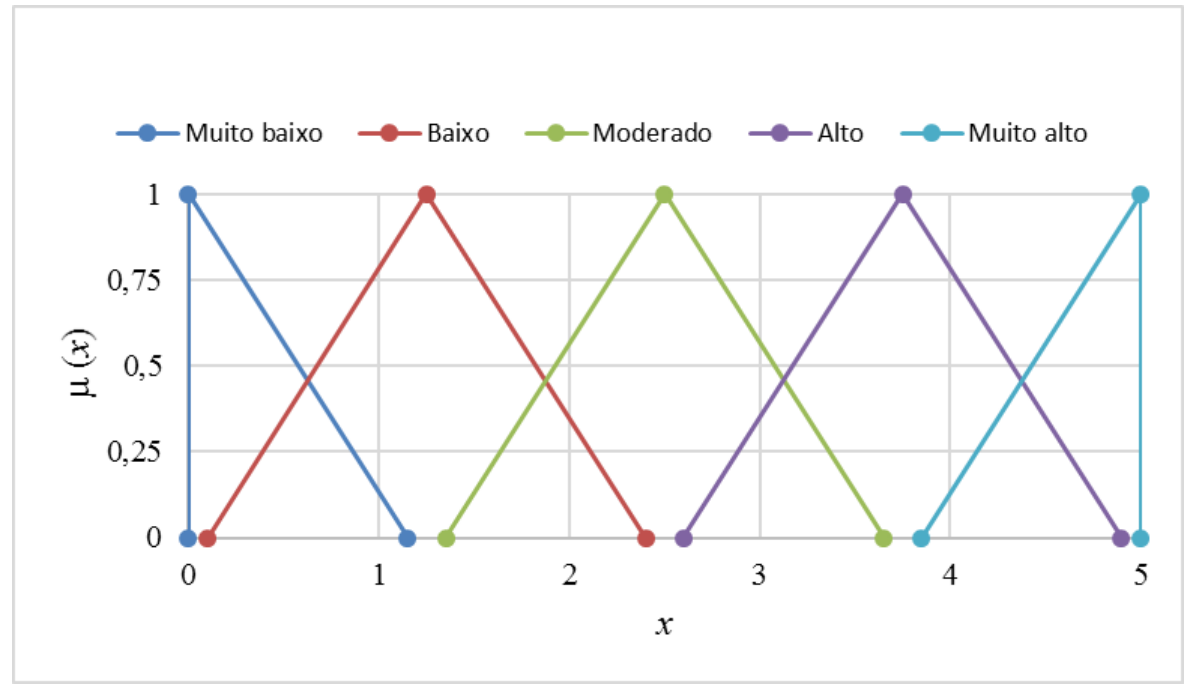

Figura 1. Exemplo de escala de termos linguístico fuzzy: Muito baixo $(0 ; 0 ; 1,15)$; Baixo $(0,10 ; 1,25 ; 2,4)$; Moderado $(1,35 ; 2,5 ; 3,65)$; Alto $(2,6 ; 3,75 ; 4,9)$; Muito alto $(3,85 ; 5 ; 5)$.

\section{Avaliação das tecnologias segundo o critério TÉCNICO}

- Confiabilidade do fornecimento de energia

\begin{tabular}{|c|c|c|c|}
\hline \multirow{2}{*}{ Tecnologia } & \multicolumn{3}{|c|}{ Valor fuzzy } \\
\cline { 2 - 4 } & $a_{1}$ & $a 2$ & $a_{3}$ \\
\hline Hidráulica & 4 & 5 & 5 \\
\hline Fotovoltaica & 2 & 3 & 5 \\
\hline Eólica & 2 & 3,5 & 5 \\
\hline Biomassa & 3 & 4 & 5 \\
\hline Ondas & 1 & 2 & 3 \\
\hline
\end{tabular}

- Simplicidade de implementação

\begin{tabular}{|c|c|c|c|}
\hline \multirow{2}{*}{ Tecnologia } & \multicolumn{3}{|c|}{ Valor fuzzy } \\
\cline { 2 - 4 } & $a_{1}$ & $a 2$ & $a_{3}$ \\
\hline Hidráulica & 1 & 2 & 2 \\
\hline Fotovoltaica & 3 & 4 & 5 \\
\hline Eólica & 3 & 4 & 5 \\
\hline Biomassa & 3 & 3 & 4 \\
\hline Ondas & 1 & 2 & 3 \\
\hline
\end{tabular}


- Disponibilidade / potencial de recursos

\begin{tabular}{|c|c|c|}
\hline Tecnologia & Potencial estimado $(\mathbf{M W})$ & Fonte \\
\hline Hidráulica & 570,8 & INEA (2014) \\
\hline Fotovoltaica & 2.685 & EPE (2016) \\
\hline Eólica & $1.524-2.813$ & $\begin{array}{c}\text { Amarante } \text { et } \text { al. } \\
(2002)\end{array}$ \\
\hline Biomassa & $35-70-93$ & USP (2012) \\
\hline Ondas & 9.800 & EPE (2016) \\
\hline
\end{tabular}

\begin{tabular}{|c|c|c|c|}
\hline \multirow{2}{*}{ Tecnologia } & \multicolumn{3}{|c|}{ Valor fuzzy } \\
\cline { 2 - 4 } & $a_{1}$ & $a 2$ & $a_{3}$ \\
\hline Hidráulica & 0,276663 & 0,291224 & 0,305786 \\
\hline Fotovoltaica & 1,301403 & 1,369898 & 1,438393 \\
\hline Eólica & 0,777551 & 1,106378 & 1,435204 \\
\hline Biomassa & 0,017857 & 0,035714 & 0,047449 \\
\hline Ondas & 4,75 & 5 & 5 \\
\hline
\end{tabular}

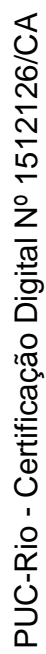

- Maturidade tecnológica

\begin{tabular}{|c|c|c|c|}
\hline \multirow{2}{*}{ Tecnologia } & \multicolumn{3}{|c|}{ Númerofuzzy } \\
\cline { 2 - 4 } & $a_{1}$ & $a 2$ & $a_{3}$ \\
\hline Hidráulica & 5 & 5 & 5 \\
\hline Fotovoltaica & 3 & 4 & 5 \\
\hline Eólica & 4 & 4 & 5 \\
\hline Biomassa & 3 & 4 & 5 \\
\hline Ondas & 1 & 2 & 3 \\
\hline
\end{tabular}

- Desempenho da tecnologia

\begin{tabular}{|l|c|c|}
\hline Tecnologia & Eficiência $\boldsymbol{\eta}(\boldsymbol{\%})$ & Fonte \\
\hline Hidráulica & 92 & $\begin{array}{c}\text { IRENA-ETSAP } \\
(2015)\end{array}$ \\
\hline Fotovoltaica & 12 & \multirow{2}{*}{ Al Garni et al. } \\
Eólica & 35 & (2016) \\
\cline { 1 - 2 } Biomassa & 25 & IRENA (2014) \\
\hline Ondas & 40 &
\end{tabular}

\begin{tabular}{|l|c|c|c|}
\hline \multirow{2}{*}{ Tecnologia } & \multicolumn{3}{|c|}{ Número fuzzy } \\
\cline { 2 - 4 } & $a_{1}$ & $a 2$ & $a_{3}$ \\
\hline Hidráulica & 4,750 & 5,000 & 5,000 \\
\hline Fotovoltaica & 0,620 & 0,652 & 0,685 \\
\hline Eólica & 1,807 & 1,902 & 1,997 \\
\hline Biomassa & 1,291 & 1,359 & 1,427 \\
\hline Ondas & 2,065 & 2,174 & 2,283 \\
\hline
\end{tabular}


- Distribuição descentralizada.

\begin{tabular}{|c|c|c|c|}
\hline \multirow{2}{*}{ Tecnologia } & \multicolumn{3}{|c|}{ Número fuzzy } \\
\cline { 2 - 4 } & $a_{1}$ & $a 2$ & $a_{3}$ \\
\hline Hidráulica & 1 & 2 & 3 \\
\hline Fotovoltaica & 3 & 4 & 5 \\
\hline Eólica & 2 & 3,5 & 5 \\
\hline Biomassa & 3 & 4 & 5 \\
\hline Ondas & 1 & 2 & 4 \\
\hline
\end{tabular}

\section{Avaliação das tecnologias segundo o critério AMBIENTAL}

- Emissões de gases do efeito estufa (GEE)

\begin{tabular}{|c|c|c|}
\hline Tecnologia & gCO2eq/kWh & Fonte \\
\hline Hidráulica & $(2-20-75)$ & \multirow{2}{*}{$\begin{array}{c}\text { Amponsah } \text { et al. } \\
(2014)\end{array}$} \\
Fotovoltaica & $(9-60,8-300)$ & \\
\hline Eólica & $(8-34,2-124)$ & \\
\hline Biomassa & $(14-88-650)$ & \\
\hline Ondas & $(12-22,8-50)$ & \\
\hline
\end{tabular}

\begin{tabular}{|c|c|c|c|}
\hline \multirow{2}{*}{ Tecnologia } & \multicolumn{3}{|c|}{ Número fuzzy } \\
\cline { 2 - 4 } & $a_{1}$ & $a 2$ & $a_{3}$ \\
\hline Hidráulica & 4,4231 & 4,8462 & 4,9846 \\
\hline Fotovoltaica & 2,6923 & 4,5323 & 4,9308 \\
\hline Eólica & 4,0462 & 4,7369 & 4,9385 \\
\hline Biomassa & 0,0000 & 4,3231 & 4,8923 \\
\hline Ondas & 4,6154 & 4,8246 & 4,9077 \\
\hline
\end{tabular}

- Conformidade com as condições naturais locais

\begin{tabular}{|c|c|c|c|}
\hline \multirow{2}{*}{ Tecnologia } & \multicolumn{3}{|c|}{ Número fuzzy } \\
\cline { 2 - 4 } & $a_{1}$ & $a 2$ & $a_{3}$ \\
\hline Hidráulica & 1 & 3 & 5 \\
\hline Fotovoltaica & 3 & 4 & 5 \\
\hline Eólica & 3 & 3,5 & 4 \\
\hline Biomassa & 3 & 3,5 & 4 \\
\hline Ondas & 2 & 3 & 4 \\
\hline
\end{tabular}


- Uso da terra

\begin{tabular}{|l|c|c|}
\hline Tecnologia & $\begin{array}{c}\text { Área requerida } \\
\left(\mathbf{m}^{\mathbf{2}} / \mathbf{k W}\right)\end{array}$ & Fonte \\
\hline Hidráulica & $(10-500-6500)$ & \\
\hline Fotovoltaica & $(10-150-500)$ & \multirow{2}{*}{$\begin{array}{c}\text { Troldborg } \text { et al. } \\
(2014)\end{array}$} \\
\cline { 1 - 2 } Eólica & $(10-200-200)$ & \\
\hline Biomassa & $(1000-4000-6000)$ & \\
\hline Ondas & $(10-150-300)$ & \\
\hline
\end{tabular}

\begin{tabular}{|c|c|c|c|}
\hline \multirow{2}{*}{ Tecnologia } & \multicolumn{3}{|c|}{ Númerofuzzy } \\
\cline { 2 - 4 } & $a_{1}$ & $a 2$ & $a_{3}$ \\
\hline Hidráulica & 0,0000 & 4,6154 & 4,9923 \\
\hline Fotovoltaica & 4,6154 & 4,8846 & 4,9923 \\
\hline Eólica & 4,8462 & 4,8462 & 4,9923 \\
\hline Biomassa & 0,3846 & 1,9231 & 4,2308 \\
\hline Ondas & 4,7692 & 4,8846 & 4,9923 \\
\hline
\end{tabular}

- Consumo de água.

\begin{tabular}{|c|c|c|}
\hline Tecnologia & $\mathbf{~ m}^{\mathbf{3}} / \mathbf{G J}$ & Fonte \\
\hline Hidráulica & 22 & \\
\cline { 1 - 2 } Fotovoltaica & 0,042 & $\begin{array}{c}\text { Hadian e Madani } \\
(2015)\end{array}$ \\
\hline Eólica & 0,001 & \\
\hline Biomassa & 39,5 & \\
\hline Ondas & 0,001 & \\
\hline
\end{tabular}

\begin{tabular}{|c|c|c|c|}
\hline \multirow{2}{*}{ Tecnologia } & \multicolumn{3}{|c|}{ Númerofuzzy } \\
\cline { 2 - 4 } & $a_{1}$ & $a 2$ & $a_{3}$ \\
\hline Hidráulica & 2,104 & 2,215 & 2,326 \\
\hline Fotovoltaica & 4,745 & 4,995 & 5,000 \\
\hline Eólica & 4,750 & 5,000 & 5,000 \\
\hline Biomassa & 0,000 & 0,000 & 0,000 \\
\hline Ondas & 4,750 & 5,000 & 5,000 \\
\hline
\end{tabular}

- Geração de resíduos.

\begin{tabular}{|c|c|c|c|}
\hline \multirow{2}{*}{ Tecnologia } & \multicolumn{3}{|c|}{ Númerofuzzy } \\
\cline { 2 - 4 } & $a_{1}$ & $a 2$ & $a_{3}$ \\
\hline Hidráulica & 1 & 2 & 3 \\
\hline Fotovoltaica & 1 & 2 & 3 \\
\hline Eólica & 1 & 2 & 3 \\
\hline Biomassa & 2 & 3 & 4 \\
\hline Ondas & 2 & 2 & 3 \\
\hline
\end{tabular}




\section{Avaliação das tecnologias segundo o critério ECONÔMICO:}

- Custo nivelado de energia

\begin{tabular}{|l|c|c|c|c|}
\hline \multirow{2}{*}{ Tecnologia } & \multicolumn{3}{|c|}{ US\$/MWh } & \multirow{2}{*}{ Fonte } \\
\cline { 2 - 4 } & Média & Mínimo & Máximo & \\
\hline Hidráulica & 93,65 & 15,61 & 202,90 & \\
\hline Fotovoltaica & 530,67 & 78,04 & 936,48 & \multirow{2}{*}{$\begin{array}{c}\text { Troldborg } \text { et al. } \\
\text { (2014) }\end{array}$} \\
\hline Eólica & 109,26 & 39,02 & 195,10 & \\
\hline Biomassa & 202,90 & 62,43 & 390,20 & \\
\hline Ondas & 288,75 & 202,90 & 624,32 & \\
\hline
\end{tabular}

\begin{tabular}{|c|c|c|c|}
\hline \multirow{2}{*}{ Tecnologia } & \multicolumn{3}{|c|}{ Númerofuzzy } \\
\cline { 2 - 4 } & $a_{1}$ & $a 2$ & $a_{3}$ \\
\hline Hidráulica & 3,9167 & 4,5000 & 4,9167 \\
\hline Fotovoltaica & 0,0000 & 2,1667 & 4,5833 \\
\hline Eólica & 3,9583 & 4,4167 & 4,7917 \\
\hline Biomassa & 2,9167 & 3,9167 & 4,6667 \\
\hline Ondas & 1,6667 & 3,4583 & 3,9167 \\
\hline
\end{tabular}

- Retorno do investimento (payback)

\begin{tabular}{|c|c|c|c|}
\hline \multirow{2}{*}{ Tecnologia } & \multicolumn{3}{|c|}{ Número fuzzy } \\
\cline { 2 - 4 } & $a_{1}$ & $a 2$ & $a_{3}$ \\
\hline Hidráulica & 1 & 2 & 4 \\
\hline Fotovoltaica & 3 & 3 & 4 \\
\hline Eólica & 3 & 4 & 5 \\
\hline Biomassa & 1 & 4 & 5 \\
\hline Ondas & 1 & 1 & 4 \\
\hline
\end{tabular}

\section{- Riscos do investimento}

\begin{tabular}{|c|c|c|c|}
\hline \multirow{2}{*}{ Tecnologia } & \multicolumn{3}{|c|}{ Número fuzzy } \\
\cline { 2 - 4 } & $a_{1}$ & $a 2$ & $a_{3}$ \\
\hline Hidráulica & 2 & 3 & 5 \\
\hline Fotovoltaica & 2 & 3 & 5 \\
\hline Eólica & 3 & 3,5 & 4 \\
\hline Biomassa & 3 & 3,5 & 4 \\
\hline Ondas & 1 & 2 & 4 \\
\hline
\end{tabular}




\section{Avaliação das tecnologias segundo o critério SOCIAL:}

- Geração de emprego e renda

\begin{tabular}{|c|c|c|}
\hline Tecnologia & Empregos/GWh & FONTE \\
\hline Hidráulica & 0,27 & \multirow{2}{*}{$\begin{array}{c}\text { Al Garni } \text { et al. } \\
\text { (2016) }\end{array}$} \\
\cline { 1 - 2 } Fotovoltaica & 0,87 & \\
\hline Eólica & 0,17 & \\
\hline Biomassa & 0,21 & estimado \\
\hline Ondas & $0,17-0,21-0,27$ & \\
\hline
\end{tabular}

\begin{tabular}{|c|c|c|c|}
\hline \multirow{2}{*}{ Tecnologia } & \multicolumn{3}{|c|}{ Número fuzzy } \\
\cline { 2 - 4 } & $a_{1}$ & $a 2$ & $a_{3}$ \\
\hline Hidráulica & 1,474138 & 1,552 & 1,62931 \\
\hline Fotovoltaica & 4,75 & 5,000 & 5 \\
\hline Eólica & 0,928161 & 0,977 & 1,025862 \\
\hline Biomassa & 1,146552 & 1,207 & 1,267241 \\
\hline Ondas & 1,18295 & 1,245 & 1,307471 \\
\hline
\end{tabular}

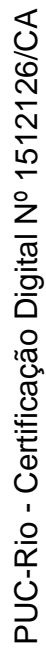

- Aceitação social da tecnologia

\begin{tabular}{|c|c|c|c|}
\hline \multirow{2}{*}{ Tecnologia } & \multicolumn{3}{|c|}{ Número fuzzy } \\
\cline { 2 - 4 } & $a_{1}$ & $a 2$ & $a_{3}$ \\
\hline Hidráulica & 3 & 4 & 4 \\
\hline Fotovoltaica & 4 & 5 & 5 \\
\hline Eólica & 3 & 4 & 5 \\
\hline Biomassa & 3 & 3 & 3 \\
\hline Ondas & 2 & 3 & 3 \\
\hline
\end{tabular}

- Segurança ocupacional

\begin{tabular}{|c|c|c|c|}
\hline \multirow{2}{*}{ Tecnologia } & \multicolumn{3}{|c|}{ Número fuzzy } \\
\cline { 2 - 4 } & $a_{1}$ & $a 2$ & $a_{3}$ \\
\hline Hidráulica & 2 & 4 & 5 \\
\hline Fotovoltaica & 1 & 3 & 5 \\
\hline Eólica & 1 & 3 & 5 \\
\hline Biomassa & 3 & 3 & 4 \\
\hline Ondas & 1 & 2 & 3 \\
\hline
\end{tabular}

- Desenvolvimento regional local

\begin{tabular}{|c|c|c|c|}
\hline \multirow{2}{*}{ Tecnologia } & \multicolumn{3}{|c|}{ Número fuzzy } \\
\cline { 2 - 4 } & $a_{1}$ & $a 2$ & $a_{3}$ \\
\hline Hidráulica & 1 & 3 & 5 \\
\hline Fotovoltaica & 1 & 3,5 & 5 \\
\hline Eólica & 1 & 2,5 & 4 \\
\hline Biomassa & 3 & 4 & 5 \\
\hline Ondas & 1 & 3 & 4 \\
\hline
\end{tabular}




\section{Avaliação das tecnologias segundo o critério POLÍTICO}

- Alinhamento com os acordos internacionais

\begin{tabular}{|c|c|c|c|}
\hline \multirow{2}{*}{ Tecnologia } & \multicolumn{3}{|c|}{ Número fuzzy } \\
\cline { 2 - 4 } & $a_{1}$ & $a 2$ & $a_{3}$ \\
\hline Hidráulica & 4 & 4 & 5 \\
\hline Fotovoltaica & 4 & 4,5 & 5 \\
\hline Eólica & 4 & 4,5 & 5 \\
\hline Biomassa & 3 & 4 & 5 \\
\hline Ondas & 4 & 4 & 5 \\
\hline
\end{tabular}

- Alinhamento às políticas públicas nas esferas federal e estadual

\begin{tabular}{|c|c|c|c|}
\hline \multirow{2}{*}{ Tecnologia } & \multicolumn{3}{|c|}{ Número fuzzy } \\
\cline { 2 - 4 } & $a_{1}$ & $a 2$ & $a_{3}$ \\
\hline Hidráulica & 4 & 4,5 & 5 \\
\hline Fotovoltaica & 4 & 4 & 5 \\
\hline Eólica & 4 & 4 & 5 \\
\hline Biomassa & 2 & 4 & 4 \\
\hline Ondas & 1 & 3 & 4 \\
\hline
\end{tabular}

- Conformidade com os requisitos legais

\begin{tabular}{|c|c|c|c|}
\hline Tecnologia & \multicolumn{3}{|c|}{ Número fuzzy } \\
\hline & $a_{1}$ & $a 2$ & $a_{3}$ \\
\hline Hidráulica & 3 & 4 & 5 \\
\hline Fotovoltaica & 4 & 4,5 & 5 \\
\hline Eólica & 3 & 4 & 5 \\
\hline Biomassa & 3 & 4 & 5 \\
\hline Ondas & 1 & 2 & 3 \\
\hline
\end{tabular}




\section{Apêndice 4 - Questionário submetido aos especialistas}

\section{AVALIAÇÃO DAS FONTES DE GERAÇÃO RENOVÁVEIS}

Prezado especialista,

Você está recebendo um questionário cujo objetivo é a avaliação e seleção de tecnologias de geração de energia elétrica a partir de fontes renováveis no Estado do Rio de Janeiro.

Ficaríamos muito agradecidos com sua resposta, uma vez que os resultados empíricos farão parte da dissertação de mestrado desenvolvida no âmbito do Programa de Metrologia da PUC-Rio e estará contribuindo para o avanço do conhecimento científico neste campo.

Atenciosamente,

Guilherme Martins / Prof. Rodrigo Calili / Prof.a Maria Fatima Ludovico

\section{Objetivo do questionário}

O objetivo deste questionário é mensurar e avaliar o potencial de aplicação de tecnologias de geração de energia a partir de fontes renováveis, a luz de cinco critérios: TÉCNICO, AMBIENTAL, ECONÔMICO, SOCIAL e POLÍTICO.

Tecnologias avaliadas

- Hidrelétrica - PCH. Potência igual ou inferior a $30 \mathrm{MW}$, área do reservatório inferior a $3,0 \mathrm{~km}^{2}$.

- Fotovoltaica. Aproveitamento da radiação solar nas coberturas das edificações.

- Eólica. Aerogeradores de eixo horizontal onshore.

- Biomassa. Termelétrica (cogeração), queima de bagaço, ponta e palha da canade-açucar.

- Ondas. Aproveitamento da energia cinética e potencial sobre a superfície oceânica.

\section{Instruções de preenchimento do questionário}

Para cada uma das cinco tecnologias focos da avaliação (hidrelétrica - PCH, fotovoltaica, eólica, biomassa e ondas), pedimos que marque apenas uma alternativa em relação ao grau do uso da tecnologia (por ex.: "muito baixo", "baixo", "moderado", "alto" e "muito alto") em relação a cada um dos subcritérios avaliados. 
Ex.: No subcritério fictício "S". A fonte hidráulica tem importância "baixa", a fotovoltaica importância "moderada", a eólica tem importância "baixa", a biomassa importância "muito alta" e, por fim, a energia advinda das ondas tem importância "alta".

\begin{tabular}{|l|c|c|c|c|c|}
\hline Tecnologia & Muito baixa & Baixa & Moderada & Alta & Muito alta \\
\hline Hidráulica & & $\mathrm{x}$ & & & \\
\hline Fotovoltaica & & & $\mathrm{x}$ & & \\
\hline Eólica & & $\mathrm{x}$ & & & \\
\hline Biomassa & & & & & $\mathrm{x}$ \\
\hline Ondas & & & & $\mathrm{x}$ & \\
\hline
\end{tabular}

\section{Questionário}

\section{Critério Técnico: subcritérios}

$T_{2}$. Maturidade tecnológica. Este subcritério avalia o estágio de evolução de uma dada tecnologia, indicando a existência de campo de ação para avanço adicional e considerando o estado- da- arte em nível mundial. A maturidade "muito baixa" indica que a tecnologia foi testada apenas em laboratório e o nível "baixo" significa que a tecnologia foi testada em campo, mas não está disponível comercialmente. "Moderada" indica que a tecnologia está nos primeiros estágios de comercialização e "muito alta" refere-se às tecnologias amplamente difundidas comercialmente.

\begin{tabular}{|l|l|l|l|l|l|}
\hline \multirow{2}{*}{ Tecnologia } & \multicolumn{5}{|c|}{ Maturidade tecnológica } \\
\cline { 2 - 6 } & Muito baixa & Baixa & Moderada & Alta & Muito alta \\
\hline Hidráulica & & & & & \\
\hline Fotovoltaica & & & & & \\
\hline Eólica & & & & & \\
\hline Biomassa & & & & & \\
\hline Ondas & & & & & \\
\hline
\end{tabular}

$T_{4}$. Confiabilidade do fornecimento de energia. Este subcritério avalia a capacidade de um sistema de energia em realizar o que foi projetado e sua resistência a falhas ou interrupções. Entende-se que se a fonte está conectada ao sistema de transmissão (tensão mais elevada), isso indica que a tecnologia possui um maior grau de confiabilidade. Se a tecnologia está conectada ao sistema de distribuição (tensão mais baixa), isso indica que está mais suscetível a falhas. 


\begin{tabular}{|l|c|c|c|c|c|}
\hline \multirow{2}{*}{ Tecnologia } & \multicolumn{5}{|c|}{ Confiabilidade do fornecimento de energia } \\
\cline { 2 - 6 } & Muito baixa & Baixa & Moderada & Alta & Muito alta \\
\hline Hidráulica & & & & & \\
\hline Fotovoltaica & & & & & \\
\hline Eólica & & & & & \\
\hline Biomassa & & & & & \\
\hline Ondas & & & & & \\
\hline
\end{tabular}

$T_{5 .}$ Distribuição descentralizada. Este subcritério avalia a facilidade de se adotar uma tecnologia de geração de energia elétrica próxima aos centros de consumo de energia e de integração com o sistema elétrico.

\begin{tabular}{|l|l|l|l|l|l|}
\hline \multirow{2}{*}{ Tecnologia } & \multicolumn{5}{|c|}{ Distribuição descentralizada } \\
\cline { 2 - 6 } & Muito baixa & Baixa & Moderada & Alta & Muito alta \\
\hline Hidráulica & & & & & \\
\hline Fotovoltaica & & & & & \\
\hline Eólica & & & & & \\
\cline { 2 - 6 } \\
Biomassa & & & & & \\
\hline
\end{tabular}

$T_{6 .}$ Simplicidade de implementação. Este subcritério avalia o período de tempo gasto durante a construção e a instalação das usinas. Quanto menor for o tempo, melhor.

\begin{tabular}{|l|l|l|l|l|l|}
\hline \multirow{2}{*}{ Tecnologia } & \multicolumn{5}{|c|}{ Simplicidade de implementação } \\
\cline { 2 - 6 } & $>5$ anos & $3-5$ anos & $2-3$ anos & $1-2$ anos & $<1$ ano \\
\hline Hidráulica & & & & & \\
\hline Fotovoltaica & & & & & \\
\hline Eólica & & & & & \\
\hline Biomassa & & & & & \\
\hline Ondas & & & & & \\
\hline
\end{tabular}

\section{Critério Ambiental: subcritérios}

$A_{3 .}$ Conformidade com as condições naturais locais. Este subcritério avalia os impactos causados pela tecnologia de geração de energia elétrica aos ecossistemas. Dentre os impactos, destacam-se ruídos, odores, reação negativa da população ao impacto visual, potenciais riscos aos animais silvestres e à biodiversidade. Conformidade com as condições locais "muito alta" significa impacto muito baixo aos ecossistemas. No extremo inferior, conformidade "muito baixa" indica impactos ambientais significativos da tecnologia aos ecossistemas. 


\begin{tabular}{|l|c|c|c|c|c|}
\hline \multirow{2}{*}{ Tecnologia } & \multicolumn{5}{|c|}{ Conformidade com as condições naturais locais } \\
\cline { 2 - 6 } & Muito baixa & Baixa & Moderada & Alta & Muito alta \\
\hline Hidráulica & & & & & \\
\hline Fotovoltaica & & & & & \\
\hline Eólica & & & & & \\
\hline Biomassa & & & & & \\
\hline Ondas & & & & & \\
\hline
\end{tabular}

$A_{5 .}$ Geração de resíduos ao final do ciclo de vida. Este subcritério avalia a geração dos resíduos pelo emprego das tecnologias de geração de energia a partir de fontes renováveis ao longo de todo o ciclo de vida.

\begin{tabular}{|l|c|c|c|c|c|}
\hline \multirow{2}{*}{ Tecnologia } & \multicolumn{5}{|c|}{ Geração de resíduos ao final do ciclo de vida } \\
\cline { 2 - 6 } & Muito baixa & Baixa & Moderada & Alta & Muito alta \\
\hline Hidráulica & & & & & \\
\hline Fotovoltaica & & & & & \\
\hline Eólica & & & & & \\
\hline Biomassa & & & & & \\
\hline Ondas & & & & & \\
\hline
\end{tabular}

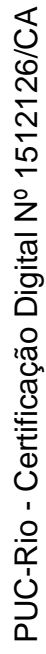

\section{Critério Econômico: subcritérios}

E2. Retorno do investimento (Payback). Este subcritério avalia o período de tempo necessário para "se pagar" o investimento original em um projeto de energia baseado em uma tecnologia a partir de fontes renováveis.

\begin{tabular}{|l|l|l|l|l|l|}
\hline \multirow{2}{*}{ Tecnologia } & \multicolumn{5}{|c|}{ Retorno do investimento (Payback) } \\
\cline { 2 - 6 } & $>15$ anos & $10-15$ anos & $7-10$ anos & $5-7$ anos & < 5anos \\
\hline Hidráulica & & & & & \\
\hline Fotovoltaica & & & & & \\
\hline Eólica & & & & & \\
\hline Biomassa & & & & & \\
\hline Ondas & & & & & \\
\hline
\end{tabular}


E. Risco do investimento. Este subcritério avalia o grau de incerteza nos custos de investimento dos projetos de geração. Dentre as incertezas e fatores de risco, destacamse problemas geológicos, ambientais, trabalhistas e de conexão à rede elétrica. "Muitas incertezas" significam a presença de vários fatores de risco simultaneamente. "Poucas incertezas" indicam probabilidade baixa de qualquer tipo de fator de risco.

\begin{tabular}{|l|l|l|l|l|l|}
\hline \multirow{2}{*}{ Tecnologia } & \multicolumn{5}{|c|}{ Risco do investimento } \\
\cline { 2 - 6 } & Muitas & $\begin{array}{c}\text { Entre muitas } \\
\text { incertezas e } \\
\text { moderada }\end{array}$ & $\begin{array}{c}\text { Incerteza } \\
\text { moderada }\end{array}$ & $\begin{array}{c}\text { Entre } \\
\text { incertezas } \\
\text { moderada e } \\
\text { poucas }\end{array}$ & $\begin{array}{c}\text { Poucas } \\
\text { incertezas }\end{array}$ \\
\hline Hidráulica & & & & & \\
\hline Fotovoltaica & & & & & \\
\hline Eólica & & & & & \\
\hline Biomassa & & & & & \\
\hline Ondas & & & & & \\
\hline
\end{tabular}

\section{Critério Social: subcritérios}

$S_{2}$. Aceitação social da tecnologia. Este subcritério avalia a aceitação da sociedade em relação a uma dada tecnologia de geração de energia a partir de fontes renováveis.

\begin{tabular}{|l|l|l|l|l|l|}
\hline \multirow{2}{*}{ Tecnologia } & \multicolumn{5}{|c|}{ Aceitação social da tecnologia } \\
\cline { 2 - 6 } & $\begin{array}{c}\text { Resistência } \\
\text { muito forte }\end{array}$ & $\begin{array}{c}\text { Forte } \\
\text { resistência }\end{array}$ & $\begin{array}{c}\text { Adesão } \\
\text { moderada }\end{array}$ & Adesão alta & $\begin{array}{c}\text { Adesão } \\
\text { muito alta }\end{array}$ \\
\hline Hidráulica & & & & & \\
\hline Fotovoltaica & & & & & \\
\hline Eólica & & & & & \\
\hline Biomassa & & & & & \\
\hline Ondas & & & & & \\
\hline
\end{tabular}

$S_{3 .}$ Segurança ocupacional. Este subcritério avalia o grau de segurança para a saúde humana do emprego de uma dada tecnologia de geração de energia a partir de fontes renováveis. Durante todas as fases de um projeto, devem ser considerados o potencial de intoxicação, o risco de acidentes ocupacionais e fatais, os perigos à saúde humana e animal, dentre outros fatores.

\begin{tabular}{|l|l|l|l|l|l|}
\hline \multirow{2}{*}{ Tecnologia } & \multicolumn{5}{|c|}{ Segurança ocupacional } \\
\cline { 2 - 6 } & Muito alta & Alta & Moderada & Baixa & Muito baixa \\
\hline Hidráulica & & & & & \\
\hline Fotovoltaica & & & & & \\
\hline Eólica & & & & & \\
\hline Biomassa & & & & & \\
\hline Ondas & & & & & \\
\hline
\end{tabular}


S4. Desenvolvimento regional local. Este subcritério avalia os impactos potenciais positivos na região na qual um novo projeto de geração de energia de fontes renováveis será desenvolvido, destacando-se a geração de empregos e renda, a criação de novos negócios e a ampliação de infraestrutura e instalação de instituições de ensino, saúde, cultura e entretenimento.

\begin{tabular}{|l|l|l|l|l|l|}
\hline \multirow{2}{*}{ Tecnologia } & \multicolumn{5}{|c|}{ Desenvolvimento regional local } \\
\cline { 2 - 6 } & Muito baixo & Baixo & Moderado & Alto & Muito alto \\
\hline Hidráulica & & & & & \\
\hline Fotovoltaica & & & & & \\
\hline Eólica & & & & & \\
\hline Biomassa & & & & & \\
\hline Ondas & & & & & \\
\hline
\end{tabular}

\section{Critério Político: subcritérios}

$\boldsymbol{P}_{1}$. Alinhamento com os acordos internacionais. Este subcritério avalia o alinhamento do emprego de uma dada tecnologia de geração de energia elétrica a partir de fontes renováveis aos acordos internacionais voltados para o desenvolvimento sustentável tratados, convenções, acordos, protocolos como COP-21 e Rio+20.

\begin{tabular}{|l|c|c|c|c|c|}
\hline \multirow{2}{*}{ Tecnologia } & \multicolumn{5}{|c|}{ Alinhamento com os acordos internacionais } \\
\cline { 2 - 6 } & Muito baixo & Baixo & Moderado & Alto & Muito alto \\
\hline Hidráulica & & & & & \\
\hline Fotovoltaica & & & & & \\
\hline Eólica & & & & & \\
\hline Biomassa & & & & & \\
\hline Ondas & & & & & \\
\hline
\end{tabular}

$P_{2}$. Alinhamento às políticas públicas nas esferas federal e estadual. Este subcritério avalia o alinhamento do emprego de uma dada tecnologia de geração de energia elétrica a partir de fontes renováveis às políticas públicas de incentivo às fontes de energias renováveis como Proinfa, PNEf e BNDES Finem - Geração de Energia.

\begin{tabular}{|l|c|c|c|c|c|}
\hline \multirow{2}{*}{ Tecnologia } & \multicolumn{5}{|c|}{ Alinhamento às políticas públicas nas esferas federal e estadual } \\
\cline { 2 - 6 } & Muito baixo & Baixo & Moderado & Alto & Muito alto \\
\hline Hidráulica & & & & & \\
\hline Fotovoltaica & & & & & \\
\hline Eólica & & & & & \\
\hline Biomassa & & & & & \\
\hline Ondas & & & & & \\
\hline
\end{tabular}


$P_{3}$. Conformidade com os requisitos legais. Este subcritério avalia o grau de conformidade de uma dada tecnologia a partir de fontes renováveis com os requisitos legais referentes à geração de energia elétrica. Exemplos: PRODIST (Normas e padrões da ANEEL dos sistemas de distribuição de energia elétrica), Resolução Normativa 482/2012 e 687/2015 (Estabelece condições gerais para microgeração e minigeração de energia elétrica), Decreto 5163/2004 (Regulamenta a comercialização, concessão e geração de energia elétrica).

\begin{tabular}{|l|l|l|l|l|l|}
\hline \multirow{2}{*}{ Tecnologia } & \multicolumn{5}{|c|}{ Conformidade com os requisitos legais } \\
\cline { 2 - 6 } & Muito baixo & Baixo & Moderado & Alto & Muito alto \\
\hline Hidráulica & & & & & \\
\hline Fotovoltaica & & & & & \\
\hline Eólica & & & & & \\
\hline Biomassa & & & & & \\
\hline Ondas & & & & & \\
\hline
\end{tabular}




\section{Anexo 1 - Processo Analítico Hierárquico (AHP)}

Este Anexo 1 descreve o método AHP, conforme proposto por Saaty (1977, 1991, 2008). Ele é parte integrante da dissertação de Arianni Fernanda Pereira de Mello, intitulada "Monitoramento e avaliação de regulamentação sobre recolhimento de alimentos no Brasil: proposição de indicadores e métricas" (Mello, 2015).

O método AHP compreende quatro etapas, de acordo com a descrição de Saaty (1991) e Costa (2006):

- Organização da estrutura hierárquica, através da identificação do foco principal, dos critérios e subcritérios (quando existirem) e das alternativas, refletindo as relações existentes entre eles;

- Aquisição dos dados e coleta de julgamentos de valor, através da comparação dos elementos dois a dois e estabelecimento das matrizes de comparações;

- Análise das matrizes de comparações geradas na fase anterior, que indicarão a prioridade de cada alternativa em relação ao foco principal;

- Análise dos indicadores de desempenho derivados, como índices de consistência, por exemplo.

No AHP, os elementos de uma hierarquia para a resolução de problemas de decisão são o foco principal (ou meta), o conjunto de alternativas viáveis e o conjunto de critérios, de acordo com o ilustrado na figura A.1.

O foco principal é o objetivo global, o que a resolução do problema trará. As alternativas viáveis são as possibilidades de escolha dentro do problema para que a decisão seja tomada. Por fim, os critérios são as características ou propriedades a partir das quais as alternativas devem ser avaliadas. 


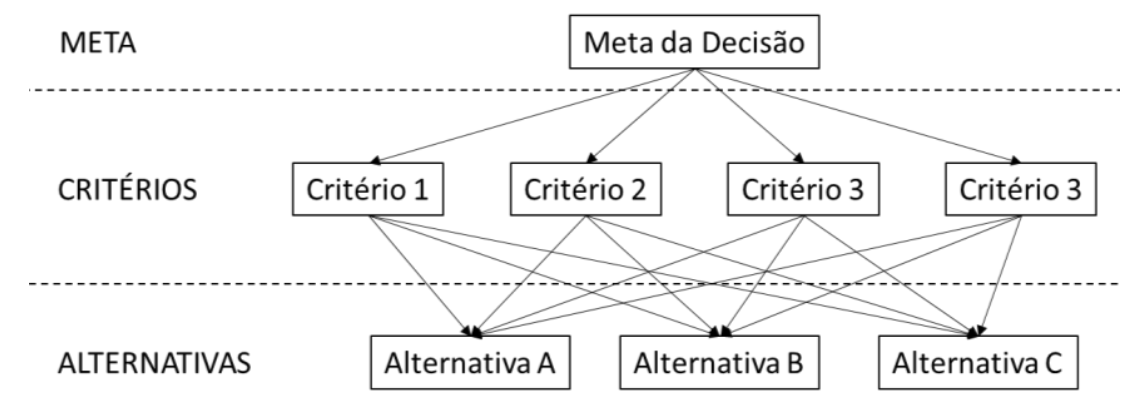

Figura A.1 - Exemplo de estrutura hierárquica de problemas de decisão (em três níveis) Fonte: Saaty, 1991.

Após a hierarquização, o método aponta para os julgamentos de valor, em que o avaliador deve comparar os elementos dois a dois à luz de um determinado critério. O julgamento é, então, a representação numérica dessa relação e o grupo de todos os julgamentos, considerando a comparação de todos os elementos em relação a um critério específico, pode ser representado através de uma matriz quadrada (Saaty, 1991).

Para o estabelecimento do processo de julgamento, Saaty (1990) definiu uma escala específica para padronizar os julgamentos de valor, escala essa que capta a subjetividade natural existente em variáveis qualitativas. O Quadro A.1, a seguir, apresenta essa escala.

Quadro A.1 - Escala para padronizar os julgamentos de valor pelo método AHP

\begin{tabular}{c|l|l}
\hline \multicolumn{1}{c|}{$\begin{array}{c}\text { Intensida } \\
\text { de de } \\
\text { importância }\end{array}$} & \multicolumn{1}{|c}{ Definição } & \multicolumn{1}{c}{ Explicação } \\
\hline 1 & Mesma importância & $\begin{array}{l}\text { As duas atividades contribuem igualmente } \\
\text { para o objetivo. }\end{array}$ \\
\hline 3 & $\begin{array}{l}\text { Importância moderada de uma sobre } \\
\text { a outra }\end{array}$ & $\begin{array}{l}\text { A experiência e o julgamento favorecem } \\
\text { levemente uma atividade em relação à outra. }\end{array}$ \\
\hline 5 & Importância grande ou essencial & $\begin{array}{l}\text { A experiência e o julgamento favorecem } \\
\text { fortemente uma atividade em relação à outra. }\end{array}$ \\
\hline 9 & $\begin{array}{l}\text { Importância muito grande ou } \\
\text { demonstrada }\end{array}$ & $\begin{array}{l}\text { Uma atividade é muito fortemente favorecida } \\
\text { em relação à outra; sua dominação de } \\
\text { importância é demosntrada na prática. }\end{array}$ \\
\hline $2,4,6,8$ & Importância absoluta & $\begin{array}{l}\text { A evidência favorece uma atividade em } \\
\text { relação à outra com o mais alto grau de } \\
\text { certeza. }\end{array}$ \\
\hline & valores adjacentes. & $\begin{array}{l}\text { Quando se procura uma condição de } \\
\text { compromisso entre as duas definiçães. }\end{array}$ \\
\hline
\end{tabular}

Fonte: Saaty, 1991.

O julgamento consiste no reflexo de duas perguntas: qual dos dois elementos é o mais importante, à luz do objetivo pretendido, e com qual 
intensidade ele é mais importante, utilizando-se a escala de 1 a 9 apresentada no Quadro A.2.

Para o elemento mais importante, é utilizado um valor inteiro, enquanto que o menos importante recebe o inverso dessa unidade, como ilustrado no exemplo didático da Figura A.2

\section{Matriz A}

$\left[\begin{array}{ccccc} & \text { A } & \text { B } & \text { C } & \text { D } \\ \text { A } & 1 & 5 & 6 & 7 \\ \text { B } & 1 / 5 & 1 & 4 & 6 \\ \text { C } & 1 / 6 & 1 / 4 & 1 & 4 \\ \text { D } & 1 / 7 & 1 / 6 & 1 / 4 & 1\end{array}\right]$

Figura A.2 - Exemplo de matriz de julgamentos para o método AHP Fonte: Saaty, 1991.

As letras A, B, C e D representam os elementos a serem comparados dois a dois. A diagonal da matriz recebe sempre 1, pois é a comparação do elemento com ele mesmo. Para o preenchimento dos outros campos, são feitos os julgamentos para determinar a intensidade de importância, utilizando a escala determinada por Saaty. Para as comparações inversas, ou seja, o que está na parte inferior esquerda da matriz, são adicionados os valores recíprocos referentes a cada julgamento, que estão na parte superior direita da mesma.

Com as matrizes recíprocas devidamente estruturadas, obtém-se o vetor de prioridades, ou pesos, a partir do cálculo do autovetor normalizado do máximo autovalor. Existem métodos específicos para o cálculo aproximado desses valores (Saaty, 1991). Tais aproximações foram desenvolvidas por limitações computacionais da época em que o método foi desenvolvido, sendo custoso o cálculo de autovetores e autovalores para matrizes de ordem elevada.

Para fins deste trabalho, será utilizado o valor preciso de ambas as grandezas, que são denotadas matricialmente por:

$$
A w=\lambda_{\max } w
$$

Onde: 
$A$ é a matriz de julgamentos (quadrada, recíproca e positiva);

$w$ é o autovetor principal, referente aos pesos;

$\lambda_{\text {max }}$ é o autovalor principal de $A$.

Com as características das matrizes de julgamentos em mãos, através do teorema de Perron-Frobenius, Saaty (1991) afirma que a solução tem um único maior autovalor que corresponde a um autovetor de componentes estritamente positivos. Os teoremas e as provas acerca das características envolvendo as matrizes geradas, a partir da avaliação de especialistas, são apresentados em seu trabalho. Computados os autovalores das respectivas matrizes, é necessário realizar análise da consistência dos julgamentos para avaliar o quão afastado da consistência os julgamentos estão. Utiliza-se uma medida para avaliar a probabilidade de os julgamentos terem sido realizados puramente ao acaso e esta medida é chamada Razão de Consistência (RC). Por exemplo, um $R C=0,3 \mathrm{diz}$ que há 30\% de chance do especialista responder as perguntas aleatoriamente.

Saaty (1991) apresenta um desenvolvimento simples e intuitivo para compreender a análise de consistência. Vamos supor uma matriz consistente, em que as comparações são baseadas em medidas exatas, isto é, os pesos já são conhecidos, então:

$$
a_{i j}=\frac{w_{i}}{w_{j}}
$$

Como o julgamento é perfeito para todas as comparações, tem-se que $a_{i k}=$ $a_{i j} . a_{j k}$ para qualquer $\mathrm{i}, \mathrm{j}, \mathrm{k}$, variando de 1 até $n$, sendo $n$ a ordem da matriz.

Também vale a afirmativa:

$$
a_{i j}=\frac{w_{j}}{w_{i}}=\frac{1}{w_{i} / w_{j}}=\frac{1}{a_{i j}}
$$

Dessa forma, caracteriza-se uma matriz consistente de comparações paritárias.

Considerando $x=\left(x_{1}, \ldots, x_{n}\right)$ e $y=\left(y_{1}, \ldots, y_{n}\right)$, pode-se escrever em notação matricial $A . x=y$, onde A é a matriz de julgamentos: 


$$
A=\left[\begin{array}{ccc}
\frac{w_{1}}{w_{1}} & \cdots & \frac{w_{1}}{w_{n}} \\
\vdots & \ddots & \vdots \\
\frac{w_{n}}{w_{1}} & \cdots & \frac{w_{n}}{w_{n}}
\end{array}\right]
$$

Algebricamente, essa operação pode ser representada por:

$$
\begin{aligned}
& \sum_{j=0}^{n} a_{i j} \cdot x_{i}=y_{i} \\
& \quad \operatorname{para} i=1, \ldots, n
\end{aligned}
$$

Como $a_{i j}=\frac{w_{i}}{w_{j}}$, obtém-se:

$$
\begin{aligned}
a_{i j} \frac{w_{j}}{w_{i}} & =1 \\
\operatorname{para} i, j & =1, \ldots, n
\end{aligned}
$$

Consequentemente:

$$
\begin{aligned}
& \sum_{j=0}^{n} a_{i j} \cdot w_{j} \frac{1}{w_{i}}=n \\
& \quad \operatorname{para} i=1, \ldots, n
\end{aligned}
$$

Que é equivalente a equação matricial:

$$
A w=n w
$$

Em álgebra linear, esta última equação expressa o fato de que $w$ é autovetor de $A$ com autovalor $n$.

Na prática, $a_{i j}$ são os pesos atribuídos pelo julgamento dos especialistas, baseado na escala fundamental, e de certa forma subjetivos. Assim, os valores $a_{i j}$ irão se afastar do "ideal" $w_{i} / w_{j}$, fazendo com que a equação $A w=n w$ não seja mais válida. 
Se $\lambda_{1}, \ldots, \lambda_{n}$ são os números que satisfazem a equação $A w=\lambda w$, então $\lambda$ é autovalor de $A$ e, se $a_{i j}=1$ para todo i, então:

$$
\sum_{i=0}^{n} \lambda_{i}=n
$$

Assim, se $A w=n w$ é válida, somente um dos autovalores é diferente de zero e valerá $n$, sendo o maior autovalor de $A$.

Caso os elementos de uma matriz recíproca positiva sofrerem pequenas variações, seus respectivos autovalores também variarão em pequenas quantidades.

Utilizando os resultados apresentados juntamente com o axioma anterior, pode-se dizer que, caso a diagonal principal de uma matriz possua os elementos iguais a 1 e for consistente, pequenas variações nos elementos $a_{i j}$ farão com que o autovalor máximo $\lambda_{\max }$ permaneça próximo de $n$ e os outros autovalores próximos de zero, sendo $\lambda_{\max } \geq n$.

Portanto, para calcular o autovetor de prioridades de uma matriz de comparações paritárias $A$, deve-se encontrar o vetor que satisfaça a equação $A w=\lambda_{\max } w$.

O valor de interesse para o desenvolvimento da metodologia é o autovetor normalizado, de forma que a soma de $w$ seja igual a 1 . Para isso, cada elemento $w_{i}$ é dividido pelo seu somatório.

Uma medida de consistência, chamada Índice de Consistência (IC), é utilizada para calcular o desvio de $\lambda_{\max }$ em relação a $n$, uma vez que a utilização da escala para os julgamentos geram variações em $a_{i j}$, alterando $\lambda_{\max }$.

$$
\text { IC }=\frac{\lambda_{\max }-n}{n-1}
$$

É comum as avaliações realizadas pelos especialistas gerarem inconsistências, pois fazem parte do julgamento humano, mas deseja-se que sejam as menores possíveis. Para verificar a coerência, utiliza-se, como citado anteriormente, a Razão de Consistência, tendo como definição:

$$
R C=\frac{I C}{I R}
$$

IR (Índice Randômico) é o índice de consistência de uma matriz recíproca gerada randomicamente, baseada na escala de 1 a 9 , com recíprocas forçadas 
(Saaty e Vargas, 2012). Este valor é tabelado e varia de acordo com a ordem da matriz. Na Tabela A.1, é apresentado o valor de IR para matrizes de ordem 1 até 10.

Tabela A.1 - Índice randômico

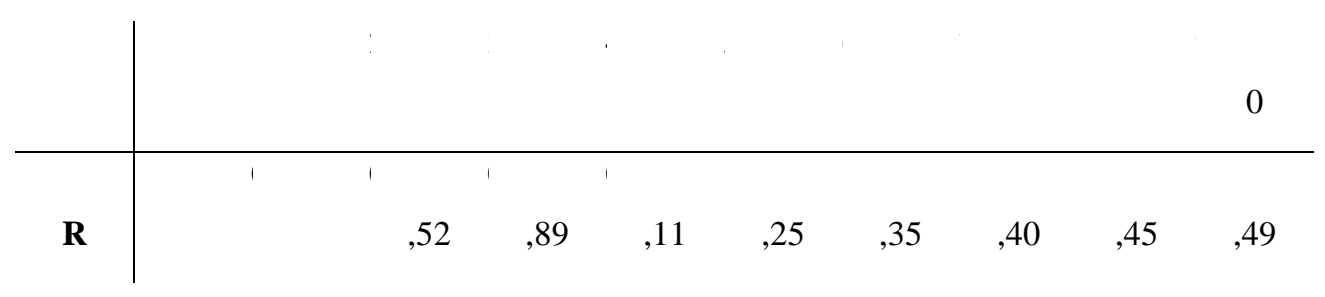

Fonte: Adaptado de Saaty e Vargas, 2012.

A avaliação final da coerência do julgamento se dá ao comparar o valor de RC. Para o presente desenvolvimento, fazem-se as seguintes considerações:

a) $R C \leq 0,1$ consiste em um julgamento coerente, premissa básica do método em relação a análise de coerência, proposta inicialmente para julgar uma avaliação como satisfatória;

b) $0,1<R C<0,2=$ Julgamento questionável, considerado para que especialista reveja seus julgamentos da respectiva etapa, analisando a matriz construída e busque melhorar alguma(s) comparação(ões) que tenha(m) sido inconsistente(s). Porém, não é obrigatório que se altere algum julgamento;

c) $R C \geq 0,2=$ Julgamento incoerente, indica que as comparações pareadas daquela etapa geraram um alto índice de inconsistência e o especialista é obrigado a refazer seus julgamentos.

Uma vez alcançada a consistência no julgamento, são calculados os vetores de prioridades, ou seja, os pesos relativos de cada elemento do problema. Este cálculo é realizado através da multiplicação das matrizes de prioridades. Em outras palavras, para cada alternativa, o cálculo consiste na soma ponderada da importância relativa de cada atributo pelo nível de preferência de determinada alternativa em relação ao respectivo critério (Souza, 2013). No AHP, cada alternativa receberá uma pontuação através de uma função de valor aditiva. As alternativas com maior valor serão as preferíveis (Passos, 2010). Formalizando, a função de valor para cada alternativa será:

$$
F(a)=\sum_{j=1}^{n} w_{j} v_{j}(a)
$$


Onde:

$F(a)$ é o valor final de alternativa $a$;

$w_{j}$ é o peso do j-ésimo critério;

$v_{j}$ é o desempenho da alternativa em relação ao j-ésimo critério.

\section{Referências}

Costa, H. G. Auxílio multicritério à decisão: método AHP. Rio de Janeiro: Abepro. 2006.

Saaty, T. L. Scaling method for priorities in hierarchical structures. Journal of Mathematical Psychology, v.15, p.234-281. 1977.

Saaty, T. L. Physics as a decision theory. European Journal of Operational Research, v. 48, p.98-104. 1990.

Saaty, T. L. Método de análise hierárquica. São Paulo: Mc-Graw-Hill, Makron. 1991.

Saaty, T. L. Decision making for leaders. Pittsburg: RWS Publications. 2000.

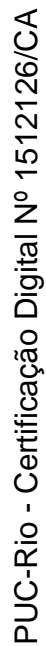

Saaty, T. L.; Vargas, L. G. Models, methods, concepts \& applications of the analytic hierarchy process. $2^{\mathrm{a}}$ ed. New York: Springer. 2012. 